UNIVERSIDADE DE SÃO PAULO

INSTITUTO DE GEOCIÊNCIAS

\title{
IMPLEMENTAÇÃO DE CROMATOGRAFIA DE TROCA IÔNICA PARA URÂNIO E TÓRIO A PARTIR DE CARBONATOS
}

Kátia Santina da Silva

Orientadora: Profa. Dra. Maria Helena Bezerra Maia de Hollanda

DISSERTAÇÃO DE MESTRADO

Programa de Pós-Graduação em Geoquímica e Geotectônica

São Paulo 
“IMPLEMENTAÇÃO CROMATOGRAFIA DE TROCA IÔNICA PARA URÂNIO E TÓRIO A PARTIR DE CARBONATOS".

\title{
KÁTIA SANTINA DA SILVA
}

Orientador: Profa. Dra. Maria Helena Bezerra Maia de Hollanda

\author{
DISSERTAÇÃO DE MESTRADO \\ COMISSÃO JULGADORA
}

Nome

Assinatura

Presidente: Profa. Dra. Maria Helena Bezerra Maia de Hollanda (GMG/IGc/USP)

Examinadores: Profa. Dra. Mari Estela de Vasconcelos (IPEN)

Prof. Dr. Pedro Vitoriano de Oliveira (Inst.Química/USP)

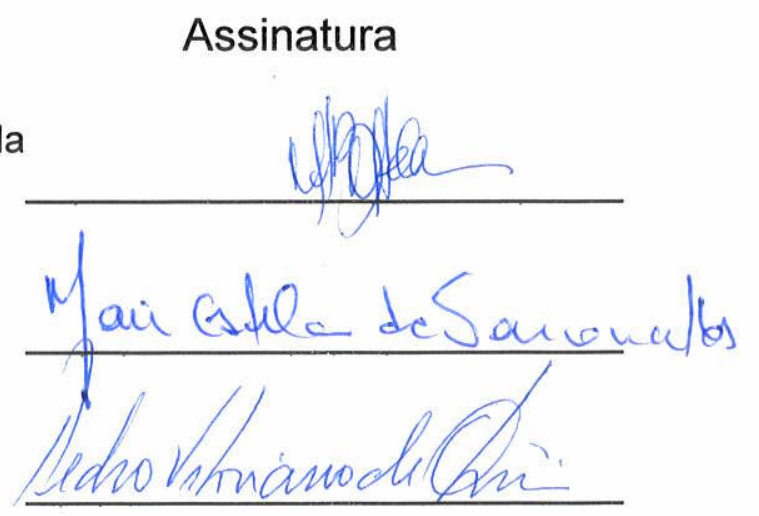




\section{IMPLEMENTAÇÃO DE CROMATOGRAFIA DE TROCA IÔNICA PARA URÂNIO E TÓRIO A PARTIR DE CARBONATOS}

Kátia Santina da Silva

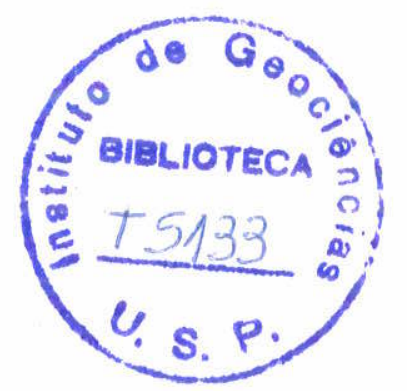

Orientadora: Profa. Dra. Maria Helena Bezerra Maia de Hollanda

$$
\text { DISSERTAÇÃO DE MESTRADO }
$$

Programa de Pós-Graduação em Geoquímica e Geotectônica

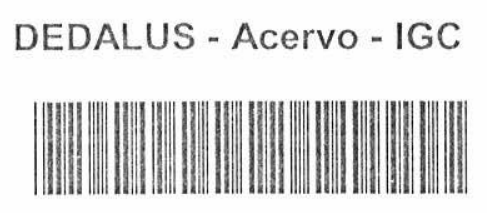

30900030685

São Paulo 


\title{
IMPLEMENTAÇÃO DE CROMATOGRAFIA DE TROCA IÔNICA PARA URÂNIO E TÓRIO A PARTIR DE CARBONATOS
}

\author{
KÁTIA SANTINA DA SILVA
}

Dissertação de Mestrado do Programa de Pós-graduação em Geoquímica e Geotectônica, área de concentração em Geoquímica de Processos Exógenos, do Instituto de Geociências da Universidade de São Paulo.

Orientadora: Profa. Dra. Maria Helena B. M. Hollanda

São Paulo 


\section{Agradecimentos}

Gostaria de expressar meus sinceros agradecimentos às pessoas que estiveram presentes no decorrer dessa jornada, em especial a minha familia, meus vários amigos e meu namorado pela paciência constante e apoio sempre presente.

Estendo esses agradecimentos a minha orientadora Maria Helena Hollanda, por proporcionar a participação neste projeto, pela amizade e apoio em todas as etapas de seu desenvolvimento. A minha participação só foi possivel com a concessão da bolsa pela CAPES, no âmbito do INCT 'Desenvolvimento de Técnicas Analíticas Inovadoras em Geoquímica Inorgânica para Exploração de Petróleo e Gás'.

Agradeço também às técnicas dos laboratórios de geoquimica e geocronologia (CPGeo), Sandra Andrade e Liliane Petronilho, pelos conhecimentos transmitidos e discussões/sugestões compartilhadas. Incluo igualmente todos os demais técnicos (de laboratório e administrativos) do Centro de Pesquisas Geocronológicas que me acolheram durante este período.

Agradecimentos especiais são deixados aos pesquisadores Jorge Sarkis, Fátima Maria Sequeira de Carvalho e Maria Luiza Godoy que gentilmente cederam alíquotas de sais de Th para nossos testes de calibração do spike ${ }^{229} \mathrm{Th}$, bem como por sugestões dadas com respeito às suas dissoluções. Ao professor Koji Kawashita tenho a agradecer os ensinamentos transmitidos com respeito à geocronometria iniciada neste projeto, esperando que sua participação venha ser estendida nas etapas subsequentes de desenvolvimento do método $U$ Th.

Por fim, agradeço a todos que passaram pela minha vida nesse período, de forma positiva ou negativa todos deixaram uma lição de crescimento. 


\section{Índice}

\section{Capitulo I - INTRODUÇÃO}

1.1 APRESENTAÇÃO E JUSTIFICATIVA PARA O PROJETO 01

1.2 OBJETIVO E DESENVOLVIMENTO DO PROJETO NO CPGEO 02

$\begin{array}{ll}1.3 \text { ESCOPO DA DISSERTAÇÃO } & 04\end{array}$

\section{Capítulo II - FUNDAMENTAÇÃO TEÓRICA}

2.1 INTRODUÇÃO 05

2.2 PRINCIPIOS GERAIS DO MÉTODO DE DATAÇÃO DA SÉRIE DE DESEQUILÍBRIO 05 DO URÂNIO

2.3 TÉCNICAS ANALÍTICAS PARA DETERMINAÇÕES DA SÉRIE DE 06 DESEQUILÍBRIO DO URÂNIO

\section{Capítulo III - PROCEDIMENTOS PRÉ-CROMATOGRAFIA LIQUUIDA}

3.1 INTRODUÇÃO 09

3.2 DESCONTAMINAÇÃO DOS MATERIAIS UTILIZADOS 09

3.2.1 Descontaminação de béqueres Savillex $\otimes \quad 10$

3.2.2 Descontaminação de colunas 11

3.2.3 Descontaminação de ponteiras 11

3.2.4 Descontaminação de tubos de centrífuga (tipo Falcon) 11

3.2.5 Lavagem de resinas de troca iônica (BioRad® AG 1-X8, Spectra/Gel@ IE 1-X8) 12

3.3 DISSOLUÇÃO ÁCIDA DE CARBONATOS 13

3.3.1 Teste com ácido nítrico 13

3.3.2 Teste com ácido clorídrico 14

3.3.3 Teste com mix fluorídrico:nítrico e perclórico:nítrico para o padrão JLs-1 14

3.3.4 Teste de dissolução de uma amostra de carbonato com fração terrígena 15

Capítulo IV - SEPARAÇÃO CROMATOGRÁFICA DE TROCA IÔNICA

4.1 INTRODUÇÃO 16

4.2 O MÉTODO DE CALIBRAÇÃO DAS COLUNAS CROMATOGRÁFICAS NO BGC 18

4.2.1 Procedimento para coluna primária (volume de empacotamento $3 \mathrm{~mL}$ ) 18 
4.2.2 Procedimento para coluna secundária (volume de empacotamento $1,2 \mathrm{~mL}$ ) 19

4.3 RESULTADOS DOS TESTES DE CALIBRAÇÃO NO CPGEO SEGUNDO O 19 PROCEDIMENTO BGC

4.3.1 Primeira Etapa de Teste 19

4.3.2 Segunda Etapa de Teste 21

4.3.3 Terceira Etapa de Teste $\quad 25$

4.3.4 Quarta Etapa de Teste $\quad 28$

4.4 O MÉTODO DE CALIBRAÇÃO DAS COLUNAS CROMATOGRÁFICAS NA UMN 30

4.4.1 Coluna de Troca Aniônica 30

4.5 RESULTADOS DOS TESTES DE CALIBRAÇÃO NO CPGEO SEGUNDO A UMN 31

4.5.1 Primeira Etapa de Teste 31

4.5.2 Segunda Etapa de Teste 31

4.5.3 Terceira Etapa de Teste 33

Capítulo V - PROCEDIMENTOS PARA PREPARAÇÃO DE SPIKES Th e U

5.1 INTRODUÇÃO 36

5.2 PROCEDIMENTO PARA CALIBRAÇÃO DOS SPIKES ${ }^{233}$ U E ${ }^{236} \mathrm{U}$

5.3 PROCEDIMENTO PARA CALIBRAÇÃO DO SPIKE ${ }^{229} \mathrm{Th}$

\section{Capítulo VI - CONSIDERAÇÕES FINAIS}

6.1 SOBRE A INFRA-ESTRUTURA PARA IMPLEMENTAÇÃO DA CROMATOGRAFIA 42 DE TROCA IÔNICA

6.2 SOBRE A ESCOLHA E PREPARAÇÃO DAS RESINAS DE TROCA IÔNICA USADAS NOS TESTES

6.3 SOBRE O PROCEDIMENTO DE CROMATOGRAFIA ADOTADO NO BGC 45

6.4 SOBRE O PROCEDIMENTO DE CROMATOGRAFIA ADOTADO NA UMN 46

6.5 SOBRE A PREPARAÇÃO DE SPIKES DE Th E U $\quad 47$

$\begin{array}{ll}6.6 \text { ETAPAS FUTURAS } & 47\end{array}$

Referências Bibliográficas 


\section{Lista de Figuras}

Figura 01. Materiais diversos utilizados nas diferentes etapas de implementação do método U-Th no Centro de Pesquisas Geocronológicas. Da esquerda para direita, de cima para baixo: A. Béquer Savillex@ (7 e $15 \mathrm{~mL}$ ); B. Colunas Bio Rad® e de teflon retrátil; C. Resinas de troca iônica; D. Garrafa, pisseta e ponteiras.

Figura 02. Destilador de quartzo com coluna de Vigreux para destilação fracionada, utilizado para produção contínua de ácidos de alta pureza a partir de reagentes P.A. O sistema de aquecimento consiste de uma manta aquecedora.

Figura 03. Da esquerda para a direita: A. Etapa de descontaminação de béquer Savillex® em meio ácido, em chapa aquecedora. B. Etapa de lavagem de colunas em meio ácido, em ultrassom.

Figura 04. Gráficos a calibração das colunas primária e secundária sem co-precipitação com $\mathrm{Fe}(\mathrm{OH})_{3}$. A. Calibração de Th na coluna primária; B. Calibração de U na coluna primária; C. Calibração de Th na coluna secundária; D. Calibração de U na coluna secundária. As frações JCp-1 [5] e [6] foram tratadas apenas na coluna primária, enquanto as frações [7] e [8] foram inicialmente tratadas na coluna primária e as coletas de Th e $U$ foram, em seguida, passadas na coluna secundária.

Figura 05. Gráficos ilustrando a calibração das colunas primária e secundária do procedimento BGC, com co-precipitação com $\mathrm{Fe}(\mathrm{OH})_{3}$. A. Calibração de Th na coluna primária; B. Calibração de U na coluna primária; C. Calibração de Th na coluna secundária; D. Calibração de U na coluna secundária. As frações JCp-1 [9] e [10] foram tratadas apenas na coluna primária, enquanto as frações [11] e [12] foram inicialmente tratadas na coluna primária e as alíquotas de Th e $U$ coletadas foram, em seguida, passadas na coluna secundária.

Figura 06. Gráficos ilustrando a calibração das colunas primária e secundária do procedimento $B G C$, na terceira etapa de testes, com os padrões JCp-1 e Fluka. A. Calibraçăo de Th na coluna primária; B. Calibração de U na coluna primária; C. Calibração de Th na coluna secundária; D. Calibração de U na coluna secundária. A fração JCp-1 [13] foi tratada apenas na coluna primária, enquanto a fração [14] foi inicialmente tratada na coluna primária e as aliquotas de Th e $U$ coletadas foram, em seguida, passadas na coluna secundária.

Figura 07. Gráficos ilustrando a calibração das colunas primária e secundária do procedimento $B G C$, na quarta etapa de testes, com os padrões JCp-1 e JLs-1. A. Calibração de Th na coluna primária; B. Calibração de U na coluna primária; C. Calibração de Th na coluna secundária; $D$. Calibração de U na coluna secundária. As frações JCp-1 [17] e JLs-1 [7] foram tratadas apenas na coluna primária, enquanto as frações $\mathrm{JCp}-1$ [18] e JLs-1 [8] foram inicialmente tratadas na coluna primária e as alíquotas de Th e U coletadas foram, em seguida, passadas na coluna secundária.

Figura 08. Gráficos ilustrando a calibração da coluna do procedimento UMN, na segunda etapa de testes, com os padrões JCp-1 [21] e JLs-1[9 a 12]. A. Calibração de Th; B. Calibração de U. 
Figura 09. Gráficos ilustrando a calibração da coluna do procedimento UMN com os padröes JCp-1 [22 a 24] e JLs-1 [13 e 14]. A. Calibração de Th; B. Calibração de U.

Figura 10. Fluxogramas ilustrando as etapas de lavagem das resinas Bio $\operatorname{Rad}(B$ e $\operatorname{Spectra} / \mathrm{Ge}(\otimes$ adotadas neste trabalho. O fluxograma 1 foi adotado para ambas as resinas, constituindo o esquema tradicionalmente realizado para resinas aniônicas utilizadas em outros métodos, no CPGeo. Os fluxogramas 2 e 3 representam os esquemas adotados no BGC e UMN, respectivamente, na cromatografia $U$ e Th.

Figura 11. Fluxograma das etapas de cromatografia de troca iônica com a resina Bio Rad@ AG 1-X8.

Figura 12. Fluxograma das etapas de cromatografia de troca iônica com a resina Spectra/Gelß IE 1-X8. 


\section{Lista de Tabelas}

Tabela 01. Parâmetros de preparação das soluções de calibração para ICP-MS (IGC/USP).

Tabela 02. Parâmetros de preparação das soluções de calibração para ICP-MS (IGc/UNICAMP).

Tabela 03. Dados de peso e percentagem de recuperação para as frações de JCp-1 e JLs-1 analisadas na primeira etapa de teste (procedimento BGC).

Tabela 04. Procedimento para coluna primária adotado pelo BGC com a definição das diferentes aliquotas coletadas para $U$ e Th na segunda etapa de testes.

Tabela 05. Procedimento para coluna secundária adotado pelo BGC com a definição das diferentes alíquotas coletadas para $U$ e Th na segunda etapa de testes.

Tabela 06. Dados de peso e percentagem de recuperação para as frações de $J C p-1$ analisadas na segunda etapa de teste (procedimento BGC).

Tabela 07. Procedimento para coluna primária adotado pelo BGC com a definição das diferentes aliquotas coletadas para $U$ e Th na terceira etapa de testes.

Tabela 08. Procedimento para coluna secundária adotado pelo BGC com a definição das diferentes alíquotas coletadas para $U$ e Th na terceira etapa de testes.

Tabela 09. Dados de peso e percentagem de recuperação para as frações de $J C p-1$ analisadas na terceira etapa de teste (procedimento BGC).

Tabela 10. Dados de peso e percentagem de recuperação para as frações de JCp-1 e JLs-1 analisadas na quarta etapa de teste (procedimento BGC).

Tabela 11. Dados de peso e percentagem de recuperação para as frações de JCp-1 analisadas na primeira etapa de teste (procedimento UMN).

Tabela 12. Procedimento para coluna adotado pelo UMN com a definição das diferentes aliquotas coletadas para $U$ e Th na segunda etapa de testes.

Tabela 13. Dados de peso e percentagem de recuperação para as frações de JCp-1 e JLs-1 analisadas na segunda etapa de teste (procedimento UMN).

Tabela 14. Procedimento para coluna adotado pelo UMN, com modificaçōes, com a definição das diferentes aliquotas coletadas para $U$ e Th na segunda etapa de testes.

Tabela 15. Dados de peso e percentagem de recuperação para as frações de JCp-1 [22 a 24] e JLs-1 [13 e 14] analisadas na terceira etapa de teste (procedimento UMN).

Tabela 16. Informações sobre as fontes usadas para preparação dos spikes ${ }^{229} \mathrm{Th},{ }^{233} \mathrm{U}$ e ${ }^{236} \mathrm{U}$. 
Tabela 17. Dados de pesagem obtidos no procedimento de uma solução-padrão de calibração para os spikes ${ }^{233} \cup$ e ${ }^{236} \mathrm{U}$.

Tabela 18. Dados de pesagem obtidos no procedimento de uma solução-padrão de calibração para o spike ${ }^{229} \mathrm{Th}$. 


\section{Resumo}

O método U-Th para datação em carbonatos recentes tem importância estratégica como ferramenta em estudos paleoclimáticos englobando o período entre Pleistoceno e Holoceno, uma vez que permite ancorar (no tempo) padrões de oscilações climáticas e ambientais globais, dependentes de temperatura e pluviosidade. Esses padrões são identificados a partir de dados isotópicos $\left(\delta^{13} \mathrm{C}, \delta^{18} \mathrm{O}\right)$ e geoquímicos (razões elementares) obtidos em espeleotemas e corais. No Brasil, inúmeros projetos científicos têm se desenvolvido nessa linha de pesquisa, mas utilizando parte das facilidades analíticas necessárias a esses estudos disponíveis em laboratórios internacionais.

A implementação do método U-Th $\left({ }^{238} \mathrm{U}-{ }^{234} \mathrm{U}-{ }^{230} \mathrm{Th}\right)$ de desequilíbrio da série do urânio foi objeto dessa dissertação. A meta foi testar rotinas de cromatografia de troca iônica para separação química de $U$ e Th a partir de amostras de carbonato, definidas nos laboratórios do Berkeley Geochronological Center (BGC) e University of Minnesota (UMN), para futura implementação no Centro de Pesquisas Geocronológicas do IGc/USP. As amostras utilizadas foram padrões de referência internacional (JCp-1 e JLs-1), e a infra-estrutura usada foi adequada a partir das instalações existentes no centro. A reprodutibilidade das rotinas escolhidas foi avaliada com base na capacidade de calibrar os picos de eluição de Th e $U$, e no fator de recuperação calculado a partir da quantidade inicial depositada na coluna.

Para o procedimento BGC foram utilizados dois conjuntos de colunas cromatográficas, primária e secundária, sendo que na primeira os picos de eluição foram estabelecidos entre 8$22 \mathrm{~mL}$ para Th e 34-38 mL para U. Na coluna secundária os resultados não foram satisfatórios para Th, com significativa fração sendo eliminada durante o descarte pré-coleta. Para U o intervalo foi estabelecido entre 13-17 mL. A recuperação de $U$ no procedimento $B G C$ foi ideal, consistentemente acima de $90 \%$ se não considerada o tratamento prévio com $\mathrm{Fe}(\mathrm{OH})_{3}$. $\mathrm{Ao}$ contrário, a recuperação de Th foi baixa e aleatória, em parte refletindo a perda em outras etapas de eluição da coluna.

Para o procedimento UMN foi considerada a exclusão na etapa de preparo/dissolução das amostra com $\mathrm{HClO}_{4}$ uma vez não se tratar de um ácido rotineiramente usado no CPGeo, tendo como função eliminar qualquer traço de matéria orgânica presente na matriz carbonática. Essa modificação pode ter influenciado fortemente os dados de recuperação de Th $(<40 \%)$, especialmente para o padrão JCp-1 que, ao contrário do padrão JLs-1, não foi submetido à calcinação pré-dissolução. Quanto ao $U$ os testes mostraram que houve perda durante a etapa de depósito+descarte obviamente afetando a recuperação em um intervalo bem definido. Uma tentativa adotada para melhorar esse comportamento foi aumentar o $\mathrm{pH}$ do 
meio (resina) imediatamente antes do depósito da amostra na coluna, buscando favorecer maior fixação/retenção de $U$. O resultado foi parcialmente favorável uma vez que restringiu o pico de eluição entre 4-6 mL, mas ainda com perda prévia.

Tendo em vista a necessidade de melhor ajustar os parâmetros de calibração e recuperação para cromatografia de Th e $U$, novos testes serão realizados com a continuidade deste projeto, quando esperamos ajustar as rotinas do BGC e UMN, e também iniciar testes com outras resinas de troca iônica específicas para actinídeos. Estabelecida a rotina no CPGeo, será iniciada a fase de implementação do método na espectrometria de massas utilizando spikes específicos $\left({ }^{229} \mathrm{Th},{ }^{233} \mathrm{U},{ }^{236} \mathrm{U}\right)$ - ID-TIMS, calibrados durante 0 desenvolvimento desse mestrado. 


\section{Abstract}

U-series dating applied for recent carbonates (speleothems, corals) has strategic importance for paleoclimatic studies developed on the Quaternary period ( $<1.5 \mathrm{ky}$ ) since they can be well-preserved archives to explore past environmental conditions. High-resolution and high-precision geochronological data are required to constrain timing of paleoclimatic changes at a wide range of spatial and temporal scales, which are mostly identified by using potential indicators such as isotopic $\left(\delta^{13} \mathrm{C}, \delta^{18} \mathrm{O}\right)$ and geochemical (elementary ratios) data. In Brazil, an increasing number of scientists have developed researches on this theme but, in part, using analytical facilities available in overseas laboratories.

The present master degree project aims to start up the $U$-series dating $\left({ }^{238} \mathrm{U}_{-}^{234} \mathrm{U}_{-}^{230} \mathrm{Th}\right)$ at CPGeo/IGc-USP on speleothems in order to give support for new researches on global (paleo)climate changes. We tested two different routines using ion exchange chromatography for chemical separation of $U$ and Th from the carbonate reference materials JCp-1 and JLs-1. These two routines were developed in U-series laboratories of Berkeley Geochronological Center (BGC) (Sharp et al., 2003) and University of Minnesota (UMN) (Chen et al., 1986; Edwards et al., 1986), USA. Reproducibility of these routines was evaluated on the ability in calibrating ideal intervals for Th and $U$ extraction, and the respective yields calculated from the initial amount deposited into the chromatographic column, which should be higher than $90 \%$.

The BGC's procedure involves a set of two chromatographic columns (called primary and secondary) with volume of $3 \mathrm{~mL}$ and $1.2 \mathrm{~mL}$, respectively, packed with anion exchange Bio $\operatorname{Rad}(A)$ AG $1-X 8$ resin. Th and $U$ were selectively extracted by acid washing using strong $(8 \mathrm{~N})$ and weak $(0,5 \mathrm{~N})$ hydrocloridric acid. Our results show that the ideal elution interval for Th between 8-22 $\mathrm{mL}$ and $34-38 \mathrm{~mL}$ for $\mathrm{U}$, at primary column; for the secondary column the results were not good for Th because its loss during loading of the sample. For $U$, however, the interval was established between $13-17 \mathrm{~mL}$. The yields were appreciable for $U$, mostly above $90 \%$ if co-precipitation $\mathrm{Fe}$ is not considered. New tests are required for defining the best Th elution interval since there is significant loss during previous and subsequent steps of the routine.

The UMN's procedure involves use of $\mathrm{FeCl}_{3}$ during acid dissolution to promote coprecipitation of Th and $\mathrm{U}$, and $\mathrm{HClO}_{4}$ for organics dissolution. Sample is loaded into column packed with anion exchange Spectra/Gelß 1-X8 resin. Th and $U$ were selectively extracted by acid washing using $6 \mathrm{~N} \mathrm{HCl}(\mathrm{Th})$ and water $(U)$. Since $\mathrm{HClO}_{4}$ is not commonly used in $\mathrm{CPGeo}$, it was excluded. Such a modification may have strongly influenced the yield for Th $(<40 \%)$, especially for the standard JCp-1 that, unlike the standard JLs-1 was not submitted to 
calcination before acid dissolution. Uranium was strongly eluted during the other previous aliquots thus decreasing its yield. In order to improve the $U$ retention the $\mathrm{pH}$ resin was increased before loading the sample into the column. This procedure helped to restrict the elution interval to $4-6 \mathrm{~mL}$, but $\mathrm{U}$ loss was still detected.

New adjustment needs to be done to improve calibration of the Bio Rad® and Spectra/Gel $\otimes$ columns for extraction of $T h$ and $U$ from carbonates. In addition, we intend to begin tests with specific resins (U/TEVA $($, TRU $($ ) that are mentioned as very effective in actinide separation. These adjustments and new tests are the object of a ongoing research that aims to set $U$-series dating using isotope dilution $\left({ }^{229} \mathrm{Th},{ }^{233} \mathrm{U},{ }^{236} \mathrm{U}\right)$ combined with mass spectrometry at CPGeo/IGc/USP. 


\section{Capítulo I - INTRODUÇÃO}

\subsection{APRESENTAÇÃO E JUSTIFICATIVA PARA O PROJETO}

Registros geológicos mostram que o clima da Terra vem sofrendo significativas mudanças ao longo do tempo reconhecidas desde o Proterozoico até o Recente. Especificamente no Neoproterozoico, variações extremas entre períodos de glaciação e aquecimento precederam a grande explosão de vida no Cambriano, e foram base para a hipótese controversa "Terra Bola de Neve" (Snowball Earth; Hoffman e Schrag, 2002). A partir do Cambriano, o clima global foi progressivamente alterado como consequência do efeitoestufa promovido por contínuas perturbações naturais no Ciclo do Carbono. Acredita-se que tais perturbações tenham sido uma das principais causas de extinção biológica em massa durante o Fanerozoico como resultado de intensa atividade geológica pretérita tais como impactos de meteoros e vulcanismos. Atualmente a atividade antrópica catastrófica é um dos principais mecanismos indutores do efeito-estufa global, contribuindo para o aquecimento generalizado do planeta, bem como para mudanças sazonais importantes que podem induzir grandes instabilidades ecológicas e migrações geográficas de populações de animais e plantas.

O crescente interesse em reconhecer os efeitos e causas das mudanças climáticas globais ao longo do tempo geológico tem levado à proposição de inúmeros projetos multidisciplinares envolvendo a integração de áreas clássicas das Geociências Sedimentologia, Estratigrafia, Paleontologia, Palinologia, Espeleologia, Geoquímica Isotópica, Geocronologia, Meteorologia, Oceanologia e Hidrogeologia, financiados por várias agências de fomento no Brasil. Essa multidisciplinaridade é especialmente aplicável para a história mais recente do planeta Terra, registrada através do estudo sistemático de paleoindicadores geológicos específicos o que representam a chave para entender as grandes mudanças globais, atuais e futuras. Nesse contexto, a Geocronologia tem papel de destaque uma vez que permite estabelecer, com alta precisão/resolução, o vínculo temporal das mudanças climáticas recentes (especialmente no Quaternário) estabelecido a partir da datação direta daqueles paleoindicadores.

O estudo das variações climáticas globais durante o Quaternário tem sido de especial interesse para vários grupo de pesquisadores no mundo, no Brasil com destaque o grupo do IGc/USP coordenado pelos Dr. Francisco William da Cruz Jr e Dr. Ivo Karmann. Esse grupo vem desenvolvendo pesquisas essencialmente relacionadas a padrões paleoclimáticos registrados em espeleotemas carbonáticos brasileiros, com ênfase na utilização de parâmetros 
isotópicos de carbono $\left(\delta^{13} \mathrm{C}\right)$ e oxigênio $\left(\delta^{18} \mathrm{O}\right)$. Esses parâmetros definem a assinatura isotópica desses carbonatos, a qual é sensivel às oscilações climáticas e ambientais dependentes de temperatura e pluviosidade. A atuação internacional do grupo liderando pesquisas relacionadas à paleoclimatologia vem se tornando crescente após a implementação, no IGc, de uma infra-estrutura analítica ideal para obtenção desses dados isotópicos que combinam, de modo on-line, extração de gás $\mathrm{CO}_{2}$ a partir da amostra e análise espectrométrica de alta precisão. Esse sistema analítico exige volume reduzido de amostra (c. 100-150 $\mu \mathrm{g}$ ) possibilitando amostragem de alta resolução (variações de crescimento decadais/anuais) em espeleotemas e corais.

A identificação de padrões isotópicos em espeleotemas deve ser bem ancorada no tempo para permitir a correlação com eventos decadais, centeniais ou milenares reconhecidos (Heinrich, Young-Dryas, Dansgaard-Oescheger, p.ex.), o que vem sendo feito através da datação dos espeleotemas pelo método ${ }^{234} \mathrm{U}-{ }^{230} \mathrm{Th}$. Uma vez que $\mathrm{U}\left(\mathrm{UO}_{2}{ }^{2+}\right)$ tende a formar complexos carbonáticos [p.ex., $\mathrm{UO}_{2}\left(\mathrm{CO}_{3}\right)_{3}{ }^{4}$ ] quando em meio aquoso saturado em $\mathrm{CO}_{3}$, minerais carbonáticos tais como calcita e aragonita tendem conter concentrações significativas de $\mathrm{U}$ e ausência de Th como função das diferentes afinidades geoquimicas (p.ex., solubilidade) entre ambos. Essas diferenças promovem o fracionamento entre esses elementos na hidrosfera, sendo que a produção de ${ }^{230} \mathrm{Th}$ em carbonatos é unicamente função do decaimento de ${ }^{234} U$.

A presente dissertação é parte das exigências para conclusão do Curso de Mestrado no Programa de Pós-Graduação em Geoquímica e Geotectônica, tendo sido submetida à área de concentração Geoquimica dos Processos Exógenos. A implementação do método U-Th para datação de espeleotemas não é necessariamente um projeto de inovação tecnológica, visto ser um método geocronológico bastante difundido no mundo e que vem sendo há quase três décadas utilizado para esse fim. Todavia, pode ser visto como de importância estratégica uma vez que o Brasil abriga inúmeras cavernas em regióes tropicais a sub-tropicais, muitas delas com notável acervo de espeleotemas com características ideais para datação, justificando-se sua utilização como ferramenta paleoclimática. Logo, é inegável que a implementação e rotineirização desses métodos em laboratórios nacionais deverá estimular pesquisas científicas relacionadas à Geologia do Quaternário e áreas afins, pois sua aplicação pode ser estendida a corais, ossos, lavas vulcânicas, etc.

\subsection{OBJETIVO E DESENVOLVIMENTO DO PROJETO NO CPGEO}

O objetivo da presente dissertação é dar início à implementação do método ${ }^{234} \mathrm{U}-{ }^{230} \mathrm{Th}$ para datação de carbonatos recentes (Pleistoceno-Holoceno), em especial espeleotemas no 
Centro de Pesquisas Geocronológicas (CPGeo) do Instituto de Geociências da USP. Esse centro existe a aproximadamente 45 anos, atuando especificamente na aplicação de sistemas isotópicos específicos ( $\left.\mathrm{Rb} / \mathrm{Sr}, \mathrm{Sm} / \mathrm{Nd}, \mathrm{U}-\mathrm{Th}-\mathrm{Pb}, \mathrm{Re} / \mathrm{Os}, \mathrm{K} / \mathrm{Ar},{ }^{40} \mathrm{Ar} /{ }^{39} \mathrm{Ar},{ }^{13} \mathrm{C} /{ }^{12} \mathrm{C}, \mathrm{D} / \mathrm{H},{ }^{18} \mathrm{O} /{ }^{16} \mathrm{O}\right)$ a problemas geológicos e ambientais, incluindo a datação absoluta de rochas precambrianas e fanerozoicas (Paleo a Cenozoico). A implementação do método U-Th permitirá ampliar a atuação do CPGeo em pesquisas voltadas também à geologia do Quaternário, o período de tempo mais recente de história da Terra em que os métodos comumente utilizados para rochas mais antigas não se aplicam devido às meia-vidas $\left(t_{1 / 2}\right)$ mais longas.

Considerando a quantidade de $U$ e Th muito pequena em carbonatos recentes (na ordem de ppb e ppt, respectivamente), faz-se necessária a separação química precisa desses elementos da matriz e, por sua vez, entre si. Assim, a implementação do método pode ser subdivido em duas etapas principais que referem-se a: (1) separação química de $U$ e Th por cromatografia líquida de troca iônica, usando-se resinas específicas, e posterior (2) determinação das composições isotópicas de $U$ e Th por espectrometria de massa, utilizandose diluição isotópica (uso de traçadores/spikes específicos). Sabendo que o tempo necessário para desenvolvimento de um projeto dessa grandeza ultrapassa o prazo de 24 meses de um mestrado, a meta desse projeto de pós-graduação fol fixada em estabelcer o procedimento de cromatografia mais adequado para ser futuramente rotineirizado no CPGeo. Para isso procurou-se adequar um espaço próprio dentro da infra-estrutura já existente que pudesse ser dedicado ao método, muito embora algumas etapas tiveram que ser executadas em equipamentos comuns às demais metodologias em rotina do centro. A adequação desse espaço implicou em: (i) uso de uma capela de fluxo laminar própria, independente dos demais métodos, (ii) uso compartilhado de chapas aquecedoras, (iii) aquisição de materiais diversos (colunas, garrafas e frascos de teflon, béqueres $S a v i l l e x \circledast$, pipetas graduadas, provetas, etc.) próprios e (iv) uso compartilhado de destiladores para purificação dos ácidos utilizados no procedimento. Tudo foi realizado em salas limpas (classe ISO7).

Precedendo à cromatografia em si, esse projeto envolveu toda a etapa prévia de preparação (descontaminação) do material requerida para a implementação de métodos baseados em diluição isotópica, além de testes de dissolução química de amostras com reagentes de diferentes normalidades (cf. publicações na literatura relacionada ao tema). Com respeito à rotina cromatográfica apresentada nesta dissertação a mesma não representa um desenvolvimento próprio. Os detalhes foram gentilmente transmitidos por pesquisadores dos laboratórios de U-Th do Berkeley Geochronological Center (Dr. Warren Sharp) e da University of Minnesota (Dr. Hai Cheng), de forma que tentamos reproduzir as rotinas visando avaliar qual delas (com ou sem modificações) poderia vir a ser implementada em rotina no CPGeo. Testes de outros procedimentos podem ainda ser considerados, mas fora do escopo dessa dissertação dado o curto prazo de dois anos. 
Por fim, apresentamos os procedimentos instrumentais e de cálculo para preparação de três spikes especificos de $U$ e Th recomendados para o método U-Th em carbonatos recentes. Essa etapa de geocronometria é fundamental para implementação de métodos baseados em diluição isotópica e, no caso dessa dissertação, representou uma contribuição inédita visto que foi integralmente planejada e desenvolvida para as finalidades do método no IGc/USP.

\subsection{ESCOPO DA DISSERTAÇÃO}

A dissertação está organizada em seis capítulos, sendo este o primeiro, de caráter introdutório, e o segundo trazendo uma breve síntese teórica sobre o sistema de desequilíbrio da série do urânio e as técnicas instrumentais utilizadas para a determinação de composições isotópicas dos geocronômetros de interesse (filhos e pais radioativos).

Considerando que a presente abordagem do tema é essencialmente metodológica, os vários procedimentos envolvidos durante a implementação do método $U$-Th em carbonatos foram organizados nos três capítulos seguintes. Assim, o terceiro capitulo apresenta todos os procedimentos de descontaminação de materiais de uso rotineiro em laboratórios de cromatografia líquida, incluindo béqueres de teflon, colunas, ponteiras e tubos de centrifuga, bem como preparação de reagentes e lavagem de resinas de troca iônica. O quarto capítulo traz os resultados dos testes de reprodução feitos segundo as rotinas cromatográficas dos dois laboratórios internacionais de U-Th mencionados anteriormente, Berkeley Geochronological Center (BGC) e University of Minnesota (UMN), ambos nos Estados Unidos. O quinto capítulo versa sobre a preparação das soluções spike enriquecidas em ${ }^{229} \mathrm{Th},{ }^{233} \mathrm{U}$ e ${ }^{236} \mathrm{U}$, incluindo detalhes sobre a soluções de calibração e cálculos de diluição. E, por fim, o sexto capítulo que traz os comentários finais e conclusões sobre os resultados obtidos neste trabalho. 


\section{Capítulo II - FUNDAMENTAÇÃo TEÓRICA}

\subsection{INTRODUÇÃO}

O texto abaixo foi elaborado com informações extraídas principalmente de livros textos em Técnicas Analiticas Instrumentais (Potts, 1987), Cromatografia (Collins et al., 1995) e Geologia Isotópica (Dickin, 1995; Faure and Mensing, 2005; Allègre, 2008) além de artigos cientificos mais especificos.

\subsection{PRINCÍPIOS GERAIS DO MÉTODO DE DATAÇÃO DA SÉRIE dE DESEQUILÍBRIO DO URÂNIO}

As séries de decaimento radioativo do $U$ e Th incluem alguns dos cronômetros mais utilizados para datação de materiais geológicos, baseados nas razões de abundâncias relativas entre os isótopos-pai, ${ }^{238} \mathrm{U}$ e ${ }^{235} \mathrm{U}$, e seus respectivos isótopos-filhos finais, ${ }^{206} \mathrm{~Pb},{ }^{207} \mathrm{~Pb}$ e ${ }^{208} \mathrm{~Pb}$, ou ainda entre esses e isótopos-filhos intermediários $-{ }^{231} \mathrm{~Pa},{ }^{234} \mathrm{U},{ }^{230} \mathrm{Th},{ }^{226} \mathrm{Ra}$. Por causa das diferenças nas propriedades químicas entre pais e filhos radioativos, existem vários processos geológicos relacionados à dinâmica externa e interna do planeta que são capazes de interferir efetivamente na sequência de decaimentos naturais das duas séries do $U$. Isso resulta em uma condição de desequilíbrio secular que é, ao contrário de outros sistemas isotópicos, de grande valia para datação de processos geológicos recentes relacionados ao intervalo Pleistoceno-Holoceno (<1,5 Ma).

A maioria dos sistemas isotópicos aplicados à geocronologia está em equilíbrio radioativo secular, ou seja, as atividades entre os produtos (pais e filhos) de decaimento são iguais entre si, podendo ser expresso por: $\lambda_{1} n_{1}=\lambda_{2} n_{2}=\lambda_{3} n_{3}=\ldots \ldots . .=\lambda_{i} n_{i}$, de onde infere-se que o número de átomos $(n)$ que decai por unidade de tempo $(\lambda)$ é igual ao número de átomos formados no mesmo intervalo de tempo. Essa situação é esperada quando o decaimento de um determinado isótopo radioativo evolui idealmente em sistema fechado. Segundo Ketcham (1996), o período necessário para que um sistema fechado atinja equilíbrio secular pode ser estimado em seis vezes a $t_{1 / 2}$ (meia-vida) do isótopo-filho radioativo de menor constante de decaimento $(\lambda)$. Assim, as séries do ${ }^{238} U,{ }^{235} \mathrm{U}$ e ${ }^{232} \mathrm{Th}$ podem ser consideradas em equilíbrio a partir de um período de tempo que se equivale a aproximadamente $1,5^{*} 10^{5}$ anos, $1,9^{*} 10^{4}$ anos e 35 anos, respectivamente, valores estes calculados a partir da $t_{1 / 2}$ de seus filhos ${ }^{234} U$ $\left(2,45^{\star} 10^{5}\right),{ }^{231} \mathrm{~Pa}\left(3,25^{\star} 10^{4}\right)$ e ${ }^{228} \mathrm{Ra}(5,76)$. Portanto, fenômenos geológicos que ocorram em intervalos de tempo inferiores a essas estimativas podem ser quantificados a partir da condição 
de desequilíbrio secular dos sistemas isotópicos relacionados ao decaimento de isótopos de $U$ e Th. Para o caso do ${ }^{238} \mathrm{U}$, a situação de desequilíbrio pode ser retratada por um conjunto de geocronômetros $\left({ }^{230} \mathrm{Th} /{ }^{232} \mathrm{Th},{ }^{234} \mathrm{U} /{ }^{230} \mathrm{Th},{ }^{238} \mathrm{U} /{ }^{234} \mathrm{U}\right)$, os quais têm sido largamente utilizados como ferramenta geocronológica.

Para carbonatos tipo espeleotemas o geocrômetro ideal é representado pela relação de abundância ${ }^{234} \mathrm{U} /{ }^{230} \mathrm{Th}$, respectivamente pai e fitho intermediários na série do ${ }^{238} \mathrm{U}$. Considerando que $U$ (na forma uranila $-{ }^{234} \mathrm{UO}_{2}^{2+}$ ) tem maior solubilidade em meio aquoso comparativamente ao ${ }^{232} \mathrm{Th}^{4+}, \mathrm{U}$ é preferencialmente mantido em solução formando facilmente complexos carbonáticos [p.ex., $\mathrm{UO}_{2}\left(\mathrm{CO}_{3}\right)_{3}{ }^{4}$ ] em meios saturados em $\mathrm{CO}_{3}$. Como resultado, minerais carbonáticos (calcita, aragonita) contém apreciáveis quantidades de $U$ em detrimento de Th uma vez que este é seletivamente acumulado na superfície de partículas minerais (sedimentos). Essas diferenças promovem o fracionamento (desequilibrio) entre esses elementos na hidrosfera, sendo que a produção de ${ }^{230} \mathrm{Th}$ em carbonatos (puros, livres de frações terrigenas) é unicamente função do decaimento de ${ }^{234} \mathrm{U}$.

Em síntese, um conjunto de parâmetros obtidos a partir da série de decaimento ${ }^{238} \mathrm{U}$ ${ }^{234} \cup-{ }^{230} \mathrm{Th}$ pode ser aplicado à determinação de idades e/ou como indicadores ambientais de processos superficiais que tenham afetado um determinado sistema geológico, em especial que tenham ocorrido nos últimos milhares de anos. Em comparação, apenas os métodos de Traço de Fissão, U-Th/He e certos geocronômetros cosmogênicos competem com os métodos de desequilibrio radioativo em obter informações temporais sobre a história mais recente da Terra, inacessiveis a outros métodos clássicos em geocronologia.

\subsection{TÉCNICAS ANALÍticas PARA DETERMINAÇÕES DA SÉRIE dE DESEQUILÍBRIO DO URÂNIO}

Desde meados dos anos 50 até o final da década de 80 , as determinações isotópicas relativas ao método de desequilibrio da série do urânio foram feitas usando espectrometria- $\alpha$, uma vez que os isótopos de $U\left({ }_{92}^{238} \mathrm{U},{ }_{92}^{235} \mathrm{U},{ }_{92}^{234} \mathrm{U}\right)$ e Th $\left({ }_{90}^{232} \mathrm{Th}\right)$, e seus produtos radioativos, são os mais notáveis emissores- $\alpha$ conhecidos na natureza. A técnica baseia-se na detecção de partículas $\alpha$ emitidas por um radionuclideo presente no material de interesse as quais, por sua vez, constituem núcleos atômicos de ${ }_{2}^{4} \mathrm{He}$. A instrumentação resume-se a uma lâmina de Si disposta dentro de uma câmara sob vácuo que está acoplada a um arranjo eletrônico que tem função de amplificar e converter o sinal recebido, transformando-o em contagens. 
Somente em meados da década de 80 a técnica de espectrometria de massa foi aplicada aos métodos de desequilibrio da série do $U$, com significativas melhorias com respeito às determinações por contagem de partículas $\alpha$. Para esse avanço destacam-se as contribuições pioneiras de Chen et al. (1986) e Edwards et al. (1987) que iniciaram o desenvolvimento por espectrometria de massa de ionização termal (TIMS) combinada com diluição isotópica (ID). A importância da espectrometria de massa relaciona-se à combinação de duas características analíticas que referem-se à capacidade de determinar razões isotópicas com elevada precisão e niveis de background muito baixos para o espectro de massa implicando em limites de detecção também muito baixos. Isso só é possível quando a amostra é previamente tratada por cromatografia de troca iônica para separação/purificação dos elementos de interesse, assim removendo possiveis interferentes isobáricos.

$\mathrm{Na}$ espectrometria de massa por ionização termal a amostra é depositada (como uma solução) sobre filamentos metálicos (frequentemente $\mathrm{Re}$ ou $\mathrm{Ta}$ ) e ionizada por aquecimento deste filamento a temperaturas controladas. Nessa etapa a amostra (elemento de interesse) e o solvente é evaporado resultando em um residuo amorfo para ser analisado. Os íons são extraídos para dentro de um sistema de lentes, induzidos pela aplicação de uma corrente de vários kilovolts ao filamento, que colimam e aceleram estes lons para o analisador de massas, donde as massas são separadas. Apesar de sua elevada precisão e exatidão, a técnica TIMS implica em extensivo tratamento químico da amostra que inclui separações dos elementos de interesse em resinas de troca iônica.

A diluição isotópica representa uma das técnicas analíticas mais precisas e sensiveis para determinar a concentração de elementos traços, especialmente quando associada à espectrometria de massa. O principio da técnica consiste em misturar uma quantidade conhecida da amostra com uma quantidade igualmente (e precisamente) bem conhecida de uma solução enriquecida em um dos isótopos naturais do elemento de interesse (spike). Essa mistura em equilíbrio é submetida à separação cromatográfica para isolar esse elemento. A separação é feita em colunas especificas (variáveis quanto a diâmetro interno e altura, p.ex.) empacotadas com resinas de troca iônica que têm a função de substituir ions de uma dada carga (cátions ou ânions) presentes em uma solução por quantidades equivalentes de outros ions de mesma carga presentes em sua constituição. Essas resinas são basicamente constituídas por uma parte rígida - o polímero carbônico, e os grupos funcionais positivamente (resina catiônica) ou negativamente (resina aniônica) carregados, ligados à cadeia carbônica. As cargas desses grupos funcionais (fixos) tendem a estar em equilíbrio com um número equivalente de ions de carga contrária os quais, por sua vez, movimentam-se livremente pelos poros da resina sendo permutados com os ions presentes na solução.

$\mathrm{Na}$ presença de uma solução as resinas de troca iônica alcançam estado de equilibrio entre os ions da solução e os íons presentes no grupo funcional. A partir deste estado de 
equilíbrio, podem ser definidos coeficientes de seletividade baseados na razão dos ions da solução versus os ions na resina. Efetivamente, esses coeficientes de seletividade são uma medida de preferência por um determinado ín, em uma solução, a um determinado pH desta solução. Quanto maior o coeficiente de seletividade, maior a preferência da resina por este determinado ion. Resinas seletivas possuem grupos funcionais específicos e, por isso, alta seletividade por determinados ions, promovendo a separação dos mesmos de uma determinada solução e permitindo a passagem dos demais íons. 


\section{Capítulo III - PROCEDIMENTOS PRÉ-CROMATOGRAFIA LÍQUIDA}

\subsection{INTRODUÇÃO}

Nesse capítulo serão descritos os procedimentos adotados para descontaminação dos materiais laboratoriais e alguns ataques ácidos testados para dissolução de carbonatos. Todos os procedimentos foram desenvolvidas em laboratório limpo do Centro de Pesquisas Geocronológicas, e no Laboratório de Geoquímica do Departamento de Mineralogia e Geotectônica, ambos do IGc/USP. As amostras utilizadas para esses fins foram principalmente padrões internacionais (JCp-1 e JLs-1) de carbonatos, frações extraídas de um espeleotema (SD) coletado na Caverna São Mateus (São Domingos-GO) cedidas pelo prof. Francisco William da Cruz Jr. (IGc-USP), e uma amostra de calcarenito miocênico (procedência Itália)

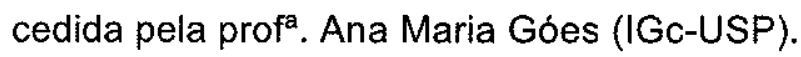

\subsection{DESCONTAMINAÇÃO DOS MATERIAIS UTILIZADOS}

A implementação do método U-Th requer um conjunto de materiais próprios para uso em rotinas de cromatografia líquida e que são comuns aos vários métodos clássicos conhecidos. Incluem-se nesse conjunto béqueres Savillex®, colunas Bio Rad® e de teflon retrátil, resinas de troca iônica (Bio Rad® $A G$ 1-X8 e Spectra/Gel $($ IE 1-X8), garrafas de armazenamento de ácidos, pissetas, ponteiras e tubos de centrifugação (Fig. 01), dentre outros menos específicos. Os procedimentos de descontaminação adotados para o presente método seguiram a rotina já estabelecida no CPGeo, e estão descritos individualmente abaixo.

Nos procedimentos foram usados os ácidos nítrico $\left(\mathrm{HNO}_{3}\right)$ e clorídrico $(\mathrm{HCl})$, comercializados pela empresa MERCK@ e classificados com grau P.A. (Pureza Analítica), além de água Milli-Q (Nanopure $18.3 \mathrm{~m} \Omega$ ). Foram utilizados tanto ácidos P.A. puros $(\mathrm{HCl} 37 \%$ e $\mathrm{HNO}_{3} 65 \%$, em massa) quanto destilados (por destilação fracionada; Fig. 02), mas sempre diluídos a $50 \%$ em volume com água Milli-Q; a exceção foi $\mathrm{HCl} 6 \mathrm{~N}$ que é obtido através da destilação do $\mathrm{HCl}$ P.A. $37 \%$ para uma concentração de aproximadamente $10 \mathrm{~N} \mathrm{e}$, a partir de então, diluído até $6 \mathrm{~N}$. 

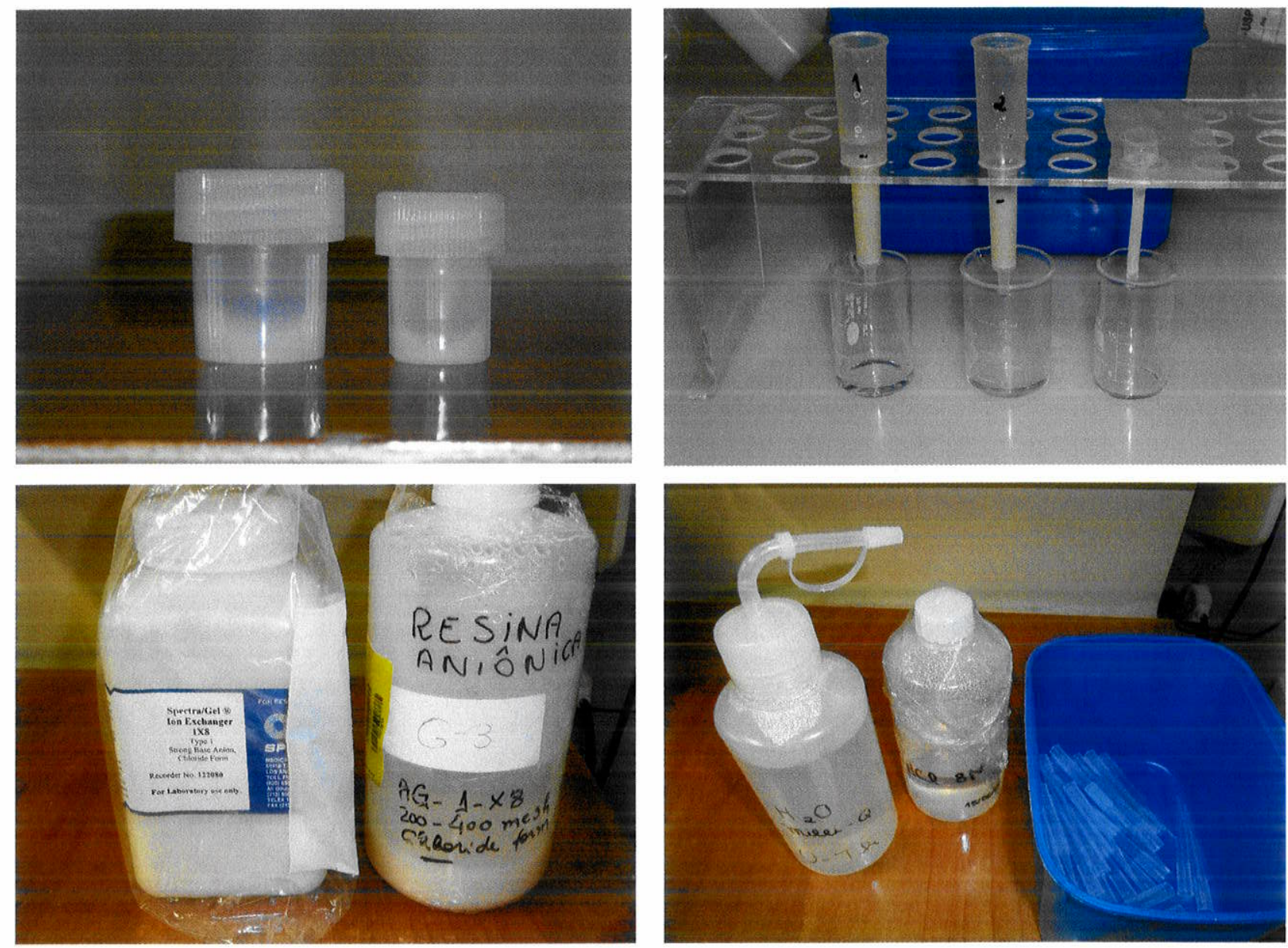

Figura 01. Materiais diversos utilizados nas diferentes etapas de implementação do método U-Th no Centro de Pesquisas Geocronológicas. Da esquerda para direita, de cima para baixo: A. Béquer Savillex® (7 e $15 \mathrm{~mL})$; B. Colunas Bio Rad® e de teflon retrátil; C. Resinas de troca iônica; D. Garrafa, pisseta e ponteiras.

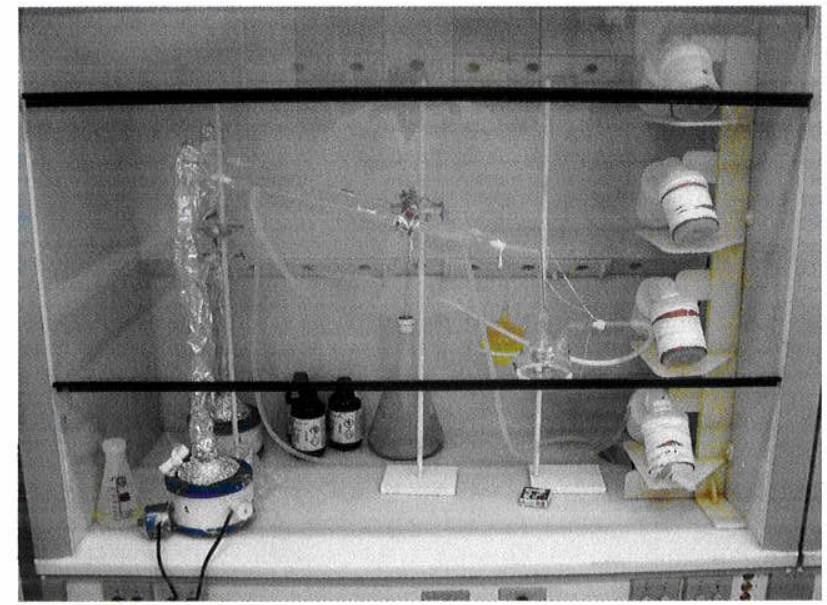

Figura 02. Destilador de quartzo com coluna de Vigreux para destilação fracionada, utilizado para produção contínua de ácidos de alta pureza a partir de reagentes P.A. O sistema de aquecimento consiste de uma manta aquecedora.

No texto, onde for referenciada apenas a identificação do ácido (p. ex., $\mathrm{HNO}_{3}$ ) entendase $\mathrm{HNO}_{3}$ P.A. diluído a $50 \%$. Outrossim, haverá procedimentos em que o ácido utilizado deve ser previamente destilado e, somente a seguir, diluído a $50 \%$ em volume. Quando for o caso, será claramente informado para diferenciar de outros em que apenas é necessário a utilização de ácido diluído. 


\subsubsection{Descontaminação de béqueres Savillex®}

Lavar os béqueres com água destilada e detergente para, a seguir, adicionar $\mathrm{HNO}_{3} \mathrm{O}$ suficiente para cobrir o fundo (aproximadamente $1 \mathrm{~mL}$ ); fechar e levar à chapa quente (a $c$. $100^{\circ} \mathrm{C}$ ) por 15 minutos (Fig. 03A). Descartar o ácido e lavar os béqueres com água Milli-Q e colocar em imersão dentro de béqueres de vidro de 2 litros preenchidos com solução de $\mathrm{HNO}_{3}$, em chapa quente. Notar que os béqueres devem estar separados das tampas, as quais devem passar pelo mesmo procedimento. Após atingir a fervura manter na chapa por aproximadamente 1 hora. Retirar, deixar esfriar, descartar o ácido e, por fim, encher duas vezes os béqueres de vidro com água Milli-Q, enxaguar os béqueres Savillex® e descartar.

Após essa primeira sequência, encher os mesmos béqueres de vidro com água Milli- $Q$, mergulhar os béqueres Savillex ${ }^{\circledR}$ e retornar à chapa quente, mantendo-os por aproximadamente 1 hora após a fervura. Deixar esfriar e descartar água. A partir de então, adicionar cerca de $1 \mathrm{~mL}$ de $\mathrm{HNO}_{3}$ destilado em cada béquer, fechar com as tampas e retornar à chapa quente por 15 minutos para, a seguir, voltar a descartar o ácido e lavar com água MilliQ. Por fim, repetir esse mesmo procedimento com ácido clorídrico destilado $(\mathrm{HCl}) 6 \mathrm{~N}$ em cada béquer, e colocar para secagem final.

\subsubsection{Descontaminação de colunas}

Lavar as colunas, uma a uma, com água Milli-Q e mergulhá-las dentro de um béquer contendo $\mathrm{HNO}_{3}$ destilado. Deixar o béquer fechado com Magipack® em ultra-som, por uma hora (Fig. 03B). Retirar do ultra-som e descartar o ácido usado. Lavar as colunas, uma a uma, com água Milli-Q e mergulhá-las dentro de um béquer com água. Deixar o béquer em ultra-som por uma hora. Retirar, descartar a água e colocar para secar.

\subsubsection{Descontaminação de ponteiras}

Lavar as ponteiras com $\mathrm{HNO}_{3}$, uma por vez, por dentro e por fora. Lavar novamente utilizando água Milli-Q, por dentro e por fora, duas vezes. Colocar as ponteiras em um béquer de vidro de 2 litros e adicionar $\mathrm{HNO}_{3}$, tendo cuidado para que fiquem completamente imersas na solução ácida. Deixar em ultra-som por 1 hora. Descartar o ácido, encher o béquer de vidro com água Milli-Q, agitar e descartar; repetir o enxágue duas vezes. Encher uma terceira vez o béquer de vidro com água Milli-Q e deixar em ultra-som por 1 hora. Retirar, descartar a água e colocar as ponteiras para secar. 


\subsubsection{Descontaminação de tubos de centrífuga (tipo Falcon)}

Lavar os tubos, um a um, com água destilada e detergente. Dispor os tubos em pé dentro de um béquer de vidro de 2 litros. Adicionar $\mathrm{HNO}_{3}$ em cada tubo, preenchendo-os completamente. Encher o béquer com água Milli-Q até o nivel correspondente à metade dos tubos e deixar em ultra-som por 1 hora. Retirar, descartar o ácido de cada tubo e despejar a água. Ainda com os tubos dentro do béquer, adicionar água Milli- $Q$ e enxaguar, por duas vezes. Encher o béquer novamente com água Milli-Q e deixar em ultra-som por mais 1 hora. Retirar, despejar a água e colocar os tubos para secar.

As tampas dos tubos devem ser colocadas em outro béquer de vidro, dispondo um peso (p. ex., "tampa" de teflon) por sobre as mesmas. Adicionar $\mathrm{HNO}_{3}$ até cobrir o peso e deixar em ultra-som por 1 hora. Retirar e descartar o ácido. Adicionar água Milli-Q e enxaguar, por duas vezes. Encher o béquer de vidro novamente com água Milli-Q e levar para o ultra-som, por mais 1 hora. Retirar, despejar a água e colocar para secar.
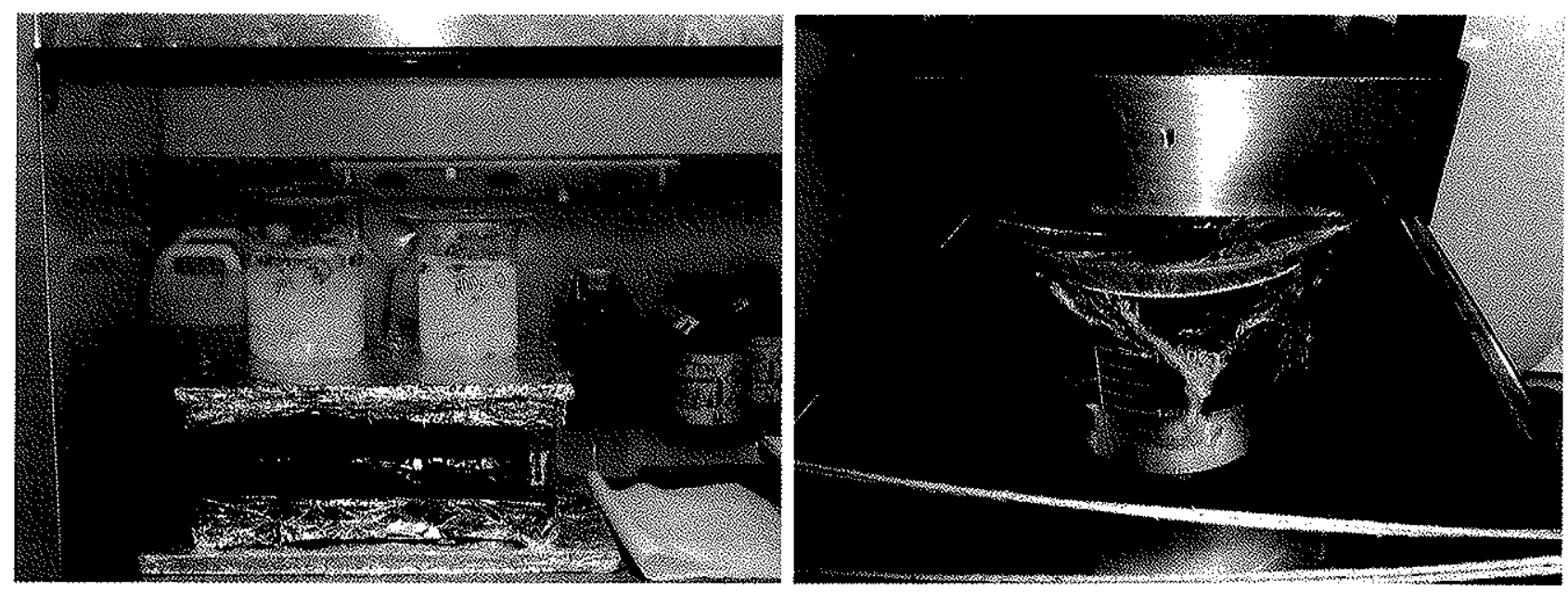

Figura 03. Da esquerda para a direita: A. Etapa de descontaminação de béquer Savillex® em meio ácido, em chapa aquecedora. B. Etapa de lavagem de colunas em meio ácido, em ultrassom.

\subsubsection{Lavagem de resinas de troca iônica (Bio Rad® AG 1-X8 e Spectra/Ge/@ IE 1-X8)}

O procedimento adotado para as resinas foi aquele já em rotina no CPGeo. A primeira etapa consiste em colocar um volume desejado da resina dentro de um béquer Savillex® e encher com água Milli-Q em proporção de aproximadamente três vezes o volume da resina. Fechar o béquer Savillex®, agitar bastante, deixar em repouso para a resina decantar, e descartar a água. Repetir o procedimento quatro vezes. A seguir, no mesmo béquer Savillex® adicionar $\mathrm{HCl} 6 \mathrm{~N}$ destilado, fechar a tampa, agitar e deixar decantar; esse movimento deve ser repetido quatro vezes antes de descartar o ácido por completo. Da mesma forma, repetir essa etapa quatro vezes, mas substituindo o $\mathrm{HCl}$ por água Milli-Q. 
O procedimento completo de lavagem $\mathrm{com} \mathrm{HCl} 6 \mathrm{~N} \mathrm{e}$, em seguida, água Milli-Q deve ser feito em dois ciclos. Após o segundo ciclo a resina pode ser acondicionada em água Milli-Q.

\subsection{DISSOLUÇÃO ÁCIDA DE CARBONATOS}

Um número razoável de procedimentos para dissolução ácida de carbonatos pode ser encontrado na literatura, incluindo: ataque com $\mathrm{HNO}_{3}$ (Hellstrom, 2003), $\mathrm{HCl}$ forte (Richards et al., 1998) ou fraco (Ohno, 2007), mistura de ácidos fortes ( $\mathrm{HNO}_{3}+\mathrm{HF}$; Chai et al., 2003), ou ainda fusão alcalina com $\mathrm{LiB}_{4} \mathrm{O}_{7}$ e $\mathrm{LiBO}_{2}$ (p.ex., Galindo et al., 2008). O uso de $\mathrm{LiB}_{4} \mathrm{O}_{7}$ ou $\mathrm{LiBO}_{2}$ não foi considerado nesse trabalho uma vez que tendem elevar significativamente os niveis de branco por ser comercializado apenas na forma P.A., não adequado para procedimentos com diluição isotópica.

Para este trabalho os testes de dissolução em meio ácido foram feitos com dois padrões internacionais JCp-1 (coral Porites Sp.) e JLs-1 (calcário com matéria orgânica) referenciados pelo Geological Survey of Japan, com amostras coletadas do espeleotema SD, e com uma amostra de calcarenito (C3/105). Como um todo, esses materiais representam carbonatos puros (JCp-1 e SD), impuros (calcarenito), e com alto teor de matéria orgânica (JLS-1), escolhidos de forma a testar a eficiência de ataques com diferentes ácidos e concentrações.

Para todos os testes foram pesados aproximadamente $200 \mathrm{mg}$ de material pulverizado, em béquer Savillex®; essa quantidade foi estabelecida como padrão para todos os testes de calibração das colunas por representar valor mais próximo daquele normalmente extraido das camadas de crescimento milimétricas em espeleotemas para datação U-Th.

De forma geral, os testes com ácido nítrico $\left(\mathrm{HNO}_{3} 7 \mathrm{~N}\right)$ e clorídrico $(\mathrm{HCl} 6 \mathrm{~N})$ seguiram a mesma rotina. Antes da colocação de qualquer um dos dois ácidos foi adicionado $1 \mathrm{~mL}$ de água Milli-Q à amostra para evitar a reação imediata, o que poderia acarretar em perda de material. O volume de água foi insatisfatório uma vez que ainda observou-se forte efervescência após a adição dos ácidos, motivo pelo qual foi considerada a adição de mais 1 $\mathrm{mL}$, totalizando $2 \mathrm{~mL}$ de água Milli-Q usados como regra no procedimento de digestão das amostras. Todos os testes foram feitos em temperatura ambiente.

\subsubsection{Teste com ácido nitrico}

O procedimento com $\mathrm{HNO}_{3} 7 \mathrm{~N}$ teve sucesso. Ao volume de $2 \mathrm{~mL}$ de água Milli-Q foi adicionado $1 \mathrm{~mL}$ do ácido, totalizando $3 \mathrm{~mL}$ de reagentes adicionados aos $200 \mathrm{mg}$ de amostra. O padrão JCp-1 e as frações do espeleotema SD foram completamente dissolvidos; ao 
contrário, o ataque para o padrão JLs-1 resultou em uma solução límpida mas com material escuro em suspensão que representa a matéria orgânica contida neste padrão.

\subsubsection{Teste com ácido clorídrico}

O mesmo procedimento usado para a dissolução com $\mathrm{HNO}_{3}$ fol adotado para $\mathrm{HCl} 6 \mathrm{~N}$, com igual eficiência para o padrão JCp-1 e frações do espeleotema SD; para o padrão JLs-1 novamente verificou-se a presença de resíduo escuro em suspensão. Também foi testado o uso de ácido clorídrico fraco $(\mathrm{HCl} 2 \mathrm{~N}$ ) conforme proposta de Ohno (2007). Aqui, o volume utilizado de $\mathrm{HCl} 2 \mathrm{~N}$ foi $3 \mathrm{~mL}$ e não $2 \mathrm{~mL}$ como recomendado pelo autor. A dissolução só foi completada após um período de 12 horas, em temperatura ambiente.

\subsubsection{Teste com mix fluorídrico:nitrico e perclórico:nítrico para o padrão JLs-1}

Esses testes foram especificamente realizados para o padrão JLs-1 uma vez que os ataques com $\mathrm{HNO}_{3} 7 \mathrm{~N}$ e HCl $6 \mathrm{~N}$ não foram satisfatórios, resultando numa solução límpida com matéria orgânica em suspensão.

Primeiro foi considerado o uso de um mix forte conforme proposto por Chai et al. (2003) para determinação de $U$ e Th em carbonatos. A aproximadamente $200 \mathrm{mg}$ do padrão JLs-1 foi adicionada uma mistura $\mathrm{HF}: \mathrm{HNO}_{3} 7 \mathrm{~N}$ na proporção 2:1, em béquer Savillex® (a c. $100^{\circ} \mathrm{C}$ ), sem uso de $\mathrm{HClO}_{4}{ }^{1}$. O ataque resultou na formação de um precipitado branco, de textura gelatinosa, insolúvel mesmo após adição subsequente de $\mathrm{HNO}_{3} 7 \mathrm{~N}$ ou $\mathrm{HCl} 6 \mathrm{~N}$, por um período de 12 horas. Esse precipitado foi evaporado até completa secura e levado ao MEV para análise EDS, mas o comportamento fortemente higroscópico não permitiu a verificação de sua composição. Situação similar foi observada em testes de digestão de carbonatos usando forno micromondas, e comentada em Kemp e Brown (1990). Esses autores apontam para a formação de fluoreto de cálcio ${ }^{2}$ gerado a partir da reação de $\mathrm{Ca}$ em excesso, com flúor.

Um segundo teste com mix forte $\mathrm{HF}: \mathrm{HNO}_{3}$ (agora na proporção $3: 1 \mathrm{~mL}$ ) foi feito em bomba Parn®. $\mathrm{O}$ ataque foi feito em estufa a $c .200^{\circ} \mathrm{C}$, por cinco dias. Ainda assim, observou-se formação do mesmo precipitado branco insolúvel.

Partiu-se então para dissolução com ácidos perclórico:nitrico. Novamente o teste foi realizado com c. $200 \mathrm{mg}$ do padrão JLs-1. Em um béquer Savillex® foram adicionados $2 \mathrm{~mL}$ de água Milli-Q e $1 \mathrm{~mL}$ de ácido nítrico $7 \mathrm{~N}$ e, logo a seguir, a solução ácida foi evaporada. Ao resíduo foram adicionados $0,5 \mathrm{~mL}$ de $\mathrm{HNO}_{3}$ concentrado e $0,5 \mathrm{~mL}$ de $\mathrm{HClO}_{4}$ e deixado em chapa quente a $c .130^{\circ} \mathrm{C}$. Após $10-15$ minutos adicionou-se mais $0,5 \mathrm{~mL}$ de ácido nítrico

\footnotetext{
${ }^{1}$ Os autores sugerem seu uso, mas esse ácido não é rotineiramente utilizado nos laboratórios do CPGeo, motivo pelo qual não foi considerado nesse procedimento.

${ }^{2} \mathrm{CaCO}_{2}+\mathrm{HF} \rightarrow \mathrm{CaF}_{2}+\mathrm{CO}_{2}$
} 
concentrado, quando notou-se a liberação de fumaça branca. Esse processo continuou por um periodo de aproximadamente 3 horas de aquecimento em chapa. Mesmo assim, a matéria orgânica não foi dissolvida; aparentemente concentrou-se como uma massa no fundo do béquer. Esse método tem sido descrito na literatura como eficaz na dissolução de matéria orgânica, mas com longo tempo de dissolução que pode chegar até 2 dias. Por esse motivo, e pelo fato de que $\mathrm{HClO}_{4}$ é potencialmente explosivo e por seu uso implicar em condições diferentes daquelas rotineiramente adotadas nos laboratórios do CPGeo (p.ex., calibração de chapa quente a temperatura superior a $100^{\circ} \mathrm{C}$, inexistência de capela de exaustão apropriada para o manuseio), esse método de dissolução foi descartado.

Como último teste para eliminar a matéria orgânica do padrão JLs-1 optou-se por calcinar os $200 \mathrm{mg}$ de JLs-1 (postos em cadinho de porcelana) numa mufla a $900^{\circ} \mathrm{C}$, durante uma hora. Após resfriamento, o sal resultante foi completamente dissolvido utilizando o procedimento descrito no item 3.3.1.

\subsubsection{Teste de dissolução de uma amostra de carbonato com fração terrígena}

Considerando que pequenas frações de material terrígeno (silicatos, óxidos, fostatos, etc) podem estar presentes em espeleotemas, fol feito teste de dissolução ácida com uma amostra de calcarenito (amostra 3/105, com fração terrígena $\leq 1 \%$ ). Foram pesados c. $200 \mathrm{mg}$ do calcarenito e aplicado o procedimento descrito no item 3.3.1 para dissolução da fração carbonática. Após secagem, o resíduo foi atacado com um $2 \mathrm{~mL}$ de $\mathrm{HF}$ e $1 \mathrm{~mL}$ de $\mathrm{HNO}_{3} 7 \mathrm{~N}$, por cerca de 3 dias, em chapa quente a c. $100^{\circ} \mathrm{C}$. Não houve dissolução, mesmo adicionandose $\mathrm{HCl} 6 \mathrm{~N}$ para dissolução de possiveis fluoretos precipitados. $\mathrm{O}$ mesmo teste foi realizado agora em bomba Parr®, utlizando-se o mix $\mathrm{HF}: \mathrm{HNO}_{3} 7 \mathrm{~N} \mathrm{em} 3: 1$, em estufa a $200^{\circ} \mathrm{C}$, por 5 dias. Esse ataque resultou em uma solução de cor esverdeada com presença de precipitado branco. O passo seguinte foi evaporar e adicionar $4 \mathrm{~mL}$ de $\mathrm{HCl} 6 \mathrm{~N}$ por mais dois dias em estufa a $200^{\circ} \mathrm{C}$. A dissolução foi completa. 


\section{Capítulo IV - SEPARAÇÃo CROMATOGRÁFICA DE TROCA IÔNICA}

\subsection{INTRODUÇÃO}

Conforme comentado no Capítulo 1, esta dissertação irá testar duas rotinas de análises cromatográficas para o método U-Th já implementadas em outros laboratórios. Detalhes sobre as duas rotinas podem ser encontradas em Sharp et al. (2003) e Edwards et al. (1987). Aqui, ambas foram reproduzidas integralmente, muito embora algumas modificações tenham sido acrescentadas buscando-se atingir resultados mais satisfatórios.

As leituras de $U$ e Th nas soluções preparadas para calibração foram feitas no Laboratório de Geoquímica do Departamento de Mineralogia e Geotectônica (IGc/USP), em um ICP-MS ELAN 6100 da Perkin Elmer, e no Laboratório de Geoquímica Analítica do Departamento de Geologia e Recursos Naturais (IGc/UNICAMP), em ICP-MS X Series II da Thermo Scientific. No laboratório do IGc/USP, a amostra é aspergida em um nebulizador do tipo Meinhard, acoplado a uma bomba peristáltica e câmara ciclônica em quartzo, que possibilita maior estabilidade no fluxo da amostra e baixos níveis de detecção. Possui um analisador de massa do tipo quadrupolar e as intensidades são medidas utilizando um detector tipo Dual. As condições operacionais e os parâmetros instrumentais do ICP-MS utilizados nas análises são: (i) fluxo de gás carregador: $0,90 \mathrm{~L} / \mathrm{min}$, (ii) fluxo de gás auxiliar: $1,2 \mathrm{~L} / \mathrm{min}$, (iii) fluxo de gás do plasma: $15 \mathrm{~L} / \mathrm{min}$, (iv) voltagem das lentes: $8,25 \mathrm{~V}$, (v) potência de rádiofrequência: $1100 \mathrm{~W}$, (vi) tensão do estágio analógico: $-2050 \mathrm{~V}$ e (vii) tensão do estágio digital: $1400 \mathrm{~V}$.

As curvas de calibração para $U$ e Th foram construídas para a faixa de concentração destes elementos nos padrões $\mathrm{JCp}-1$ e JLs-1, que foram utilizados para a calibração das colunas cromatográficas. Os dados são apresentados na tabela 01 . Cinco soluções-padrão (Padrões 1, 2, 3, 4 e 5) foram preparadas a partir de soluções de $U\left(1000 \mathrm{mg} / \mathrm{mL}\right.$, em $\mathrm{HNO}_{3}$ a $1,06 \%$ em massa) e Th $\left(986 \mu \mathrm{g} / \mathrm{mL}\right.$, em $\mathrm{HNO}_{3}$ a $5 \%$ em massa) para absorção atômica, comercializadas pela Fluka Analytical. As soluções-padrão foram obtidas a partir de duas soluções-mãe (A e B) com as seguintes concentrações: (i) $A$ com $1250 \mathrm{ng} / \mathrm{g}$ de $U$, que foi diluída para $B$ com $15,625 \mathrm{ng} / \mathrm{g}$ de U; (ii) A com $616,25 \mathrm{ng} / \mathrm{g}$ de $\mathrm{Th}$, que foi diluída para $B$ com $7,7031 \mathrm{ng} / \mathrm{g}$ de Th. Pequenas aliquotas das duas diluições (soluções-mãe $A$ e $B$ ) de ambos $U$ e Th foram pesadas e o volume final foi completado para $10 \mathrm{~mL}$ com $\mathrm{HNO}_{3} 0,1 \mathrm{~N}$ de forma que as concentrações finais de cada solução-padrão representem valores mínimo, máximo e intermediários para a faixa estimada das amostras a serem analisadas - JCp-1 e JLs-1. 
Tabela 01. Parâmetros de preparação das soluções de calibração para ICP-MS (IGc/USP).

\begin{tabular}{|c|c|c|c|c|c|}
\hline & $\begin{array}{c}\text { Solução diluída U } \\
\text { (gramas) }\end{array}$ & $\begin{array}{c}\text { Solução diluída Th } \\
\text { (gramas) }\end{array}$ & $\begin{array}{l}\mathrm{HNO}_{3} 0,1 \mathrm{~N} \\
\text { (gramas) }\end{array}$ & $U(n g / g)$ & Th $(n g / g)$ \\
\hline Branco & & & & 0,0 & 0,0 \\
\hline Padrão 1 & $0,31656($ de $B)$ & $0,13159($ de $B)$ & 9,39805 & 0,5 & 0,1 \\
\hline Padrão 2 & 3,15885 (de B) & $0,31223(\mathrm{de} B)$ & 6,38245 & 5,0 & 0,25 \\
\hline Padrão 3 & $0,08173(\mathrm{de} A)$ & 0,64345 (de B) & 9,09727 & 10,0 & 0,5 \\
\hline Padrão 4 & $0,16129($ de $A)$ & 1,28297 (de B) & 8,40306 & 20,0 & 1,0 \\
\hline Padrão 5 & 0,27428 (de A) & $1,91317(\mathrm{de} \mathrm{B})$ & 7,62534 & 35,0 & 1,5 \\
\hline
\end{tabular}

As leituras de $U$ e Th realizadas no laboratório da UNICAMP também foram obtidas utilizando ICP-MS com analisador quadrupolar. O sistema de introdução de amostras consiste em um amostrador automático (modelo SC.Fast da Elemental Scientific) acoplado a uma bomba peristáltica operando em $38 \mathrm{rpm}$. A nebulização é realizada em um nebulizador concêntrico acoplado à uma câmara de nebulização de impacto com temperatura estabilizada em $4^{\circ} \mathrm{C}$. Um conjunto de cones de níquel (modelo $\mathrm{Xt}$ ) foi utilizado. As condições operacionais e os parâmetros instrumentais do ICP-MS foram: (i) Potência - $1370 \mathrm{~W}$; (ii) extração - $160 \mathrm{~V}$; (iii) fluxo de gás do plasma - 13 L. $\mathrm{min}^{-1}$; (iv) fluxo nebulizador - 0,82 L. $\mathrm{min}^{-1}$; (v) tempo de permanência para os isótopos ${ }^{232} \mathrm{Th} \mathrm{e}^{238} \mathrm{U}-30 \mathrm{~ms}$.

As curvas de calibração para $U$ e Th foram construídas para a faixa de concentração destes elementos nos padrões JCp-1 e JLs-1, que foram utilizados para a calibração das colunas cromatográficas. As concentrações nominais são apresentadas na tabela 02. Assim como no IGc, as cinco soluções-padrão (Padrões 1, 2, 3, 4 e 5) foram preparadas a partir de soluções de $U\left(10 \mu \mathrm{g} / \mathrm{mL}\right.$, em $\mathrm{HNO}_{3}$ a $\left.2 \%\right)$ e Th $\left(10 \mu \mathrm{g} / \mathrm{mL}\right.$, em $\mathrm{HNO}_{3}$ a $\left.2 \%\right)$ para ICP-MS, comercializadas pela High Purity Standards. Diariamente foi preparada uma solução-mãe mista com as seguintes concentrações: $1000 \mathrm{ng} / \mathrm{g}$ de $U$ e $50 \mathrm{ng} / \mathrm{g}$ de Th. Pequenas aliquotas dessa solução mista foram pesadas e o volume final foi completado para $10 \mathrm{~mL}$ com HNO $30,1 \mathrm{~N}$ de forma que as concentrações finais de cada solução-padrão representem valores mínimo, máximo e intermediários para a faixa estimada das amostras a serem analisadas.

Tabela 02. Parâmetros de preparação das soluções de calibração para ICP-MS (IGc/UNICAMP).

\begin{tabular}{l|c|c|c|c|}
\hline & $\begin{array}{c}\text { Solução mista de } \\
\text { Ue Th } \\
\text { (gramas) }\end{array}$ & $\begin{array}{c}\mathrm{HNO}_{3} \text { 0,1 N } \\
\text { (gramas) }\end{array}$ & $U$ (ng/g) & Th (ng/g) \\
Branco & 0,0100 & 10,000 & 0,0 & 0,0 \\
Padrão 1 & 0,0200 & 10,000 & 1,0000 & 0,0500 \\
Padrão 2 & 0,0500 & 10,000 & 2,0000 & 0,1000 \\
Padrão 3 & 0,1000 & 10,000 & 5,0000 & 0,2500 \\
Padrão 4 & 0,2000 & 10,000 & 10,0000 & 0,5000 \\
Padrão 5 & & 20,0000 & 1,0000 \\
\hline
\end{tabular}


Todas as leituras obtidas por ICP-MS estão disponiveis no Anexo I.

\subsection{O MÉTOdO DE CALIBRAÇÃO DAS COLUNAS CROMATOGRÁFICAS NO BGC}

De forma geral, o método no BGC consiste na separação de $U$ e Th em aliquotas independentes a partir da utilização de dois conjuntos de colunas de troca iônica, com volumes de empacotamento distintos. A resina utilizada foi AG 1-X8 comercializada por Bio Rad® Laboratories, uma resina de troca aniônica seletiva fortemente básica, de grau analítico, na forma iônica de cloreto e de granulometria 200-400 mesh, grupo funcional $\mathrm{R}-\mathrm{CH}_{2} \mathrm{~N}-\left(\mathrm{CH}_{3}\right)_{3}$ e matriz estireno-divinil-benzeno. A ordem de seletividade é dada por $\mathrm{I}^{-}>\mathrm{NO}_{3}{ }^{-}>\mathrm{Br}^{-}>\mathrm{Cl}^{-}>$ acetato $>\mathrm{F}^{-}>\mathrm{OH}^{*}$. Todos os ácidos utilizados nessa etapa foram purificados por destilação fracionada em destilador de quartzo e o peso inicial para todas as frações dos padrões $\mathrm{JCp}-1$ e JLs-1 foi de aproximadamente $200 \mathrm{mg}$.

Após a dissolução em $\mathrm{HNO}_{3} 7 \mathrm{~N}$, conforme o item 3.3.1 deste capítulo, a soluçãoamostra representada pelos padrões dissolvidos foi evaporada à secura, a temperatura de $c$. $100^{\circ} \mathrm{C}$. Ao resíduo foi adicionado $1,5 \mathrm{~mL}$ de $\mathrm{HNO}_{3} 7 \mathrm{~N}$ e, após completa dissolução em temperatura ambiente, foi iniciado o procedimento em coluna primária descrito passo-a-passo abaixo. Contudo, antes do depósito da solução-amostra é necessário ambientar a resina (previamente descontaminada cf. item 3.2.5) com a eluição de $6 \mathrm{~mL}$ de $\mathrm{HNO}_{3} 1 \mathrm{~N}$ seguido de 6 $\mathrm{mL}$ de $\mathrm{H}_{2} \mathrm{O}$ Milli-Q e, a seguir, $3 \mathrm{~mL}$ de $\mathrm{HNO}_{3} 7 \mathrm{~N}$.

\subsubsection{Procedimento para coluna primária (volume de empacotamento $3 \mathrm{~mL}$ )}

Depositar a solução-amostra na coluna e, após completo escoamento, adicionar $6 \mathrm{~mL}$ de $\mathrm{HNO}_{3} 7 \mathrm{~N}$. Durante essa etapa todo o volume escoado deve ser descartado. Na sequência, deve-se proceder a coleta de Th adicionando duas medidas de $12 \mathrm{~mL}$ (cada) de $\mathrm{HCl} 8 \mathrm{~N}$, as quais deverão ser recolhidas em béqueres Savillex® com volume adequado. A coleta do $U$ sucede imediatamente a coleta de Th e é feita a partir da adição de $12 \mathrm{~mL}$ de $\mathrm{HCl} 0,5 \mathrm{~N}$, que deve ser recolhido em um terceiro béquer Savillex®. $O$ passo seguinte consiste em levar à secura os volumes coletados de $U$ e Th, em chapa quente a c. $100^{\circ} \mathrm{C}$.

Os resíduos pós-secura são dissolvidos separadamente acrescentando-se $0,1 \mathrm{~mL}$ de $\mathrm{HNO}_{3}$ e, a seguir, $0,1 \mathrm{~mL}$ de $\mathrm{H}_{2} \mathrm{O}$ Mili-Q a cada um deles. Garantida a completa dissolução, as três alíquotas devem ser juntadas em um único béquer totalizando $0,6 \mathrm{~mL}$ de solução-amostra $\mathrm{U}+\mathrm{Th}$ em $\mathrm{HNO}_{3} 7 \mathrm{~N}$. Novamente, antes do depósito da solução-amostra é necessário ambientar a resina com a eluição de $2,4 \mathrm{~mL}$ de $\mathrm{H}_{2} \mathrm{O}$ Milli-Q seguidos de $1,2 \mathrm{~mL}$ de $\mathrm{HNO}_{3} 7 \mathrm{~N}$. 


\subsubsection{Procedimento para coluna secundária (volume de empacotamento 1,2 $\mathrm{mL}$ )}

Depositar a solução-amostra na coluna e, após completo escoamento, adicionar $2,4 \mathrm{~mL}$ de $\mathrm{HNO}_{3} 7 \mathrm{~N}$. Como feito na coluna primária, todo o volume deve ser descartado antes da coleta das alíquotas de interesse. Em seguida, o Th é coletado após adição de duas medidas de $4,8 \mathrm{~mL}$ de $\mathrm{HCl} 8 \mathrm{~N}$, que podem ser recolhidas no mesmo béquer Savillex®. Para a coleta do $\mathrm{U}$ adicionar $4,8 \mathrm{~mL}$ de $\mathrm{HCl} 0,5 \mathrm{~N}$ e recolher em um segundo béquer. Por fim, levar à secura as alíquotas de $\mathrm{U}$ e $\mathrm{Th}$, em chapa quente a c. $100^{\circ} \mathrm{C}$.

\subsection{RESUltados dos testes de CALIBRAÇÃo No CPGEO SEgundo O PROCEDIMENTO BGC}

\subsubsection{Primeira Etapa de Teste}

Seguindo esse procedimento foram pesadas quatro frações de c. $200 \mathrm{mg}$ de cada um dos padrões JCp-1 e JLs-1 (tabela 03). Apesar de garantida a dissolução completa do JCp-1 (mas não exatamente do $\mathrm{JLS}-1$ ) com $\mathrm{HNO}_{3}$ ou com HCl, duas das frações foram atacadas com $\mathrm{HNO}_{3} 7 \mathrm{~N}$ e $\mathrm{HF}$ para avaliar se o precipitado branco invariavelmente formado quando adicionado o ácido fluorídrico reteve $U$ e/ou Th, prejudicando a recuperação pós-cromatografia. Assim, duas frações do JCp-1 e JLs-1 ([1] e [2]) foram atacadas com mix $\mathrm{HNO}_{3}: \mathrm{HF}$ em 1:1, antes adicionando $2 \mathrm{~mL}$ de água Milii- $Q^{3}$; as outras duas frações ([3] e [4]) de ambos os padrões foram dissolvidas somente com $\mathrm{HNO}_{3} 7 \mathrm{~N}$ (cf. sub-item 3.3.1), sendo que a fração JLs-1[4] foi centrifugada para descarte da matéria orgânica não-dissolvida.

Todas as frações foram colocadas na coluna primária seguindo o procedimento descrito em 4.2.1 e, a seguir, na coluna secundária conforme descrito em 4.2.2. Das sete frações (excluindo JCp-1 [2]), apenas JCp-1 [3] e [4] e JLs-1 [4] foram completamente dissolvidas no volume proposto para o depósito na coluna primária $1,5 \mathrm{~mL} \mathrm{HNO} 37 \mathrm{~N}$. Para as demais $\mathrm{JCp}-1$ [1], e JLs-1 [1], [2] e [3] não foi possível garantir dissolução completa dada a presença de pequenos residuos aderidos fortemente ao fundo do béquer, mesmo após atrito com a ponteira. Já para a coluna secundária todas as coletas foram idealmente dissolvidas com adição de $0,6 \mathrm{~mL}$ de $\mathrm{HNO}_{3} 7 \mathrm{~N}$.

As percentagens de recuperação de $U$ e Th foram calculadas a partir das concentrações recomendadas para o padrão JLs- $1(U=1,75 \mathrm{ppm}$ e Th $=0,0287 \mathrm{ppm}$; Imai et al., 1996) e a média dos valores estimados das concentrações de U e Th para o padrão JCp-1 $\left(U_{\text {média }}=2,7 \mathrm{ppm}\right.$ e $\mathrm{Th}_{\text {media }}=0,055 \mathrm{ppm}$; Ohde, 2002; Inoue et al., 2004; Watanabe e Nakai,

\footnotetext{
${ }^{3} \mathrm{O}$ precipitado branco da fração $\mathrm{JCp}-1$ [2] foi levado para análise de sua composição em MEV, resultando em insucesso por ser muito higroscópico.
} 
2006a, b; Aizawa, 2008). A partir do peso inicial foram calculadas as concentrações de U e Th em cada fração, e estas comparadas com as concentrações determinadas pela análise por ICP-MS. Os resultados são apresentados na tabela 03.

Os dados de recuperação para $U$ foram satisfatórios, acima de $90 \%$. O mesmo não foi observado para Th, onde as recuperações não ultrapassaram $72 \%$ permanecendo, na maioria das amostras analisadas, entre 40 e $60 \%$. Considerando que a quantidade de Th medida nas aliquotas de $U$ é desprezível $(<0,1 \%)$, é provável que a baixa recuperação esteja associada às dificuldades na dissolução da fração de Th coletada na coluna secundária com ácido fraco, antes da análise no ICP-MS. Esse procedimento foi feito inicialmente com adição direta de 5 $\mathrm{mL}$ (volume solicitado para a leitura) de $\mathrm{HNO}_{3} \mathrm{O}, 1 \mathrm{~N}$. Nenhumas das coletas de $\mathrm{U}$ ou Th foram dissolvidas motivo pelo qual foram levadas a ultra-som por 1 hora para potencializar a solubilidade. Com esse procedimento todas as coletas de $U$, bem como a coleta de Th do JCp1 [4], foram dissolvidas. As demais coletas de Th não tiveram o mesmo sucesso sendo que optou-se, num segundo momento, por adicionar $50 \mu \mathrm{L}$ de $\mathrm{HNO}_{3}$ concentrado diretamente no béquer Savillex® e completar com água Milli-Q para o volume total requerido de $5 \mathrm{~mL}$. Mesmo tendo sido observado que esse último procedimento de transferência foi efetivo, entendemos que o manuseio excessivo pode ter alterado a quantidade real do material a ser recuperado.

Tabela 03. Dados de peso e percentagem de recuperação para as frações de JCp-1 e JLs-1 analisadas na primeira etapa de teste (procedimento BGC).

\begin{tabular}{|c|c|c|c|c|c|c|c|c|}
\hline Frações & $\begin{array}{c}\text { Peso } \\
\text { (gramas) }\end{array}$ & $\begin{array}{c}\text { Peso U } \\
\text { calculado } \\
\text { (ng) }\end{array}$ & $\begin{array}{c}\text { Peso U } \\
\text { medido } \\
\text { (ng) }\end{array}$ & $\begin{array}{c}\text { Peso Th } \\
\text { calculado } \\
\text { (ng) }\end{array}$ & $\begin{array}{c}\text { Peso Th } \\
\text { medido } \\
\text { (ng) }\end{array}$ & $\begin{array}{c}\% \text { rec. } \\
\text { U }\end{array}$ & $\begin{array}{c}\% \text { rec. } \\
\text { Th }\end{array}$ \\
\hline $\mathrm{JCp}-1[1]$ & 0,19722 & 532,494 & 515,00 & 10,847 & 3,95 & 96,71 & 36,41 \\
\hline $\mathrm{JCp}-1[2]$ & 0,19867 & - & - & - & - & - & - \\
\hline $\mathrm{JCp}-1[3]$ & 0,19856 & 536,112 & 495,50 & 10,920 & 6,10 & 92,42 & 55,86 \\
\hline $\mathrm{JCp}-1[4]$ & 0,19902 & 537,354 & 525,00 & 10,946 & 7,85 & 97,70 & 71,71 \\
\hline $\mathrm{JLS}-1[1]$ & 0,19670 & 344,225 & 311,00 & 5,645 & 2,30 & 90,35 & 40,74 \\
\hline $\mathrm{JLs}-1[2]$ & 0,19851 & 347,392 & 361,50 & 5,697 & 2,20 & 104,06 & 38,62 \\
\hline $\mathrm{JLS}-1[3]$ & 0,19996 & 349,930 & 330,00 & 5,738 & 2,75 & 94,30 & 47,92 \\
\hline $\mathrm{JLS}-1[4]$ & 0,19774 & 346,045 & 314,00 & 5,675 & 2,75 & 90,74 & 48,46 \\
\hline
\end{tabular}

A partir dos resultados parcialmente satisfatórios, especialmente para Th, foi idealizada uma segunda etapa de testes para calibração das colunas pelo método BGC, agora adotando um procedimento de co-precipitação de $U$ e Th pré-cromatografia. Os detalhes são apresentados a seguir.

\footnotetext{
${ }^{4}$ Quantidade de $U$ (peso em ng) calculada na amostra, a partir do peso inicial considerado.

${ }^{5}$ Quantidade determinada de U (em ng) na amostra por medida direta em ICP-MS.

${ }^{6}$ Quantidade de Th (peso em ng) calculada na amostra, a partir do peso inicial considerado.

${ }^{7}$ Quantidade determinada de Th (em ng) na amostra por medida direta em ICP-MS.
} 


\subsubsection{Segunda Etapa de Teste}

Com objetivo de melhorar a recuperação para Th foi adotado o uso de soluções de cloreto de Fe e hidróxido de amônia, com as quais $U$ e Th têm afinidade química (Chen et al., 1986). O procedimento consiste em dissolver o resíduo que resta após a dissolução ácida com $\mathrm{HNO}_{3} 7 \mathrm{~N}$ adicionando-se $2 \mathrm{~mL}$ de $\mathrm{HCl} 2 \mathrm{~N}$, em seguida transferindo esta solução para um tubo de centrífuga. A ela são adicionadas 3 gotas (c. $150 \mu \mathrm{L}$ ) de solução de $\mathrm{FeCl}_{3} 1 \mathrm{~N}$ (obtida a

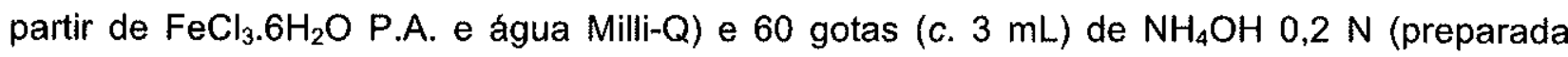
através da ebulição de $\mathrm{NH}_{3(g)}$ em água Milli-Q). Há formação de um precipitado de cor castanha - o $\mathrm{Fe}(\mathrm{OH})_{3}$, que tem forte potencial para co-precipitar $U$ e Th. A seguir, a amostra (precipitado+sobrenadante) é centrifugada por 4 vezes (15 minutos a $1500 \mathrm{rpm}$, cada) sendo que, após cada etapa, o sobrenadante é descartado e adicionado novo volume de água (c. 3 $\mathrm{mL})$.

O precipitado de $\mathrm{Fe}(\mathrm{OH})_{3}$ contendo $\mathrm{U}+\mathrm{Th}$ é dissolvido com 4 gotas (c. $200 \mu \mathrm{L}$ ) de $\mathrm{HNO}_{3}$ $7 \mathrm{~N}$, ainda no tubo, e a solução incolor resultante é transferida para um béquer Savillex® (previamente limpo $^{8}$ ) e colocada para evaporar. Após evaporação, adiciona-se 4 gotas de $\mathrm{HClO}_{4}$ P.A. para dissolução do novo precipitado amarelado à temperatura de c. $150^{\circ} \mathrm{C}$ (com béquer aberto). Finalmente, após evaporação e resfriamento, foram adicionadas 2 gotas (c. $100 \mu \mathrm{L}$ ) de $\mathrm{HNO}_{3}$ concentrado e o béquer então recolocado para evaporar a c. $100^{\circ} \mathrm{C}$. Todo esse procedimento foi adotado como preparação das amostras a serem manipuladas nessa segunda etapa de testes.

Dois conjuntos de quatro frações do padrão JCp-1 foram preparados para a coprecipitação, sendo preferido com respeito ao $\mathrm{JLs}-1^{9}$ por ser de mais rápida dissolução. Para o primeiro conjunto de JCp-1 (frações [5], [6], [7] e [8]) o objetivo foi avaliar se Th estava sendo eliminado antes ou depois do intervalo pré-determinado na rotina, o que explicaria a baixa recuperação observada no primeiro teste. Sendo assim, após dissolução, essas quatro frações foram submetidas às etapas normais de eluição da rotina sendo que duas delas foram eluídas apenas na coluna primária, e coletadas aliquotas fracionadas de 2 ou $3 \mathrm{~mL}$ durante todo o processo (tabela 04). Nas duas outras frações $U$ e Th foram coletados normalmente na coluna primária e então re-depositados na coluna secundária, seguindo exatamente os procedimentos descritos nos itens 4.2.1 e 4.2.2. Após o depósito, foram também coletadas alíquotas a cada 2 ou $3 \mathrm{~mL}$ (tabela 05$)$.

\footnotetext{
${ }^{8} \mathrm{O}$ procedimento de limpeza consiste em: (i) enxágüe com água Milli-Q, (ii) adição de água $\mathrm{Milli-Q}$ e $\mathrm{HNO}_{3} 7 \mathrm{~N}$ na proporção de $3: 1$, (iii) aquecimento dos béqueres fechados por 20 minutos em chapa quente e (iv) descarte da mistura água:ácido.

${ }^{9}$ Nessa época ainda não havia sido testado a calcinação prévia do JLs-1, antes da dissolução ácida; por esse motivo optou-se por utilizar apenas o JCp-1 nessa nova fase de testes.
} 
Tabela 04. Procedimento para coluna primária adotado pelo BGC com a definição das diferentes aliquotas coletadas para $U$ e Th na segunda etapa de testes.

\begin{tabular}{|c|c|c|c|c|}
\hline $\begin{array}{l}\text { COLUNA } \\
\text { PRIMÁRIA }\end{array}$ & $\begin{array}{c}\text { Depósito } \\
1,5 \mathrm{~mL} \mathrm{HNO}_{3} 7 \mathrm{~N}\end{array}$ & $\begin{array}{c}\text { Descarte } \\
6 \mathrm{~mL} \mathrm{HNO}_{3} 7 \mathrm{~N}\end{array}$ & $\begin{array}{c}\text { Coleta Th } \\
24 \mathrm{~mL} \mathrm{HCl} 8 \mathrm{~N}\end{array}$ & $\begin{array}{c}\text { Coleta U } \\
12 \mathrm{~mL} \mathrm{HCl} 0,5 \mathrm{~N}\end{array}$ \\
\hline Aliquota A1 & $1,5 \mathrm{~mL}$ & & $\therefore \cdots$ & \\
\hline Alíquota B1 & $\therefore \because$ & $2 \mathrm{~mL}$ & $\because$ & $\therefore \therefore$ \\
\hline Alíquota B2 & & $2 \mathrm{~mL}$ & $\because \because$ & \\
\hline Alíquota B3 & $a^{\prime} \quad \checkmark \quad \checkmark$ & $2 \mathrm{~mL}$ & $\therefore$ & 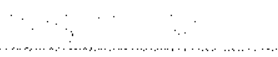 \\
\hline Alíquota C1 & $\because \quad \because$ & 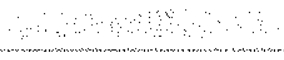 & $3 \mathrm{~mL}$ & $\therefore \quad:$ \\
\hline Aliquota $\mathrm{C} 2$ & $\because \because \cdots$ & बा & $3 \mathrm{~mL}$ & $\cdots$ \\
\hline Aliquota $\mathrm{C} 3$ & 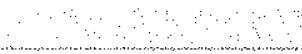 & & $3 \mathrm{~mL}$ & $\because$ \\
\hline Alíquota $\mathrm{C} 4$ & 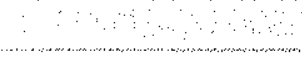 & 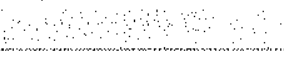 & $3 \mathrm{~mL}$ & $\therefore$ \\
\hline Aliquota D1 & & 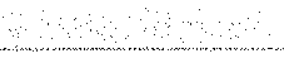 & $3 \mathrm{~mL}$ & .. \\
\hline Aliquota D2 & : : & & $3 \mathrm{~mL}$ & \\
\hline Alíquota D3 & $\cdots$ & & $3 \mathrm{~mL}$ & \\
\hline Alíquota D4 & $\therefore \quad \therefore$ & s o s o & $3 \mathrm{~mL}$ & \\
\hline Aliquota E1 & $\ldots$ & - & $\because \quad \vdots$ & $2 \mathrm{~mL}$ \\
\hline Alíquota E2 & & & & $2 \mathrm{~mL}$ \\
\hline Aliquota $\mathrm{E} 3$ & a $\quad \cdots \quad$ a & & & $2 \mathrm{~mL}$ \\
\hline Alíquota E4 & $a \quad \therefore \quad \cdots$ & $\therefore-4$ & 4 & $2 \mathrm{~mL}$ \\
\hline Alíquota E5 & $\because \quad \therefore \quad \therefore \quad \therefore$ & बि & 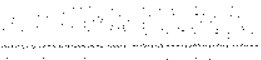 & $2 \mathrm{~mL}$ \\
\hline Alíquota E6 & & 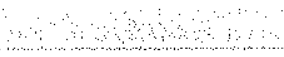 & 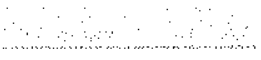 & $2 \mathrm{~mL}$ \\
\hline
\end{tabular}

Tabela 05. Procedimento para coluna secundária adotado pelo BGC com a definição das diferentes alíquotas coletadas para U e Th na segunda etapa de testes.

\begin{tabular}{|c|c|c|c|c|}
\hline $\begin{array}{l}\text { COLUNA } \\
\text { SECUNDÁRIA }\end{array}$ & $\begin{array}{c}\text { Depósito } \\
0,6 \mathrm{~mL} \mathrm{HNO}_{3} 7 \mathrm{~N}\end{array}$ & $\begin{array}{c}\text { Descarte } \\
2,4 \mathrm{~mL} \mathrm{HNO}_{3} 7 \mathrm{~N}\end{array}$ & $\begin{array}{c}\text { Coleta Th } \\
9,6 \mathrm{~mL} \text { HCl } 8 \mathrm{~N}\end{array}$ & $\begin{array}{c}\text { Coleta U } \\
4,8 \mathrm{~mL} \mathrm{HCl} 0,5 \mathrm{~N}\end{array}$ \\
\hline Alíquota A1 & $0,6 \mathrm{~mL}$ & : & & \\
\hline Aliquota B1 & $\sqrt{25}$ & $1,2 \mathrm{~mL}$ & 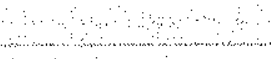 & $\therefore$ \\
\hline Alíquota B2 & \% & $1,2 \mathrm{~mL}$ & & \\
\hline Aliquota $\mathrm{C} 1$ & 8 & 8 & $2,4 \mathrm{~mL}$ & 3 \\
\hline Alíquota C2 & 8 & बिंद्य & $2,4 \mathrm{~mL}$ & $\cdots$ \\
\hline Aliquota C3 & & 5 & $2,4 \mathrm{~mL}$ & 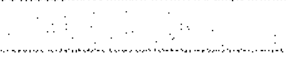 \\
\hline Alíquota $\mathrm{C} 4$ & 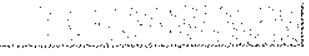 & 20 & $2,4 \mathrm{~mL}$ & 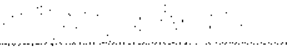 \\
\hline Alíquota D1 & 40 & & 8 & $1,2 \mathrm{~mL}$ \\
\hline Aliquota D2 & 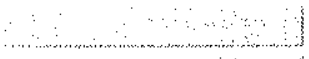 & 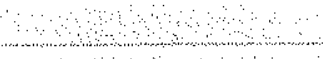 & $\therefore$ & $1,2 \mathrm{~mL}$ \\
\hline Aliquota D3 & & & & $1,2 \mathrm{~mL}$ \\
\hline Aliquota D4 & & & $\because$ & $1,2 \mathrm{~mL}$ \\
\hline
\end{tabular}

O segundo conjunto de quatro frações do JCp-1 ([9], [10], [11] e [12]) foi submetido a exatamente o mesmo procedimento descrito para as frações anteriores, todavia antes foram preparadas com cloreto de Fe e hidróxido de amônia. O objetivo foi promover a co-precipitação 
de $U$ e Th antes do depósito em coluna e avaliar possíveis diferenças nas percentagens de recuperação quando comparadas com a cromatografia sem co-precipitação.

A figura 04A-D representa a coleta fracionada de Th e $U$ no procedimento sem a coprecipitação com Fe (frações [5] a [8]) e com a co-precipitação (frações [9] a [12]). Para o primeiro conjunto de amostras, tanto Th quanto $U$ tiveram picos bem definidos no intervalo prédefinido para sua maior recuperação na coluna primária, muito embora pequenas quantidades de Th tenham sido eliminadas nas coletas seguintes (a aproximadamente 20, 32 e $40 \mathrm{~mL}$; Fig. 04A). A recuperação foi francamente satisfatória para $U$, com valores acima de $90 \%$, mas para Th as contagens permitiram calcular recuperações em torno de 16\%. Na coluna secundária, as duas frações de JCp-1 ([7] e [8]) também tiveram comportamento semelhante para ambos os elementos, com recuperação ideal de $U$ acima de $90 \%$. O Th foi eluído principalmente nos primeiros $2 \mathrm{~mL}$ da coleta, mas também em proporções significativas na etapa de descarte, pós a deposição da amostra (Fig. 04C). Os valores de recuperações estão listados na tabela 06.
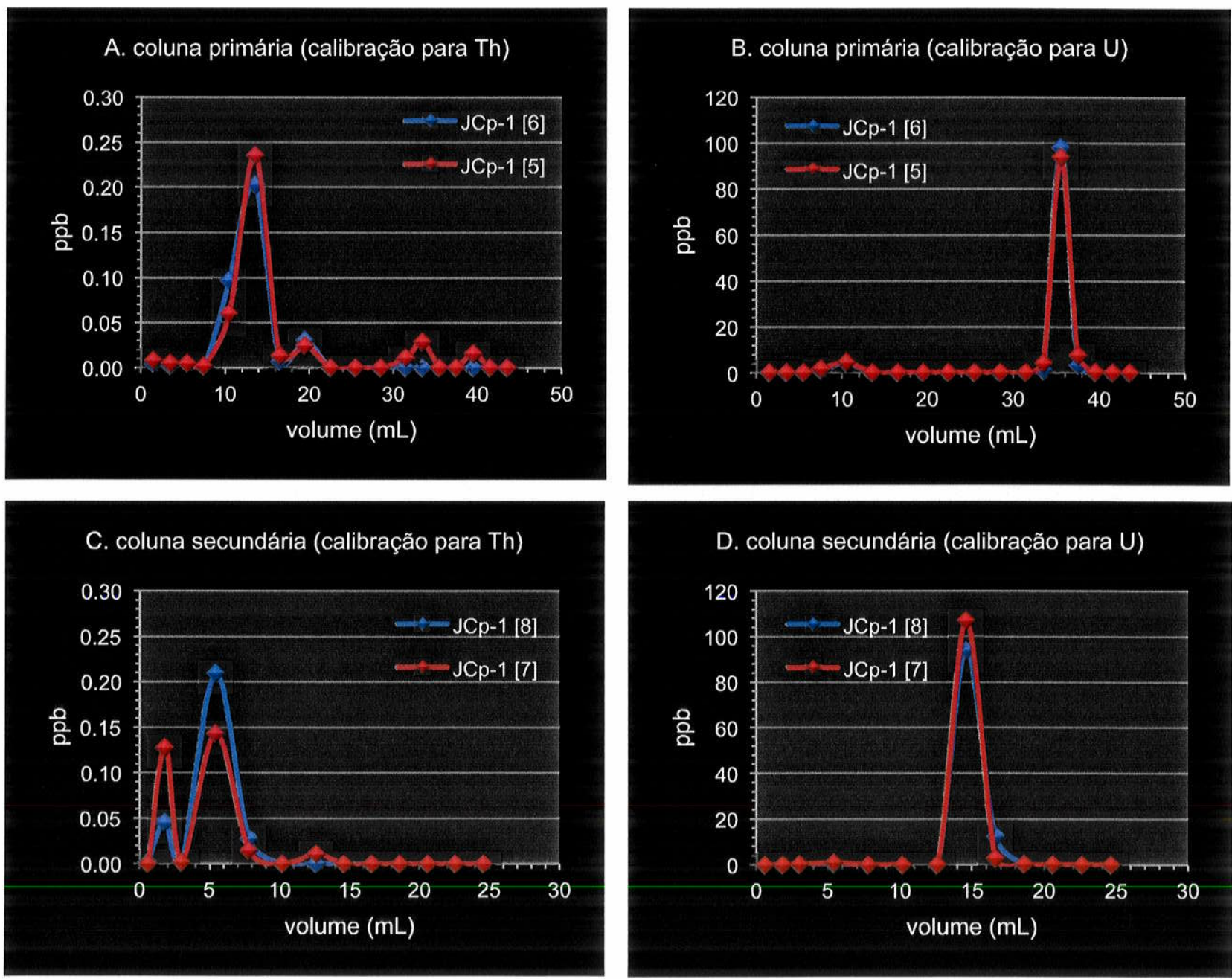

Figura 04. Gráficos a calibração das colunas primária e secundária sem co-precipitação $\operatorname{com} \mathrm{Fe}(\mathrm{OH})_{3}$. A. Calibração de Th na coluna primária; B. Calibração de U na coluna primária; C. Calibração de Th na coluna secundária; D. Calibração de U na coluna secundária. As frações JCp-1 [5] e [6] foram tratadas apenas na coluna primária, enquanto as frações [7] e [8] foram inicialmente tratadas na coluna primária e as coletas de Th e U foram, em seguida, passadas na coluna secundária. 
O procedimento com $\mathrm{Fe}$ adotado para o segundo conjunto de amostras mostrou resultados diferentes (Fig. 05A-D). O intervalo de eluição do Th foi mais restrito na coluna primária (entre 8 - $22 \mathrm{~mL}$ ) em comparação com o conjunto que não foi tratado com $\mathrm{Fe}(\mathrm{OH})_{3}$. De forma geral, notou-se que a boa recuperação para $U$ obtida sem a co-precipitação não foi reproduzida. Aqui, os valores variaram entre 58-63\% na coluna primária e $68-75 \%$ na coluna secundária, sendo que nas duas colunas houve perda em proporções distintas nas etapas de descarte e de início da coleta de Th (Figs. 05B e 05D), sendo bem mais acentuada na coluna secundária. Para Th as recuperações foram maiores nesse teste (entre 20-25\% na coluna primária e 50-65\% na coluna secundária), mas ainda assim abaixo do ideal. Os valores precisos de recuperação para cada fração estão também listados na tabela 06.
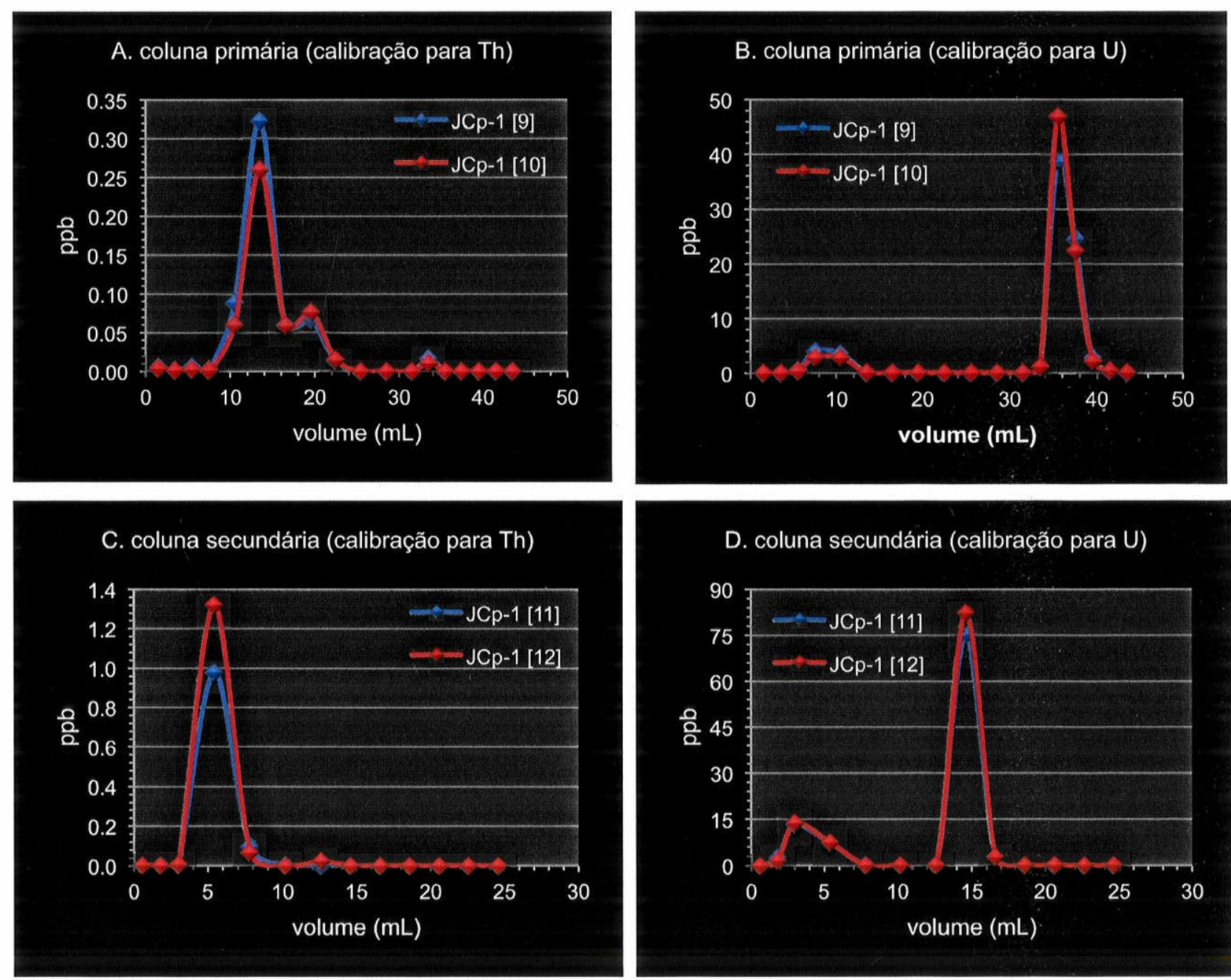

Figura 05. Gráficos ilustrando a calibração das colunas primária e secundária do procedimento BGC, com co-precipitação com $\mathrm{Fe}(\mathrm{OH})_{3}$. A. Calibração de Th na coluna primária; B. Calibração de U na coluna primária; C. Calibração de Th na coluna secundária; D. Calibração de U na coluna secundária. As frações JCp-1 [9] e [10] foram tratadas apenas na coluna primária, enquanto as frações [11] e [12] foram inicialmente tratadas na coluna primária e as aliquotas de Th e $U$ coletadas foram, em seguida, passadas na coluna secundária. 
Tabela 06. Dados de peso e percentagem de recuperação para as frações de $\mathrm{JCp}-1$ analisadas na segunda etapa de teste (procedimento BGC).

\begin{tabular}{|c|c|c|c|c|c|c|c|}
\hline Frações & $\begin{array}{c}\text { Peso } \\
\text { (gramas) }\end{array}$ & $\begin{array}{l}\text { Peso U } \\
\text { calculado } \\
\text { (ng) }\end{array}$ & $\begin{array}{c}\text { Peso U } \\
\text { medido } \\
\text { (ng) }\end{array}$ & $\begin{array}{l}\text { Peso Th } \\
\text { calculado } \\
\text { (ng) }\end{array}$ & $\begin{array}{c}\text { Peso Th } \\
\text { medido } \\
\text { (ng) }\end{array}$ & $\begin{array}{c}\% \text { rec. } \\
\text { U }\end{array}$ & $\begin{array}{c}\% \text { rec. } \\
\text { Th }\end{array}$ \\
\hline $\mathrm{JCp}-1[5]$ & 0,1965 & 569,850 & 531,71 & 10,8075 & 1,72 & 93,30 & 15,91 \\
\hline JCp-1 [6] & 0,19374 & 561,846 & 515,48 & 10,6557 & 1,69 & 1 & 15,86 \\
\hline $\mathrm{JCp}-1[7]$ & 0,19646 & 578,434 & 551,44 & 10,9703 & 0,85 & 95,33 & 7,75 \\
\hline$J C p-1[8]$ & 0,19616 & 568,864 & 534,66 & 10,7888 & 1,19 & 93,98 & 11,03 \\
\hline $\mathrm{JCp}-1[9]$ & 0,20175 & 585,075 & 339,62 & 11,0962 & 2,77 & 58,04 & 24,92 \\
\hline $\mathrm{JCp}-1[10]$ & 0,19928 & 577,912 & 366,275 & 10,9604 & 2,36 & 63,37 & 21,48 \\
\hline $\mathrm{JCp}-1[11]$ & 0,19700 & 571,300 & 390,775 & 10,8350 & 5,40 & 68,40 & 49,84 \\
\hline $\mathrm{JCp}-1$ [12] & 0,19740 & 572,460 & 426,210 & 10,8570 & 7,00 & 74,45 & 64,47 \\
\hline
\end{tabular}

\subsubsection{Terceira Etapa de Teste}

A segunda etapa de teste para reprodução do procedimento do BGC mostrou resultados conflitantes quando utilizada ou não a co-precipitação de Th e $U$ com $\mathrm{Fe}(\mathrm{OH})_{3}$. Os resultados mostraram-se muito variáveis quando adotada a co-precipitação; contrariamente, no procedimento sem co-precipitação vimos uma excelente recuperação para $U$ a despeito dos percentuais bem inferiores obtidos para Th. Desta forma, a co-precipitação foi temporariamente desconsiderada e procurou-se manter o foco em entender em qual etapa do procedimento Th estava sendo perdido. Iniciou-se, então, uma terceira etapa de testes para verificar exclusivamente se Th estava sendo parcialmente hidrolisado durante a dissolução com $\mathrm{HNO}_{3}+\mathrm{H}_{2} \mathrm{O}$ 1:2 ou ainda durante o "tempo de espera" para a leitura no ICP-MS, uma vez que a coleta foi diluída para uma solução ácida de $\mathrm{HNO}_{3} 0,1 \mathrm{~N}$ (ver item 4.3.1). Qualquer uma dessas possibilidades poderia, presumivelmente, afetar a quantidade inicial depositada na coluna. Para isso foram preparadas:

- Quatro amostras do padrão JCp-1, sendo que duas passaram pelas colunas primária ([13] e [14]) e secundária (somente a [14]), e duas foram dissolvidas e levadas para leitura direta de Th e U no ICP-MS, sem separação cromatográfica ([15] e [16]);

- Duas amostras de padrão sintético (Fluka [1] e Fluka [2]) preparadas a partir de uma solução para absorção atômica de Th $\left(986 \mu \mathrm{g} / \mathrm{mL}\right.$, em $\mathrm{HNO}_{3}$ a $5 \%$ em massa), e que foram depositadas nas colunas seguindo o mesmo procedimento adotado para as frações JCp-1 [13] e [14];

- Uma amostra de padrão sintético (Fluka [3]) fol preparada apenas para leitura direta de Th no ICP-MS;

- Duas amostras do padrão JLs-1 ([5] e [6]) previamente calcinadas a $900^{\circ} \mathrm{C}$ por 1 hora para eliminar a matéria orgânica, foram preparadas diretamente para análise por ICP. 
MS sem passar por colunas, também para verificar se as quantidades de $U$ e Th são reprodutíveis para esse padrão. A dissolução das amostras de JLs-1 após a calcinação foi realizada com $1 \mathrm{~mL}$ de água Milli-Q e 1,5 $\mathrm{mL}$ de $\mathrm{HNO}_{3}$ concentrado.

Para essa terceira etapa as coletas foram fracionadas conforme demonstrado nas tabelas 07 e 08, abaixo.

Tabela 07. Procedimento para coluna primária adotado pelo BGC com a definição das diferentes aliquotas coletadas para $U$ e Th na terceira etapa de testes.

\begin{tabular}{|c|c|c|c|c|}
\hline $\begin{array}{l}\text { COLUNA } \\
\text { PRIMÁRIA }\end{array}$ & $\begin{array}{c}\text { Depósito } \\
1,5 \mathrm{~mL} \mathrm{HNO}_{3} 7 \mathrm{~N}\end{array}$ & $\begin{array}{c}\text { Descarte } \\
6 \mathrm{~mL} \mathrm{HNO}_{3} 7 \mathrm{~N}\end{array}$ & $\begin{array}{c}\text { Coleta Th } \\
24 \mathrm{~mL} \mathrm{HCl} \mathrm{8N}\end{array}$ & $\begin{array}{c}\text { Coleta U } \\
12 \mathrm{~mL} \mathrm{HCl} 0,5 \mathrm{~N}\end{array}$ \\
\hline Aliquota A & $1,5 \mathrm{~mL}$ & (3) & 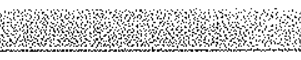 & 1) \\
\hline Aliquota B & 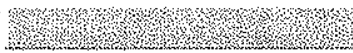 & $6 \mathrm{~mL}$ & 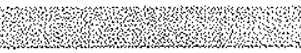 & 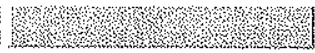 \\
\hline Alíquota C1 & 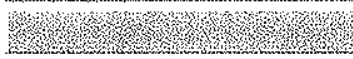 & W. & $12 \mathrm{~mL}$ & W \\
\hline Alíquota $\mathrm{C} 2$ & 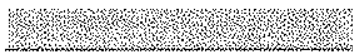 & W & $12 \mathrm{~mL}$ & 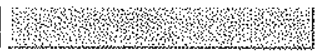 \\
\hline Alíquota D & Hetis & 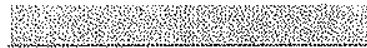 & 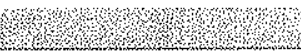 & $12 \mathrm{~mL}$ \\
\hline
\end{tabular}

Tabela 08. Procedimento para coluna secundária adotado pelo BGC com a definição das diferentes aliquotas coletadas para $U$ e Th na terceira etapa de testes.

\begin{tabular}{|c|c|c|c|c|}
\hline $\begin{array}{c}\text { COLUNA } \\
\text { SECUNDÁRIA }\end{array}$ & $\begin{array}{c}\text { Depósito } \\
0,6 \mathrm{~mL} \mathrm{HNO}_{3} 7 \mathrm{~N}\end{array}$ & $\begin{array}{c}\text { Descarte } \\
2,4 \mathrm{~mL} \mathrm{HNO}_{3} 7 \mathrm{~N}\end{array}$ & $\begin{array}{c}\text { Coleta Th } \\
9,6 \mathrm{~mL} \mathrm{HCl} 8 \mathrm{~N}\end{array}$ & $\begin{array}{c}\text { Coleta U } \\
4,8 \mathrm{~mL} \text { HCI } 0,5 \mathrm{~N}\end{array}$ \\
\hline Aliquota A & $0,6 \mathrm{~mL}$ & 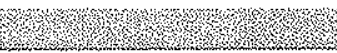 & ivis & 13 \\
\hline Allquota B & 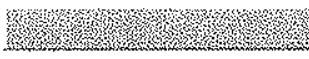 & $2,4 \mathrm{~mL}$ & 2 & S- \\
\hline Aliquota C & 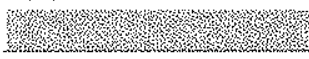 & Prit & $9.6 \mathrm{~mL}$ & W - \\
\hline Aliquota D & Wrevery & (2) & 1 & $4,8 \mathrm{~mL}$ \\
\hline
\end{tabular}

As curvas de calibração das amostras tratadas nas colunas são mostradas na figura 06. Como resultados temos que os dois padrões JCp-1 [13] e [14] tiveram comportamentos semelhantes a aqueles obtidos na segunda etapa de testes, ou seja, recuperação satisfatória de U ( $80 \%$ na coluna primária, $83 \%$ na coluna secundária), mas também com baixa e variável recuperação para Th ( $48 \%$ na coluna primária, $18 \%$ na coluna secundária) (tabela 09). Comportamento errático foi também observado para as duas frações JCp-1 [15] e [16] que não passaram por colunas: alta recuperação para U (89-99\%) e razoável recuperação de Th (65$110 \%$ ). A recuperação de Th superior a $100 \%$ pode ser reflexo de sua inhomogeneidade nesse padrão (Watanabe e Nakai, 2006b). Entretanto, valores semelhantes de recuperação também foram obtidos para o padrão JLs-1 ([5] e [6]) entre 103-134\% calculados com o valor recomendado de $28,7 \mathrm{ng} / \mathrm{g}$ (Aizawa, 2008). Essas frações que não foram eluídas em colunas 
foram diluídas antes da análise em ICP-MS tomando-se uma alíquota de $0,250 \mathrm{~mL}$ da solução de $0,1 \mathrm{~N}$ e avolumada para $5 \mathrm{~mL}$, portanto, com fator de diluição de 20 vezes.

Para as soluções de padrão sintético Fluka, tratadas em coluna (Fluka [1] e [2]) os resultados foram superiores à quantidade prevista de Th (22-26 ng) a partir do volume considerado de $20 \mu \mathrm{L}$. Os valores de recuperação foram estranhamente mais elevados que o intervalo de valores estimado existir na solução, o que pode significar alguma "contaminação" ou problemas na leitura instrumental.
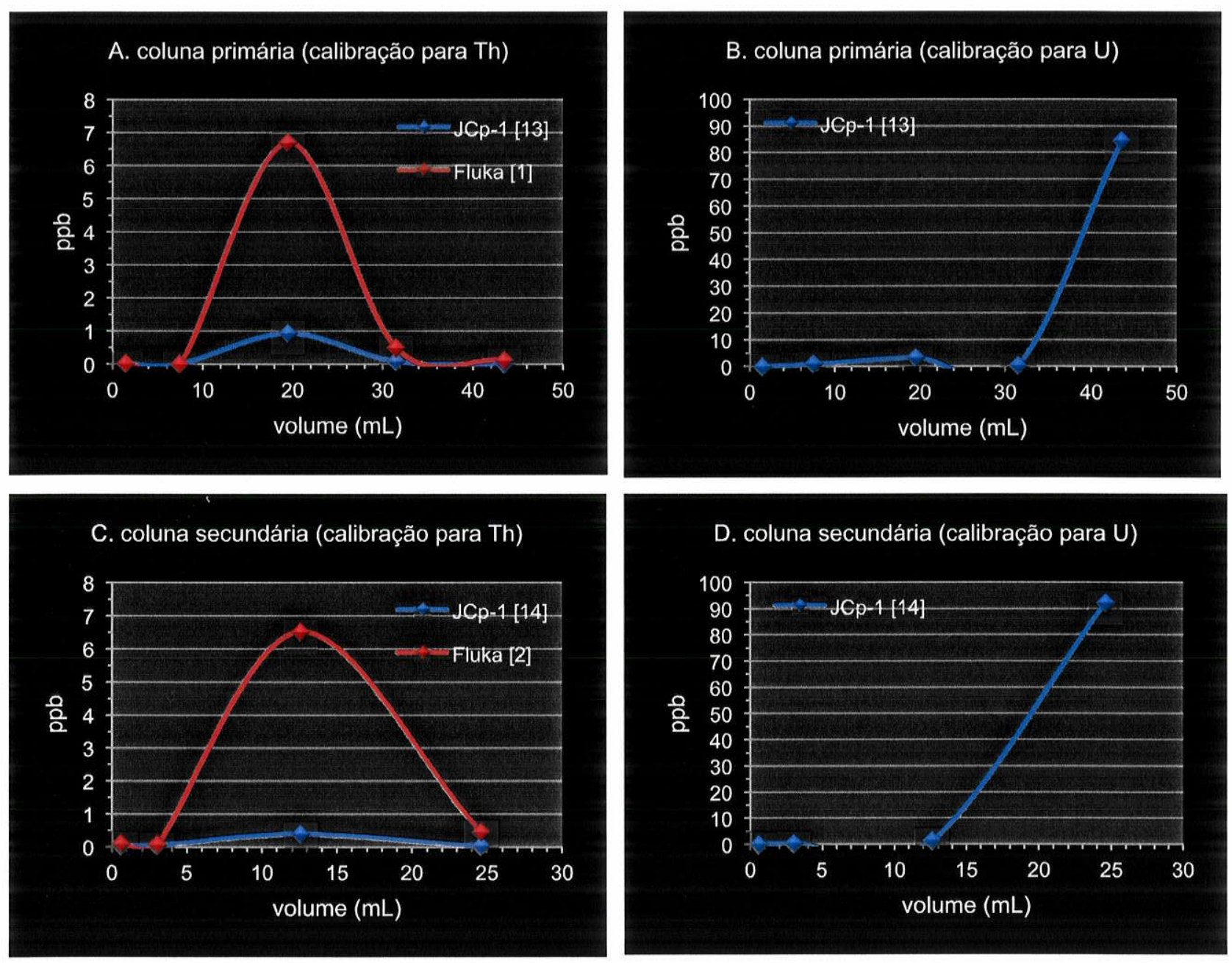

Figura 06. Gráficos ilustrando a calibração das colunas primária e secundária do procedimento BGC, na terceira etapa de testes, com os padrões JCp-1 e Fluka. A. Calibração de Th na coluna primária; B. Calibração de U na coluna primária; C. Calibração de Th na coluna secundária; D. Calibração de $U$ na coluna secundária. A fração JCp-1 [13] foi tratada apenas na coluna primária, enquanto a fração [14] foi inicialmente tratada na coluna primária e as alíquotas de Th e U coletadas foram, em seguida, passadas na coluna secundária. 
Tabela 09. Dados de peso e percentagem de recuperação para as frações de $J C p-1$ analisadas na terceira etapa de teste (procedimento BGC).

\begin{tabular}{|c|c|c|c|c|c|c|c|}
\hline Frações & $\begin{array}{c}\text { Peso } \\
\text { (gramas) }\end{array}$ & $\begin{array}{l}\text { Peso U } \\
\text { calculado } \\
\text { (ng) }\end{array}$ & $\begin{array}{l}\text { Peso U } \\
\text { medido } \\
\text { (ng) }\end{array}$ & $\begin{array}{c}\text { Peso Th } \\
\text { calculado } \\
\text { (ng) }\end{array}$ & $\begin{array}{c}\text { Peso Th } \\
\text { medido } \\
\text { (ng) }\end{array}$ & $\begin{array}{c}\% \text { rec. } \\
\text { U }\end{array}$ & $\begin{array}{c}\% \text { rec. } \\
\text { Th }\end{array}$ \\
\hline $\mathrm{JCp}-1[13]$ & 0,19708 & 532,116 & 423,85 & 10,839 & 5,150 & 79,65 & 47,51 \\
\hline$J C p-1[14]$ & 0,20560 & 555,120 & 461,75 & 11,308 & 2,020 & 83,18 & 17,86 \\
\hline$J C p-1[15]$ & 0,19755 & 533,380 & 499,00 & 10,870 & 12,000 & 93,55 & 110,4 \\
\hline$J C p-1[16]$ & 0,19520 & 527,040 & 490,00 & 10,740 & 7,000 & 92,97 & 65,18 \\
\hline Fluka [1] & $20 \mu \mathrm{L}$ & - & - & $22-26^{*}$ & 36,035 & - & - \\
\hline Fluka [2] & $20 \mu \mathrm{L}$ & - & - & $22-26^{*}$ & 32,600 & - & $\therefore$ \\
\hline Fluka [3] & $20 \mu \mathrm{L}$ & - & - & $22-26^{*}$ & 31,670 & - & - \\
\hline JLs-1 [5] & 0,19629 & 343,507 & 330,20 & 5,633 & 7,58 & 96,12 & 134,5 \\
\hline$J L s-1[6]$ & 0,19416 & 339,780 & 329,35 & 5,572 & 5,75 & 96,93 & 103,2 \\
\hline
\end{tabular}

* estimativa obtida a partir da concentração nominal da solução original, considerando um erro de $\pm 5 \%$.

\subsubsection{Quarta Etapa de Teste}

Com os resultados obtidos na terceira etapa parece que a baixa recuperação de Th na reprodução do procedimento do BGC não está associada à hidrólise de Th durante a dissolução ou ainda quando a alíquota coletada de Th é avolumada em ácido fraco para leitura no ICP-MS. A recorrência na obtenção de resultados insatisfatórios levou-nos considerar a possibilidade de condicionamento inadequado da resina Bio $\operatorname{Rad} B$ AG 1-X8 impedindo a eluição total de Th, mesmo usando ácido forte. É importante reafirmar que a resina utilizada nos testes anteriores foi tomada de um volume maior, previamente "descontaminada" de acordo com o procedimento rotineiramente usado no CPGeo para recuperação de $\mathrm{U}$ e $\mathrm{Pb}$, envolvendo lavagem com $\mathrm{H}_{2} \mathrm{O}$ e $\mathrm{HCl} 6 \mathrm{~N}$ (cf. explicitado no item 3.2.5).

Buscando entender e reverter o problema de recuperação para Th, uma fração de cerca de 250 gramas de resina Bio Rad® $A G$ 1-X8 foi pesada e submetida a nova lavagem. $O$ procedimento envolveu sucessivas etapas com $\mathrm{H}_{2} \mathrm{O}$ Milli-Q e com etanol P.A. para, em seguida, ser submetida a uma etapa de c. 4 horas em que a resina foi mantida em solução 1:1 de água régia e $\mathrm{H}_{2} \mathrm{O}$. Ao fim, a resina permaneceu em aquecimento por 12 horas em $\mathrm{HCl}$ concentrado, sob temperatura de $c .60^{\circ} \mathrm{C}$.

Os testes de recuperação foram feitos com duas novas frações do padrão JCp-1 ([17] e [18]) e duas frações do JLs-1 ([7] e [8]), sendo que JCp-1 [17] e JLs-1 [7] foram tratadas apenas na coluna primária, enquanto $\mathrm{JCp}-1$ [18] e JLs-1 [8] foram tratadas primeiro na coluna primária e suas coletas de Th e $U$ avolumadas em uma única solução para nova separação na coluna secundária. As etapas de eluição em ambas as colunas, primária e secundária, foram 
as mesmas descritas nas tabelas 07 e 08, respectivamente. A figura 07 ilustra as curvas de calibração e a tabela 10 apresenta os cálculos de recuperação.
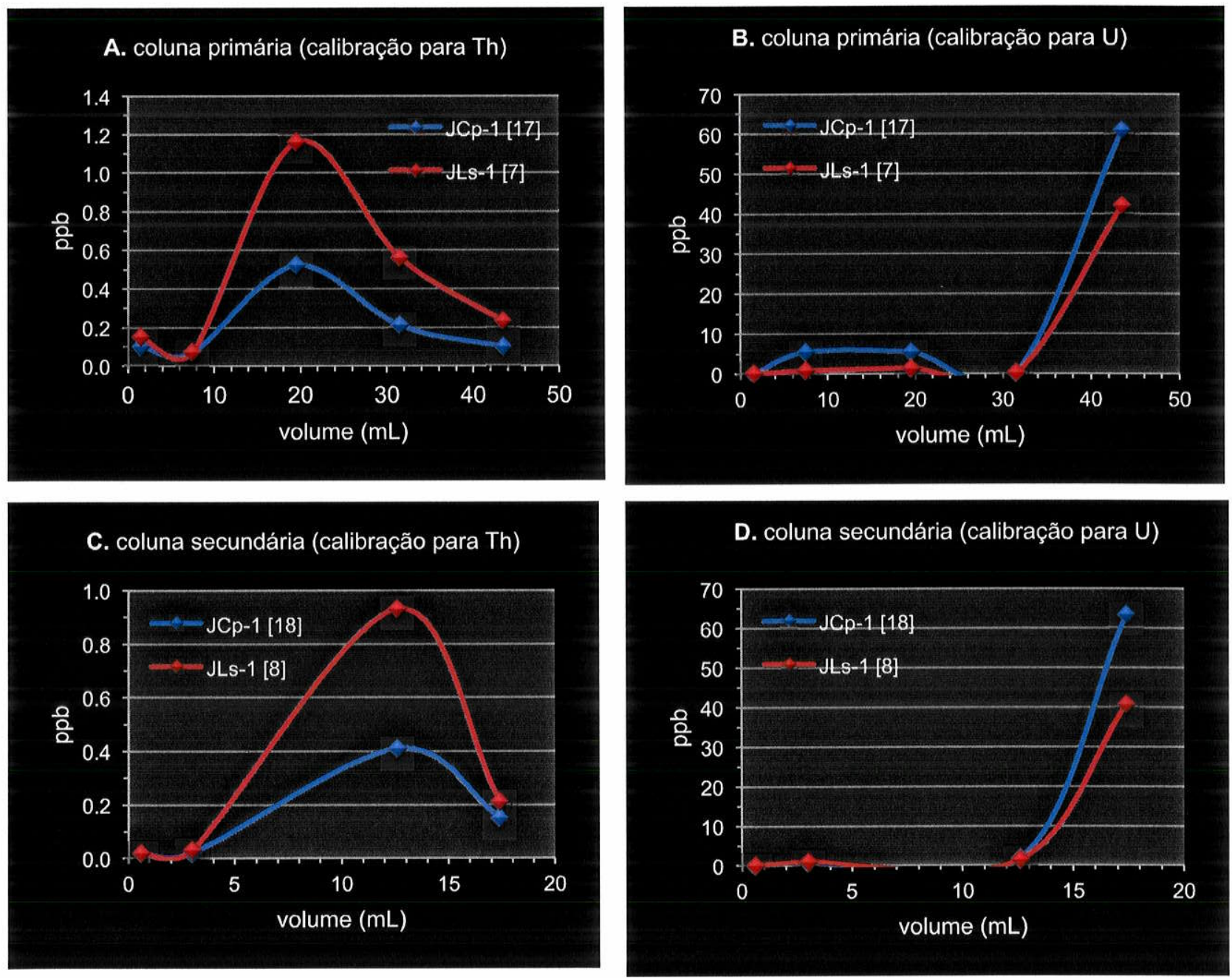

Figura 07. Gráficos ilustrando a calibração das colunas primária e secundária do procedimento BGC, na quarta etapa de testes, com os padrões JCp-1 e JLs-1. A. Calibração de Th na coluna primária; B. Calibração de U na coluna primária; C. Calibração de Th na coluna secundária; D. Calibração de $U$ na coluna secundária. As frações JCp-1 [17] e JLs-1 [7] foram tratadas apenas na coluna primária, enquanto as frações JCp-1 [18] e JLs-1 [8] foram inicialmente tratadas na coluna primária e as alíquotas de Th e U coletadas foram, em seguida, passadas na coluna secundária.

Tabela 10. Dados de peso e percentagem de recuperação para as frações de JCp-1 e JLs-1 analisadas na quarta etapa de teste (procedimento BGC).

\begin{tabular}{|l|c|c|c|c|c|c|c|}
\hline Frações & $\begin{array}{c}\text { Peso } \\
\text { (gramas) }\end{array}$ & $\begin{array}{c}\text { Peso U } \\
\text { calculado } \\
\text { (ng) }\end{array}$ & $\begin{array}{c}\text { Peso U } \\
\text { medido } \\
\text { (ng) }\end{array}$ & $\begin{array}{c}\text { Peso Th } \\
\text { calculado } \\
\text { (ng) }\end{array}$ & $\begin{array}{c}\text { Peso Th } \\
\text { medido } \\
\text { (ng) }\end{array}$ & $\begin{array}{c}\% \\
\text { rec. } \\
\text { U }\end{array}$ & $\begin{array}{c}\text { \% } \\
\text { rec. } \\
\text { Th }\end{array}$ \\
\hline JCp-1 [17] & 0,19619 & 529,71 & 304,5 & 10,79 & 3,65 & 57,48 & 33,83 \\
\hline JCp-1 [18] & 0,19217 & 518,85 & 317,0 & 10,57 & 2,05 & 61,10 & 19,39 \\
\hline JLs-1 [7] & 0,19696 & 344,68 & 209,5 & 5,65 & 8,60 & 60,78 & 152,21 \\
\hline JLs-1 [8] & 0,19749 & 345,61 & 203,0 & 5,67 & 4,65 & 58,74 & 82,01 \\
\hline
\end{tabular}


Com a nova lavagem da resina observa-se que as recuperações para $U$ foram semelhantes para os dois padrões, tanto na coluna primária quanto na secundária, em torno de $60 \%$. No entanto, foram significativamente inferiores aos valores que estavam sendo obtidos em torno de $80-95 \%$ nos testes anteriores. Nota-se que uma fração menor de $U$ está sendo perdido na coluna primária, no intervalo de coleta de Th, mas que não justifica a baixa recuperação. Para Th novamente têm-se resultados erráticos, difíceis de serem correlacionados com algum parâmetro isoladamente.

\subsection{O MÉTODO DE CALIBRAÇÃO DA COLUNA CROMATOGRÁFICA NA UMN}

Ao contrário do procedimento cromatográfico no $B G C$, a rotina $U-T h$ na UMN consiste na separação de $U$ e Th em alíquotas independentes utilizando-se apenas uma coluna de troca lônica, empacotada com a resina Spectra/Gel@ IE 1-X8. Essa constitui-se em resina aniônica seletiva, fortemente básica, comercializada pela Spectrum Chromatography na forma iônica de cloreto, com granulometria 100-200 mesh, grupo funcional trimetilbenzilamonio $\left(\mathrm{R}-\mathrm{C}_{10} \mathrm{H}_{16}-\mathrm{N}\right)$ e matriz estireno-divinil-benzeno. A ordem de seletividade é dada por $\mathrm{I}^{-}>\mathrm{NO}_{3}{ }^{-}>\mathrm{Br}^{-}>\mathrm{Cl}^{-}>$ acetato $>\mathrm{F}^{-}>\mathrm{OH}^{-}$. A preparação das amostras pré-cromatografia seguiu o procedimento descrito no item 4.3.2 que envolve tratamento com cloreto de ferro e hidróxido de amônio, tendo como objetivo co-precipitar $\mathrm{U}$ e Th com $\mathrm{Fe}(\mathrm{OH})_{3}$. Como nos testes do procedimento BGC, todos os ácidos utilizados foram igualmente purificados por destilação fracionada em destilador de quartzo e o peso inicial para todas as frações dos padrões $\mathrm{JCp}-1$ e $\mathrm{JLs}-1$ foi de aproximadamente $200 \mathrm{mg}$.

\subsubsection{Coluna de Troca Aniônica}

As colunas utilizadas nesse procedimento foram modeladas manualmente em teflon retrátil para um diâmetro interno de aproximadamente $0,5 \mathrm{~cm}$, altura em torno de $4 \mathrm{~cm}$ e reservatório avolumado para c. 1,2 mL. Toda a altura da coluna é empacotada com resina, précondicionada com duas vezes o volume total do reservatório de água Milli- $Q$, sendo que na segunda vez é acrescida uma gota (c. $50 \mu \mathrm{L}$ ) de $\mathrm{HNO}_{3}$ concentrado. Após as duas lavagens com água, adiciona-se $\mathrm{HNO}_{3} 7 \mathrm{~N}$ em $2 / 3$ do volume do reservatório. O tempo médio de escoamento do volume referente a um reservatório cheio é de 20 minutos.

Às amostras já dissolvidas (cf. item 4.3.2) e secas são adicionadas 4 gotas (c. $200 \mu \mathrm{L}$ ) de $\mathrm{HNO}_{3} 7 \mathrm{~N}$. Essa solução-amostra é depositada na coluna, descartada, e sucedida por um volume de aproximadamente $2 / 3$ do reservatório de $\mathrm{HNO}_{3} 7 \mathrm{~N} \mathrm{e}$, logo em seguida, mais $1 / 3$ de $\mathrm{HNO}_{3} 7 \mathrm{~N}$. A coleta de Th é feita em duas etapas de eluição, cada uma com $2 / 3$ do reservatório 
de $\mathrm{HCl} 6 \mathrm{~N}$ para, na sequência, efetuar a coleta de $\mathrm{U}$ também com duas vezes o volume total do reservatório de água Milli-Q. As alíquotas de $U$ e Th são coletadas em béqueres Savillex® individuais e levadas para evaporação lenta. Os precipitados são dissolvidos em $50 \mu \mathrm{L}$ de $\mathrm{HNO}_{3}$ concentrado colocado diretamente no béquer Savillex®, e o volume final de $5 \mathrm{~mL}$ é completado com água Milli-Q para subsequente análise no ICP-MS.

\subsection{RESUltados dos testes de CALIBRAÇÃo NO CPGEO SEgundo A UMN}

\subsubsection{Primeira Etapa de Teste}

Seguindo o procedimento da UMN foram pesadas duas frações com c. $200 \mathrm{mg}$ do padrão JCp-1 ([19] e [20]), dissolvidas conforme o item 3.3.1 e tratadas com $\mathrm{FeCl}_{3}$ e $\mathrm{NH}_{4} \mathrm{OH}$ (ver item 4.3.2). Na tabela 11, abaixo, estão os primeiros resultados obtidos para esse procedimento que, de forma geral, mostra razoável recuperação para $U$ (em torno de 62-63\%) e boa a excelente recuperação para Th, em $82 \%$ e $94 \%$. Uma vez que notamos Th sendo eluído no intervalo de coleta de $U$, e vice-versa, partiu-se para nova etapa de testes para verificar a calibração analisando-se individualmente as aliquotas de depósito+descarte e de coletas de The U.

Tabela 11. Dados de peso e percentagem de recuperação para as frações de JCp-1 analisadas na primeira etapa de teste (procedimento UMN).

\begin{tabular}{|c|c|c|c|c|c|c|c|}
\hline Frações & $\begin{array}{c}\text { Peso } \\
\text { (gramas) }\end{array}$ & $\begin{array}{c}\text { Peso U } \\
\text { calculado } \\
\text { (ng) }\end{array}$ & $\begin{array}{c}\text { Peso U } \\
\text { medido } \\
\text { (ng) }\end{array}$ & $\begin{array}{l}\text { Peso Th } \\
\text { calculado } \\
\text { (ng) }\end{array}$ & $\begin{array}{c}\text { Peso Th } \\
\text { medido } \\
\text { (ng) }\end{array}$ & $\begin{array}{c}\% \text { rec. } \\
\text { U }\end{array}$ & $\begin{array}{c}\% \text { rec. } \\
\text { Th }\end{array}$ \\
\hline$J C p-1[19]$ & 0,19790 & 534,330 & 332,10 & 10,884 & 8,935 & 62,15 & 82,11 \\
\hline$J C p-1[20]$ & 0,19764 & 533,628 & 340,85 & 10,870 & 10,26 & 63,87 & 94,39 \\
\hline
\end{tabular}

\subsubsection{Segunda Etapa de Teste}

Nessa segunda etapa de teste optou-se por retirar do procedimento a etapa com ácido perclórico (após as centrifugações) por ele não ser um ácido normalmente utilizado no CPGeo e também por estar disponivel apenas na forma P.A. A co-precipitação foi mantida. O objetivo nessa etapa foi testar a possibilidade de que a percentagem de recuperação de $U$ aumentaria se a coleta fosse duplicada; assim, adequamos a coleta para o volume de quatro reservatórios cheios, em vez de dois. Além disso, para comparar a eficiência das resinas Bio Rad( e Spectra/Gel® nesse procedimento, foram empacotadas duas colunas com a primeira e três 
com a segunda. Assim, uma fração de JCp-1 ([21]) e duas de JLs-1 ([9] e [10]) foram tratadas com resina Spectra/Gel@, e duas frações de JLs-1 ([11] e [12]) foram tratadas com resina Bio Rad®. As coletas totais de cada uma das etapas foram analisadas individualmente, sendo que a coleta de $U$ foi fracionada em duas alíquotas de $2,4 \mathrm{~mL}$ (tabela 12). Os dados de pesagem e recuperação estão listados na tabela 13 e os gráficos ilustrando as curvas de calibração são apresentados na figura 08.

Tabela 12. Procedimento para coluna adotado pelo UMN com a definição das diferentes alíquotas coletadas para U e Th na segunda etapa de testes.

\begin{tabular}{|c|c|c|c|c|}
\hline COLUNA & $\begin{array}{c}\text { Depósito } \\
0,2 \mathrm{~mL} \mathrm{HNO}_{3} 7 \mathrm{~N}\end{array}$ & $\begin{array}{c}\text { Descarte } \\
1,2 \mathrm{~mL} \mathrm{HNO}_{3} 7 \mathrm{~N}\end{array}$ & $\begin{array}{c}\text { Coleta Th } \\
1,6 \mathrm{~mL} \mathrm{HCl} 6 \mathrm{~N}\end{array}$ & $\begin{array}{c}\text { Coleta U } \\
4,8 \mathrm{~mL} \mathrm{H}_{2} \mathrm{O} \text { Milli-Q }\end{array}$ \\
\hline Aliquota A & $0,2 \mathrm{~mL}$ & $1,2 \mathrm{~mL}$ & & \\
\hline Alíquota B & & & $1,6 \mathrm{~mL}$ & \\
\hline Aliquota C1 & & $\therefore$ & & $2,4 \mathrm{~mL}$ \\
\hline Alíquota C2 & & $\because$ & & $2,4 \mathrm{~mL}$ \\
\hline
\end{tabular}

Tabela 13. Dados de peso e percentagem de recuperação para as frações de JCp-1 e JLs-1 analisadas na segunda etapa de teste (procedimento UMN).

\begin{tabular}{|c|c|c|c|c|c|c|c|}
\hline Frações & $\begin{array}{c}\text { Peso } \\
\text { (gramas) }\end{array}$ & $\begin{array}{c}\text { Peso U } \\
\text { calculado } \\
\text { (ng) }\end{array}$ & $\begin{array}{c}\text { Peso U } \\
\text { medido } \\
\text { (ng) }\end{array}$ & $\begin{array}{c}\text { Peso Th } \\
\text { calculado } \\
\text { (ng) }\end{array}$ & $\begin{array}{c}\text { Peso Th } \\
\text { medido } \\
\text { (ng) }\end{array}$ & $\begin{array}{c}\% \text { rec. } \\
\text { U }\end{array}$ & $\begin{array}{c}\% \text { rec. } \\
\text { Th }\end{array}$ \\
\hline JCp-1 [21] & 0,19854 & 536,058 & 357,85 & 10,91 & 1,00 & 66,75 & $9,16^{*}$ \\
\hline JLs-1 [9] & 0,19628 & 343,49 & 505,4 & 5,63 & 3,45 & 147,1 & 61,28 \\
\hline JLs-1 [10] & 0,19479 & 340,88 & 249,7 & 5,59 & 2,25 & 73,25 & 40,25 \\
\hline JLs-1 [11] & 0,19521 & 341,61 & 276,5 & 5,60 & 2,00 & 80,94 & 35,71 \\
\hline$J L s-1[12]$ & 0,19315 & 338,01 & 290 & 5,54 & 9,00 & 85,80 & 162,4 \\
\hline
\end{tabular}

De forma geral, as recuperações para $U$ foi reproduzida (e até otimizada) com relação à primeira etapa, com valores que atingiram $86 \%$, sendo que os melhores resultados foram obtidos para a resina Bio Rad@ (JLs-1 [11] e [12]). Para as amostras tratadas nessa resina nota-se que aproximadamente 6 a $8 \%$ do $U$ está sendo eliminado na etapa de depósito+descarte e coleta de Th, e que 2 a $5 \%$ está sendo eliminado na etapa de depósito+descarte e coleta de U. Th, no entanto, está sendo preferencialmente eliminado em seu intervalo de coleta. Já para as amostras tratadas com resina Spectra/Gel@, 19 a $24 \%$ do U está sendo eliminado na etapa de depósito+descarte e coleta de Th, enquanto uma quantidade desprezivel é eliminada nos últimos $2,4 \mathrm{~mL}$ de seu volume total de coleta. Da mesma forma, a calibração para Th não é ideal visto que 8 a $17 \%$ do que é recuperado está sendo eliminado no depósito+descarte e coleta de U.

Em particular para a fração $\mathrm{JCp}-1[21]\left(^{*}\right)$ observa-se que Th teve baixissima recuperação. Antes da análise por ICP-MS notou-se que essa amostra apresentava um pouco 
de "sólido alaranjado" que foi filtrado antes da análise, o que pode ter afetado a recuperação final.

Como informação adicional deste teste viu-se que o tempo de escoamento na coluna empacotada com resina Spectra/Gel囚 é de aproximadamente 20 minutos, bem inferior quando comparado com a coluna empacotada com a resina Bio Rad $\circledast$ cuja velocidade de escoamento foi estimada em torno de $1 \mathrm{~mL} / \mathrm{h}$ ora.
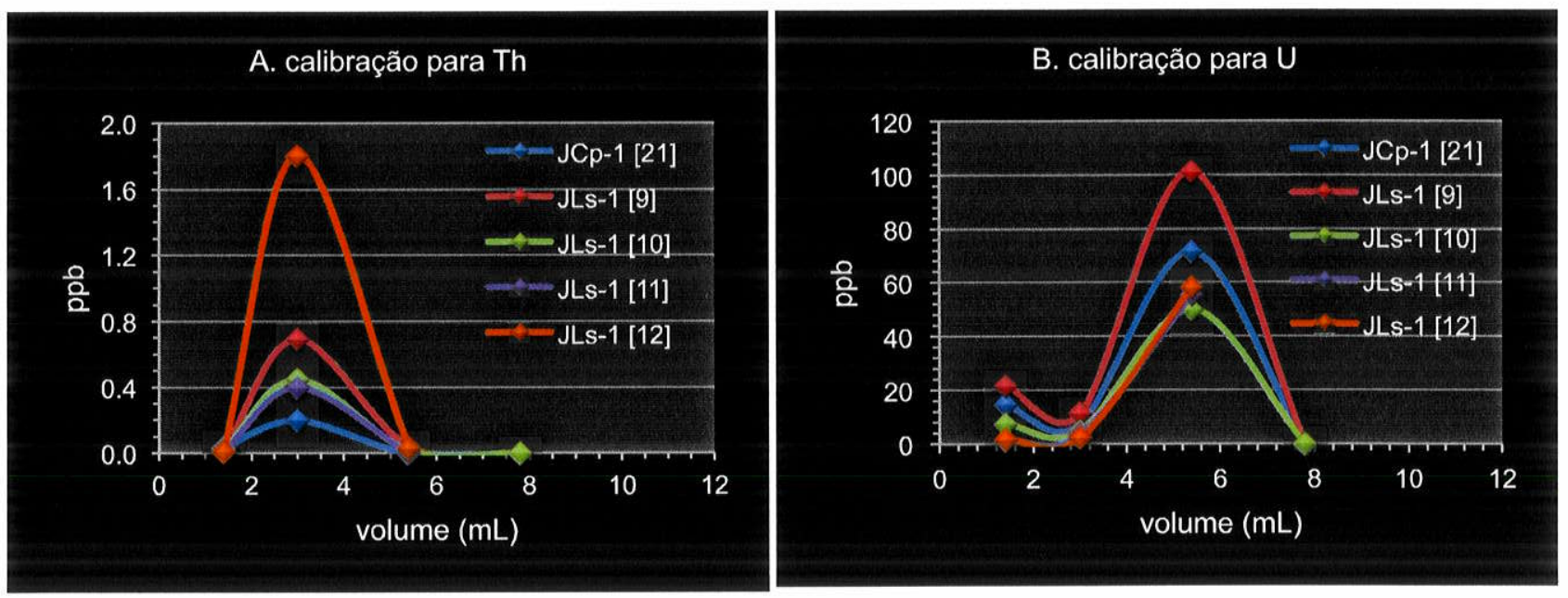

Figura 08. Gráficos ilustrando a calibração da coluna do procedimento UMN, na segunda etapa de testes, com os padrões JCp-1 [21] e JLs-1[9 a 12]. A. Calibração de Th; B. Calibração de U.

\subsubsection{Terceira Etapa de Teste}

O maior ajuste a ser feito após o teste da segunda etapa é calibrar bem o intervalo de eluição de $U$ e Th, principalmente $U$ que está sendo eliminado nas etapas anteriores à sua coleta. Algumas modificações foram estabelecidas buscando aumentar a acidez do meio (resina) antes do depósito da amostra na tentativa de garantir maior retenção de $U$ na resina durante o depósito e descarte. Para isso a resina foi previamente condicionada com volume três vezes maior de $\mathrm{HNO}_{3}$ (de $50 \mu \mathrm{L}$ para $150 \mu \mathrm{L}$ ) $+\mathrm{H}_{2} \mathrm{O}$. A coleta de Th foi aumentada para 2,4 $\mathrm{mL}$ (ao invés dos 1,6 $\mathrm{mL}$ originalmente pré-definido) buscando melhorar a recuperação. $\mathrm{Da}$ mesma forma o intervalo de coleta de $U$ foi expandido para $3,6 \mathrm{~mL}$.

Para esse teste foram preparadas três frações de JCp-1 ([22], [23] e [24]) e duas frações de JLs-1 ([13] e [14]). A coleta foi fracionada apenas para os intervalos de eluição de U e Th (tabela 14). Os dados de pesagem e recuperação para cada fração analisada estão listados na tabela 15 e as curvas de calibração apresentadas na figura 9. Nota-se que a eliminação do Th está concentrada entre 1,5 e $3 \mathrm{~mL}$ sem quaisquer perdas nas demais alíquotas analisadas. No entanto, $U$ se sobrepõe significativamente neste mesmo intervalo em proporções que se aproximam (ou mesmo ultrapassam) a recuperação obtida para o intervalo 
pré-definido (entre 3,5 e $6 \mathrm{~mL}$ ). Percebe-se que 38 a $61 \%$ do $U$ está sendo eliminado nas etapas de depósito+descarte e em todas as coletas de Th, entretanto a quantidade de $U$ é desprezível nos últimos $1,2 \mathrm{~mL}$ da coleta de $\mathrm{U}$.

Tabela 14. Procedimento para coluna adotado pelo UMN, com modificações, com a definição das diferentes alíquotas coletadas para U e Th na segunda etapa de testes.

\begin{tabular}{|c|c|c|c|c|}
\hline COLUNA & $\begin{array}{c}\text { Depósito } \\
0,2 \mathrm{~mL} \mathrm{HNO}_{3} 7 \mathrm{~N}\end{array}$ & $\begin{array}{c}\text { Descarte } \\
\text { 1,2 } \mathrm{mL} \mathrm{HNO}_{3} 7 \mathrm{~N}\end{array}$ & $\begin{array}{c}\text { Coleta Th } \\
2,4 \mathrm{~mL} \mathrm{HCl} 6 \mathrm{~N}\end{array}$ & $\begin{array}{c}\text { Coleta U } \\
3,2 \mathrm{~mL} \mathrm{H}_{2} \mathrm{O} \text { Milli-Q }\end{array}$ \\
\hline Alíquota A & $0,2 \mathrm{~mL}$ & $1,2 \mathrm{~mL}$ & & \\
\hline Alíquota B1 & & & $0,8 \mathrm{~mL}$ & \\
\hline Alíquota B2 & & & $0,8 \mathrm{~mL}$ & \\
\hline Alíquota B3 & & & $0,8 \mathrm{~mL}$ & \\
\hline Alíquota C1 & & & 3 & $1,2 \mathrm{~mL}$ \\
\hline Alíquota C2 & & & & $1,2 \mathrm{~mL}$ \\
\hline Alíquota C3 & & & 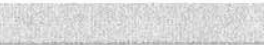 & $1,2 \mathrm{~mL}$ \\
\hline
\end{tabular}

Tabela 15. Dados de peso e percentagem de recuperação para as frações de JCp-1 [22 a 24] e JLs-1 [13 e 14] analisadas na terceira etapa de teste (procedimento UMN).

\begin{tabular}{|c|c|c|c|c|c|c|c|}
\hline Frações & $\begin{array}{c}\text { Peso } \\
\text { (gramas) }\end{array}$ & $\begin{array}{c}\text { Peso U } \\
\text { calculado } \\
\text { (ng) }\end{array}$ & $\begin{array}{c}\text { Peso U } \\
\text { medido } \\
\text { (ng) }\end{array}$ & $\begin{array}{c}\text { Peso Th } \\
\text { calculado } \\
\text { (ng) }\end{array}$ & $\begin{array}{c}\text { Peso Th } \\
\text { medido } \\
\text { (ng) }\end{array}$ & $\begin{array}{c}\text { \% rec. } \\
\text { U }\end{array}$ & $\begin{array}{c}\text { \% rec. } \\
\text { Th }\end{array}$ \\
\hline JCp-1 [22] & 0,19508 & 526,716 & 249,5 & 10,729 & 2,10 & 47,37 & 19,57 \\
\hline JCp-1 [23] & 0,19728 & 532,656 & 253,4 & 10,850 & 2,05 & 47,57 & 18,89 \\
\hline JCp-1 [24] & 0,19620 & 529,740 & 242,4 & 10,791 & 1,90 & 45,76 & 17,60 \\
\hline JLs-1 [13] & 0,20270 & 354,725 & 242,4 & 5,817 & 4,25 & 68,35 & 73,06 \\
\hline JLs-1 [14] & 0,19842 & 347,235 & 130,7 & 5,694 & 3,90 & 37,64 & 68,49 \\
\hline
\end{tabular}
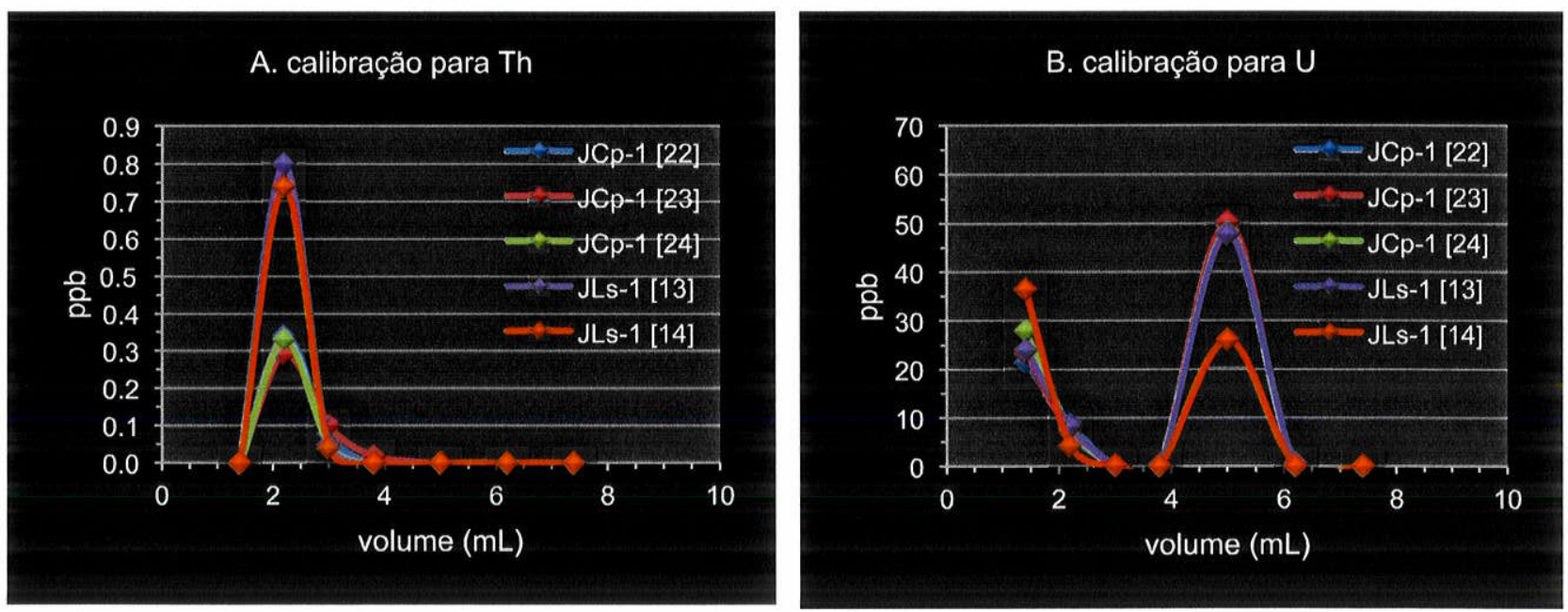

Figura 09. Gráficos ilustrando a calibração da coluna do procedimento UMN com os padrões JCp-1 [22 a 24] e JLs-1 [13 e 14]. A. Calibração de Th; B. Calibração de U. 
Embora não ideais, as recuperações calculadas para Th e $U$ nos intervalos prédefinidos são equivalentes nas frações JCp-1 (em torno de $45 \%$ e 20\%, respectivamente) e variável para o JLs-1, sendo que para a fração JLs-1 [13] os valores calculados foram de $68 \%$ para Th e $73 \%$ para U. 


\section{Capítulo V - PROCEDIMENTOS PARA PREPARAÇÃO DE SPIKES Th E U}

\subsection{INTRODUÇÃO}

Nesse trabalho foram preparados três spikes (traçadores) a partir de soluções (fontes) ácidas enriquecidas nos isótopos ${ }^{229} \mathrm{Th},{ }^{233} \mathrm{U}$ e ${ }^{236} \mathrm{U}$, todos manipulados pelo Instituto de Radioproteção e Dosimetria (IRD) da Comissão Nacional de Energia Nuclear (CNEN). As informações referentes a essas soluções-spikes são dadas integralmente na tabela 16.

Tabela 16. Informações sobre as fontes usadas para preparação dos spikes ${ }^{229} \mathrm{Th},{ }^{233} \mathrm{U}$ e ${ }^{236} \mathrm{U}$.

\begin{tabular}{|c|c|c|c|}
\hline & ${ }^{2 z y} \mathrm{Th}$ & ${ }^{233} \mathrm{U}$ & ${ }^{236} \mathrm{U}$ \\
\hline Atividade/massa & $1,224 \mathrm{~Bq} / \mathrm{g}$ & $2,480 \mathrm{~Bq} / \mathrm{g}$ & $1,027 \mathrm{Bg} / \mathrm{g}$ \\
\hline Atividade total & $3,285 \mathrm{~Bq}$ & $6,831 \mathrm{~Bq}$ & $1,498 \mathrm{~Bq}$ \\
\hline $\begin{array}{l}\text { Concentração } \\
\text { Calculada }\end{array}$ & $155,5 \mathrm{pg} / \mathrm{g}$ & $6,94 \mathrm{ng} / \mathrm{g}$ & $429 \mathrm{ng} / \mathrm{g}$ \\
\hline Data referência & $31 / 10 / 2005$ & $31 / 10 / 2005$ & $31 / 10 / 2005$ \\
\hline $\mathrm{T}_{1 / 22^{*}}$ (anos) & $7340( \pm 160)$ & $1,592( \pm 0,002)^{*} 10^{5}$ & $2,342( \pm 0,003)^{*} 10^{7}$ \\
\hline $\begin{array}{l}\text { Origem da solução- } \\
\text { mãe }\end{array}$ & IPL & LMRI & IPL \\
\hline Tipo da fonte & Liquida, em ampola & Líquida, em ampola & Líquida, em ampola \\
\hline Massa & 2,684484 gramas & 2,754402 gramas & 1,458574 gramas \\
\hline Meio & $\mathrm{HNO}_{3} 2 \%$ & $\mathrm{HNO}_{3} 1 \mathrm{~mol} / \mathrm{L}$ & $\mathrm{HNO}_{3} 2 \%$ \\
\hline Impurezas & - & - & - \\
\hline Descendentes & $\begin{array}{c}{ }^{225} \mathrm{Ra},{ }^{225} \mathrm{Ac},{ }^{221} \mathrm{Fr}, \\
{ }^{217} \mathrm{At},{ }^{213} \mathrm{Bi},{ }^{213} \mathrm{Po}, \\
{ }^{209} \mathrm{Tl},{ }^{209} \mathrm{~Pb},{ }^{209} \mathrm{Bi}\end{array}$ & - & ${ }^{232} \mathrm{Th}$ \\
\hline Incerteza** & $\begin{array}{c}\text { Tipo A: } 1,3 \% \\
\text { Tipo B: } 0,58 \% \\
\text { Incerteza total: } 2,9 \% \\
k=2\end{array}$ & $\begin{array}{c}\text { Tipo A: } 0,22 \% \\
\text { Tipo B: } 0,20 \% \\
\text { Incerteza total: } 2,0 \% \\
k=2\end{array}$ & $\begin{array}{c}\text { Tipo A: } 0,15 \% \\
\text { Tipo B: } 1,0 \% \\
\text { Incerteza total: } 0,6 \% \\
k=2\end{array}$ \\
\hline Sistema de medição & $\begin{array}{l}\text { Cintilação líquida } \\
\text { com método do } \\
\text { Padrão Interno }\end{array}$ & $\begin{array}{l}\text { Cintilação líquida } \\
\text { com método do } \\
\text { Padrão Interno }\end{array}$ & $\begin{array}{l}\text { Cintilação liquida } \\
\text { com método do } \\
\text { Padrão Interno }\end{array}$ \\
\hline Rastreabilidade $e^{* * *}$ & Vide notas & Vide notas & Vide notas \\
\hline
\end{tabular}

* ref. LNHB 2005.

** Tipo A: são aquelas estimadas aplicando-se métodos estatisticos em uma série de $n$ medições $\left(u_{i}\right) ; \operatorname{logo}, u_{A}=$ $\sqrt{\sum\left(u_{i}^{2}\right)}$ sendo $(i=1, n)$. Típo B: são aquelas estimadas de $m$ valores obtidos por outros métodos, não estatísticos, associados ao sistema de mediçăo $\left(u_{j}\right)$; logo, $u B=\sqrt{\sum\left(u_{i}^{2}\right)}$ sendo $(j=1, \mathrm{~m})$. Na determinaçăo de $u_{j}$ deve-se levar em conta o divisor cf. a distribuição adotada; na determinação de $u_{i}$ e $u_{j}$ deve-se levar em conta os fatores de propagação de incerteza. A incerteza combinada $\left(\boldsymbol{u}_{c}\right)$ é obtida utilizando-se a raiz quadrada da soma das variâncias das incertezas do Tipo A e do Tipo B. O valor da incerteza total expandida é obtido por $U=k u_{c}$ ( $k=2$, intervalo de confiança $2 \sigma)$. 
...(continuação da legenda da tabela 11)...

*** Os Sistemas de Medição utilizados no SEMRA/LNMRI estão calibrados com padrões rastreados, implicitamente, ao Sistema Internacional de Referencia ou a Laboratórios Primários, por meio de programas interlaboratoriais de comparação de atividade de radionuclídeos. A saber: SEMRA/LNMRI refere-se a Serviço de Metrologia de Radionuclideos/Laboratório Nacional de Metrologia das Radiações lonizantes.

Em negrito estão especificadas as concentrações calculadas a partir dos dados de atividade total.

\subsection{PROCEDIMENTO PARA CALIBRAÇÃO DOS SPIKES ${ }^{233} \mathrm{U}$ E ${ }^{236} \mathrm{U}$}

O primeiro passo consistiu em preparar uma solução de calibração de $U$ com concentração precisamente determinada, a partir do sal $\mathrm{U}_{3} \mathrm{O}_{8}(99,99 \%$ de pureza) gentilmente cedido pelo Dr. Koji Kawashita. Para isso, um cadinho de porcelana foi lavado com água destilada e detergente, e calcinado gradualmente em uma mufla, até atingir $900^{\circ} \mathrm{C}$. Nessa temperatura foi mantido por 1 hora, e depois resfriado até $200^{\circ} \mathrm{C}$ ainda na mufla para, em seguida, ser transferido para um dessecador. O mesmo procedimento foi adotado para o sal, após ter sido pesada sua massa inicial. A calcinação foi feita dentro do cadinho de porcelana. Como a quantidade disponivel do sal $U_{3} \mathrm{O}_{8}$ era relativamente pequena, todo o material foi utilizado na preparação da solução-padrão.

Após a calcinação, o sal foi transferido para um béquer Savillex® e a ele foram adicionados aproximadamente $35 \mathrm{~mL}$ de ácido nítrico $1 \mathrm{~N}$ para dissolver a quantidade final pesada do sal. Não foi observada dissolução completa, motivo pelo qual a solução foi evaporada em chapa quente, e o resíduo foi tomado em $3 \mathrm{~mL}$ de $\mathrm{HCl} 6 \mathrm{~N}$ quando, então, observou-se dissolução total do resíduo. A solução de $\mathrm{HCl}$ foi evaporada e ao resíduo final foram adicionados $50 \mathrm{~mL}$ de água Milli-Q, e mantido em estoque. Os dados de pesagem do sal e do cadinho, pré- e pós-calcinação, bem como os dados de pesagem finais constam na tabela17.

A concentração final da solução-padrão de calibração foi calculada em $588,5 \mu \mathrm{g} / \mathrm{g}$ de U. No entanto, não é possivel calcular a incerteza desse dado uma vez que foi realizada apenas uma pesagem do material devido a pouca quantidade disponivel. Ademais, a incerteza do valor de concentração da solução de calibração deve ser propagada para a incerteza final na concentração do spike. Sendo assim, optou-se por utilizar uma outra solução de $U$, comercial, que constitui um Material de Referência Certificado (CRM 135) da New Brunswick Laboratory, enriquecida em ${ }^{235} \mathrm{U}$ para calibrar os dois spikes ${ }^{233} \mathrm{U}$ e ${ }^{236} \mathrm{U}$. Essa solução contém aproximadamente $100 \mathrm{mg}$ de $U$ dissolvidos em $\mathrm{HNO}_{3} 0,8 \mathrm{~N}$, cuja concentração é de 28,270 \pm $0,051 \mu$ moles de U/grama.

Para a calibração foram preparadas 5 aliquotas iguais para cada um dos spikes, as quais terão suas concentrações finais medidas por MC-ICP-MS. Para ambos ${ }^{233} U$ e ${ }^{236} U$, foram efetuadas misturas com a solução enriquecida de ${ }^{235} \mathrm{U}$ na proporção $1: 2\left({ }^{233} \mathrm{U}:{ }^{235} \mathrm{U}\right.$ e $\left.{ }^{236} \mathrm{U}:{ }^{235} \mathrm{U}\right)$. Essas estimativas foram baseadas na informação de que a quantidade mínima de $U$ a ser 
medida com precisão ideal para diluição isotópica (por TIMS ou MC-ICP-MS) deve ser de 50 picogramas. Dessa forma as quantidades das alíquotas de ${ }^{235} \mathrm{U}$ estão em torno de 40 picogramas e as quantidades dos spikes ${ }^{233} \cup$ e ${ }^{236} \mathrm{U}$ estão em torno de 20 picogramas.

Tabela 17. Dados de pesagem obtidos no procedimento de uma solução-padrão de calibração para os spikes ${ }^{233} \cup$ e ${ }^{236} \mathrm{U}$.

\begin{tabular}{|c|c|c|c|c|c|}
\hline & \multicolumn{2}{|c|}{ Pré-calcinação } & \multicolumn{3}{|c|}{ Pós-calcinação } \\
\hline & Cadinho & $\mathrm{U}_{3} \mathrm{O}_{8}$ & $\begin{array}{l}\mathrm{Cad} \\
+\mathrm{U}\end{array}$ & & $\mathrm{U}_{3} \mathrm{O}_{8}$ \\
\hline \multirow[t]{3}{*}{$\begin{array}{l}\text { Peso } \\
\text { (gramas) }\end{array}$} & 26,46446 & 0,03818 & 26,4 & & 0,03547 \\
\hline & \multicolumn{2}{|c|}{ Dados de Transferência } & \multicolumn{3}{|c|}{ Solução-padrão de U } \\
\hline & Papel & $\mathrm{U}_{3} \mathrm{O}_{8}$ & béquer & $\begin{array}{l}\text { béquer + } \\
\mathrm{H}_{2} \mathrm{O}-\mathrm{U}_{3} \mathrm{O}_{8}\end{array}$ & $\mathrm{H}_{2} \mathrm{O}-\mathrm{U}_{3} \mathrm{O}_{8}$ \\
\hline $\begin{array}{l}\text { Peso } \\
\text { (gramas) }\end{array}$ & 0,11467 & 0,03488 & 94,71820 & 144,97374 & 50,25554 \\
\hline
\end{tabular}

Obs: o peso do sal diminuiu aproximadamente $7 \%$ em relação ao inicial, após calcinação a $900^{\circ} \mathrm{C}$.

Obs: o peso do sal diminuiu aproximadamente $1,7 \%$ em relação a valor pós-calcinação, após a transferência para o béquer Savillex®.

As aliquotas de ${ }^{233} \mathrm{U}:{ }^{235} \mathrm{U}$ e ${ }^{236} \mathrm{U}:{ }^{235} \mathrm{U}$ foram preparadas da seguinte maneira: inicialmente a solução enriquecida ${ }^{235} \mathrm{U}$ foi diluída duas vezes. Na primeira diluição pesou-se $0,250 \mathrm{~g}$ dessa solução (com concentração de ${ }^{235} \mathrm{U}$ calculada em 6,629 $\mu \mathrm{g} / \mathrm{g}$ ) e avolumou-se para $80 \mathrm{~mL}\left(c .80 \mathrm{~g}\right.$ ) com $\mathrm{HNO}_{3} 1 \mathrm{~N}$; a concentração dessa primeira diluição é ${ }^{235} \mathrm{U}=20,71$ $\mathrm{ng} / \mathrm{g}$. Na segunda diluição pesou-se $0,5 \mathrm{~g}$ dessa primeira solução diluída e avolumou-se novamente para $80 \mathrm{~mL}$ (c. $80 \mathrm{~g}$ ) com $\mathrm{HNO}_{3} 1 \mathrm{~N}$; a concentração dessa segunda solução diluída foi de $129,4 \mathrm{pg} / \mathrm{g}$.

O spike ${ }^{233} \mathrm{U}$ (concentração original de $6,94 \mathrm{ng} / \mathrm{g}$ ) fol diluído apenas uma vez. Pesou-se $0,250 \mathrm{~g}$ e avolumou-se para $17,35 \mathrm{~mL}$ (ou c. 17,35 g) com $\mathrm{HNO}_{3} 1 \mathrm{~N}$; a concentração dessa solução diluída de ${ }^{233} \mathrm{U}$ é $100 \mathrm{pg} / \mathrm{g}$. Por ser mais concentrado, o spike ${ }^{236} \mathrm{U}$ (concentração 429 $\mathrm{ng} / \mathrm{g}$ ) foi diluido duas vezes. Pesou-se $0,5 \mathrm{~g}$ e avolumou-se para $6 \mathrm{~mL}(c .6 \mathrm{~g}) \mathrm{com} \mathrm{HNO}_{3} 1 \mathrm{~N}$; a concentração dessa primeira solução diluída de ${ }^{236} \mathrm{U}$ é $35,75 \mathrm{ng} / \mathrm{g}$. Na segunda diluição pesouse $0,1 \mathrm{~g}$ da primeira solução e avolumou-se para $17,9 \mathrm{~mL}$ (c. $17,9 \mathrm{~g}$ ) com $\mathrm{HNO}_{3} 1 \mathrm{~N}$; a concentração dessa solução final diluída de ${ }^{236} \mathrm{U}$ é $200 \mathrm{pg} / \mathrm{g}$.

As aliquotas de ${ }^{233} \mathrm{U}:{ }^{235} \mathrm{U}$ foram preparadas em béqueres Savillex® adicionando-se 310 $\mu \mathrm{L}$ da solução diluida final de ${ }^{235} \mathrm{U}$ e $200 \mu \mathrm{L}$ da solução diluída de ${ }^{233} \mathrm{U}$, para cada uma das cinco aliquotas preparadas. O mesmo procedimento foi feito para preparação das cinco alíquotas de ${ }^{236} \mathrm{U}:{ }^{235} \mathrm{U}$, sendo que os volumes tomados foram $310 \mu \mathrm{L}$ da solução diluída final de 
${ }^{235} \mathrm{U}$ e $100 \mu \mathrm{L}$ da solução diluída final de ${ }^{236} \mathrm{U}$. Após homogeneização, as 10 alíquotas foram colocadas para evaporação, até completa secura. $O$ volume final para análise por espectrometria de massa será de $2 \mathrm{~mL}$ de $\mathrm{HNO}_{3} 0,1 \mathrm{~N}$.

Considerando que existe pequena fração de ${ }^{236} \mathrm{U}$ na solução enriquecida de ${ }^{235} \mathrm{U}$, esse valor deverá ser corrigido da concentração calculada do spike ${ }^{236} \mathrm{U}$ (abundâncias de outros isótopos de $U$ na solução enriquecida de ${ }^{235} U$ (CRM 135) com $99,8195 \pm 0,0013:{ }^{234} U-0,0442$ $\left.\pm 0,0004 ;{ }^{236} U-0,0574 \pm 0,0004 ;{ }^{238} U-0,0789 \pm 0,0004\right)$.

\subsection{PROCEDIMENTO PARA CALIBRAÇÃO DO SPIKE ${ }^{229} \mathrm{Th}$}

O procedimento para calibração do spike ${ }^{229}$ Th seguiu as mesmas etapas descritas no item anterior. Para preparar a solução de calibração foi, de início, utilizado o sal $\mathrm{ThO}_{2}(99,99 \%$ de pureza), da Johnson Matthey Chemicals Ltd, gentilmente cedido pelo Dr. Jorge Sarkis (IPEN/CNEN/USP). Um cadinho de porcelana foi previamente limpo com água destilada e detergente e, a seguir, calcinado. Após resfriamento, o cadinho foi pesado de 2 a 3 vezes/dia, por 2 dias consecutivos, para se obter a massa exata do mesmo. $O$ sal foi pesado no cadinho, e levado à mufla para calcinação a $900^{\circ} \mathrm{C}$, durante 1 hora. Foi resfriado ainda na mufla, até aproximadamente $200^{\circ} \mathrm{C}$ quando, então, foi levado à estufa e finalmente colocado em dessecador antes da pesagem da massa final, pós-calcinação. Após resfriamento, sal + cadinho foram pesados 2 vezes/dia, por 2 dias consecutivos. Os dados de pesagem do sal e do cadinho, pré- e pós-calcinação constam na tabela 18 , abaixo.

Tabela 18. Dados de pesagem obtidos no procedimento de uma solução-padrão de calibração para o spike ${ }^{229}$ Th.

\begin{tabular}{|c|c|c|c|c|}
\hline \multirow[b]{2}{*}{$\begin{array}{l}\text { Peso } \\
\text { (gramas) }\end{array}$} & \multicolumn{2}{|c|}{ Pré-calcinação } & \multicolumn{2}{|c|}{ Pós-calcinação } \\
\hline & Cadinho & $\mathrm{ThO}_{2}$ & $\begin{array}{c}\text { Cadinho } \\
+\mathrm{ThO}_{2}\end{array}$ & $\mathrm{ThO}_{2}$ \\
\hline & 26,46404 & \multirow{6}{*}{0,06337} & 26,52710 & 0,06308 \\
\hline & 26,46424 & & 26,52714 & 0,06312 \\
\hline & 26,46435 & & 26,52714 & 0,06312 \\
\hline & 26,46395 & & 26,52706 & 0,06304 \\
\hline & 26,46416 & & - & - \\
\hline & 26,46406 & & - & - \\
\hline Média (gramas) & 26,46402 & & Média (gramas) & 0,06309 \\
\hline
\end{tabular}

Após a calcinação o sal $\mathrm{ThO}_{2}$ foi transferido para uma bomba Parr® e a ele foram adicionados $3 \mathrm{~mL}$ de $\mathrm{HF}$ e $1 \mathrm{~mL}$ de $\mathrm{HNO}_{3}$ concentrado, e deixado em estufa a $200^{\circ} \mathrm{C}$, por um 
período de 5 dias. Ao fim notou-se que a dissolução não se completou, restando um resíduo branco.

Após pesquisas na literatura descobriu-se que o óxido de tório é um composto de difícil dissolução em ácido nítrico, uma vez que a taxa de dissolução é muito lenta (Filgueiras, 1984). A presença de pequena quantidade de ácido fluorídrico acelera em até 10 mil vezes a taxa de dissolução, já que o ácido fluorídrico atua como catalisador nessa reação. Todavia, o procedimento deve ser feito com aparehagem adequada que consiste em um balão de três bocas de fundo redondo $(125 \mathrm{~mL}$ ) acoplado a um condensador de reflluxo, sendo que a dissolução pode levar horas ou até dias, dependendo da densidade do óxido utilizado (Lopes e Filgueiras, 1985). Por falta dessa instrumentação não foi possivel reproduzir esse teste e, assim, a possibilidade de preparar uma solução de calibração a partir de $\mathrm{ThO}_{2}$.

A literatura traz ainda a possibilidade de dissolução de óxidos de tório utilizando-se ácido sulfúrico, comumente usado em digestão de areias monazíticas (que contêm $\mathrm{ThO}_{2} \mathrm{e}$ óxidos de urânio e terras raras; Zini, 2010). O inconveniente desse procedimento diz respeito à limitação de trabalhar com ácido sulfúrico de alta pureza, uma exigência para a técnica de espectrometria de massa com diluição isotópica.

Novos testes foram realizados com outro sal - Th $\left(\mathrm{NO}_{3}\right)_{4} \cdot 6 \mathrm{H}_{2} \mathrm{O}$, de pureza nuclear, gentilmente cedido pela $\mathrm{Dr}^{\mathrm{a}}$. Fátima Maria Sequeira de Carvalho (IPEN/CNEN/USP). O procedimento incluiu o aquecimento em estufa (c. de $80^{\circ} \mathrm{C}$ ) e várias pesagens sequenciais, duas vezes/dia, sendo que nos intervalos o sal era mantido em dessecador. O aquecimento objetivou a retirada do excesso de umidade para determinação, o mais precisamente possível, da massa antes da dissolução com $\mathrm{HNO}_{3} 1 \mathrm{~N}$. Após sucessivas tentativas observou-se que 0 nitrato de tório tem caráter fortemente higroscópico sendo impossivel determinar sua massa com precisão. Ainda utilizou-se uma bomba à vácuo na tentativa de precisar a pesagem, mas com insucesso.

Finalmente, foi feito um contato com a $\mathrm{Dr}^{\mathrm{a}}$. Maria Luiza Godoy (LEM/IRD/CNEN) que cedeu uma solução padrão de referência Th NIST (SRM 3159). Esse padrão apresenta concentração original de $9,98 \mathrm{mg} / \mathrm{g} \pm 0,04 \mathrm{mg} / \mathrm{g}$. A solução de trabalho foi diluída a partir dessa solução original, para uma concentração final de $99,99 \mathrm{ng} / \mathrm{g} \pm 0,01 \mathrm{ng} / \mathrm{g}$, em $\mathrm{HNO}_{3} 2 \%$.

Assim como foi feito para os spikes de $U$, para a calibração do spike ${ }^{229}$ Th foram preparadas cinco aliquotas iguais. Cada aliquota contém ${ }^{229} \mathrm{Th}:{ }^{232} \mathrm{Th}$ na proporção de $1: 2$, sendo preparadas da seguinte maneira: adição de $0,1 \mathrm{~mL}$ do spike ${ }^{229} \mathrm{Th}$ e $1,1 \mathrm{~mL}$ de solução de Th na concentração de $31,25 \mathrm{pg} / \mathrm{g}$. Os cálculos foram baseados na informação de que a quantidade minima de Th a ser medida com precisão ideal para diluição isotópica (por TIMS ou MC-ICP-MS) deve ser de 50 picogramas. Dessa forma a quantidade das alíquotas de ${ }^{229} \mathrm{Th}$ está em torno de 15,5 picogramas e a quantidade das aliquotas de ${ }^{232} \mathrm{Th}$ está em torno de 34,5 picogramas. 
A solução final de Th que foi usada para calibrar o spike ${ }^{229}$ Th teve concentração de $31,25 \mathrm{pg} / \mathrm{g}$, tendo sido preparada a partir de duas diluições da solução de trabalho com 99,99 $\mathrm{ng} / \mathrm{g}$ de Th. Assim, foram pesados $0,250 \mathrm{~g}$ dessa solução e avolumada para $80 \mathrm{~mL}$ com $\mathrm{HNO}_{3}$ $2 \%$, atingindo assim uma concentração de $312,5 \mathrm{pg} / \mathrm{g}$. Um grama dessa primeira solução diluida foi, por sua vez, pesado e avolumado para $10 \mathrm{~mL}$ com $\mathrm{HNO}_{3} 2 \%$, obtendo-se, ao fim, uma solução de trabalho diluida de concentração $31,25 \mathrm{pg} / \mathrm{g}$, a qual foi utilizada para calibrar o spike ${ }^{229}$ Th.

Após homogeneização, cada uma das cinco alíquotas iguais foram colocadas para evaporação até completa secura. $O$ volume final para análise por espectrometria de massa será de $2 \mathrm{~mL}$ de $\mathrm{HNO}_{3} 0,1 \mathrm{~N}$. 


\section{Capítulo VI - CONSIDERAÇÕES FINAIS}

O término do prazo para conclusão dessa dissertação de mestrado não necessariamente coincide com o término deste projeto, uma vez que não foi possivel obter resultados consistentemente satisfatórios para os procedimentos de cromatografia testados. Algumas dificuldades podem ser comentadas, mas consideramos que o fator tempo foi decisivo em não permitir atingir os objetivos almejados. Nesse aspecto, citamos a prolongada demora em adquirir os padrões JCp-1 e JLs-1 do Geological Survey of Japan, somente disponivel após 7 meses do início do mestrado, e da inesperada quebra do equipamento ICP-MS do IGc/USP, em abril/2011 coincidindo com o início dos testes de cromatografia. A situação fez-nos recorrer a outros laboratórios, muitos sem instrumentação adequada a medir concentrações muito baixas de $U$ e Th (ppb, ppt), até conseguir a parceria com a UNICAMP. Esse período acarretou em um atraso adicional de 3 meses ao projeto, sem considerar o cronograma apertado do equipamento devido o atendimento a outros projetos acadêmicos.

Apesar das dificuldades, o projeto de implementação do método U-Th para carbonatos recentes foi iniciado, seus primeiros resultados estão apresentados no corpo dessa dissertação e comentados neste último capítulo. Certamente novas etapas de testes até o ajuste ideal dos procedimentos deverão ser desenvolvidas a posteriori.

\subsection{SOBRE A INFRA-ESTRUTURA PARA IMPLEMENTAÇÃO DA CROMATOGRAFIA DE TROCA IÔNICA}

Consideramos que nossa pretensão tenha sido atingida uma vez que o método está sendo desenvolvido em uma capela de fluxo laminar própria (classe ISO5), com béqueres Savillex®, colunas, resinas e demais acessórios de uso exclusivo, e reagentes com a qualidade analítica requerida para a técnica de diluição isotópica. Todos esses materiais são rotineiramente descontaminados, com procedimentos bem estabelecidos, garantindo niveis ideais de branco laboratorial.

Considerando que o método U-Th está sendo implementado para carbonatos recentes, todos os testes realizados foram conduzidos com padrões internacionais de carbonatos, usando-se uma quantidade inicial de massa (c. $200 \mathrm{mg}$ ) que aproxima-se às quantidades de material normalmente utilizadas em laboratórios internacionais que trabalham com esse tipo de matriz geológica (espeleotemas e corais). Nossa intenção foi reproduzir o mais fielmente as condições que deverão ser estabelecidas quando da rotineirização do método, já antecipando as dificuldades em manusear quantidades reduzidas de amostra e, em adição, que têm 
concentrações de $\mathrm{U}$ (na ordem de $\mathrm{ng} / \mathrm{g}$ ) e Th (na ordem de $\mathrm{pg} / \mathrm{g}$ ) muito baixas. Os testes de dissolução foram realizados com ambos padrões $\mathrm{JCp}-1$ (coral) e JLs-1 (calcário com matéria orgânica) e, apesar de garantida a dissolução com ácidos nítrico e clorídico (forte ou fraco), optamos por estabelecer o uso rotineiro da dissolução com $\mathrm{HNO}_{3} 7 \mathrm{~N}$, que é rápida e completa em temperatura ambiente. Além do que, torna-se desnecessário "ambientar" a amostra antes da cromatografia com $\mathrm{HNO}_{3}$, como seria o caso se a dissolução fosse feita com $\mathrm{HCl}$, assim otimizando o tempo total do procedimento. Para as amostras que porventura contenham matéria orgânica, os testes de dissolução com o padrão JLs-1 mostraram ser necessária e efetiva a calcinação prévia em temperatura de c. $900^{\circ} \mathrm{C}$, com posterior dissolução com $\mathrm{HNO}_{3} 7$ N.

\subsection{SOBRE A ESCOLHA E PREPARAÇÃo DAS RESINAS DE TROCA IÔNICA USADAS NOS TESTES}

Como comentado nos capítulos anteriores, nosso projeto visou testar dois procedimentos de cromatografia de troca iônica já em rotina em outros laboratórios (BGC e UMN), de forma que as resinas usadas foram aquelas indicadas por cada laboratório - Bio $\operatorname{Rad} \circledast A G 1-X 8$ e Spectra/Gel@ IE 1-X8, ambas aniônicas, comercializadas na forma de cloreto. Resinas especificas U/TEVA®, TEVA® e TRU®, comercializadas pela Eichrom, têm sido aplicadas à cromatografia de U e Th em várias matrizes geológicas (p.ex., Yokoyama et al., 1999; Watanabe e Nakai, 2006a), combinadas ou não com a resina aniônica da Bio Rad(B. Todavia, dadas as dificuldades já mencionadas acima testes com essas resinas não puderam ser executados nesta primeira etapa do projeto, os quais serão certamente realizados e considerados quando da escolha de uma rotina cromatográfica ideal a ser implementada no CPGeo.

A preparação das resinas Bio $\operatorname{Rad}(\circledast$ e Spectra/Gel® diz respeito à lavagem e condicionamento que precedem a separação cromatográfica. Os fluxogramas da figura 10 ilustram as etapas em detalhe. Neste trabalho os testes iniciais de ambos os procedimentos foram desenvolvidos com resinas lavadas e condicionadas conforme o fluxograma 1 utilizandose essencialmente rinsagens alternadas de água e $\mathrm{HCl}$ (procedimento semelhante também é descrito por Watanabe e Nakai, 2006a). Dados alguns resultados insatisfatórios de recuperação para Th e $U$, nos testes seguintes foram considerados os procedimentos originais do BGC e UMN (fluxogramas 2 e 3), que incluem uma etapa de rinsagem/repouso em $\mathrm{HNO}_{3} 7 \mathrm{~N}$ ou água régia. Não há informação clara na literatura sobre a eficiência dessa etapa 'oxidante'. Acreditamos ser um cuidado adicional (desnecessário ?) acrescido para eliminar quaisquer traços mínimos de impurezas (p.ex., Th) contido nessas resinas. De qualquer forma, não foram observadas melhoras que viessem justificar a mudança na rotina já estabelecida no CPGeo. 
Procedimentos de lavagem das resinas

Bio Rad AG 1-X8 e Spectra/Gel IE 1-X8 adotados

neste trabalho

1. Procedimento tradicional realizado no $\mathrm{CPGeo}$

(adotado nas etapas 'Primeira', 'Segunda' e 'Terceira' do BGC e nas etapas 'Primeira', 'Segunda' e'Terceira' da UMN)

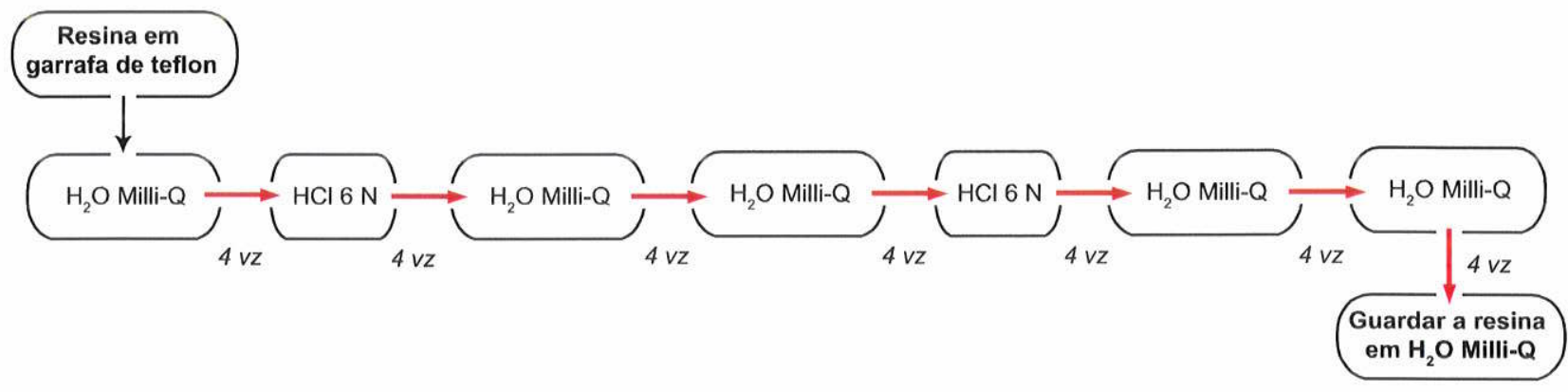

2. Procedimento modificado para a resina Bio Rad AG 1-X8 ('Quarta' etapa do BGC)

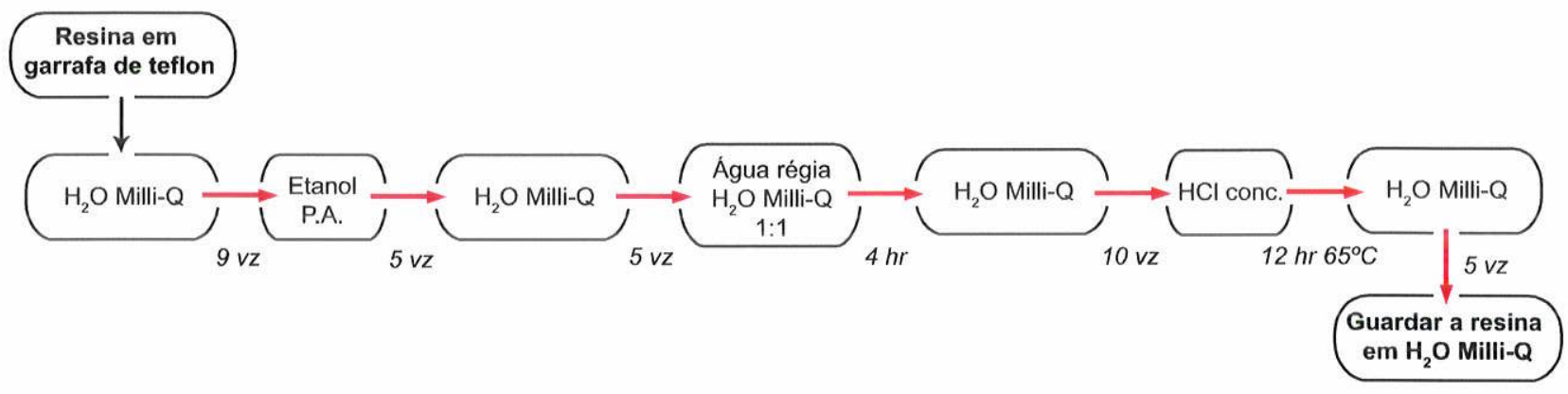

3. Procedimento modificado para a resina Spectra/Gel (vide comentários na terceira etapa da UMN)
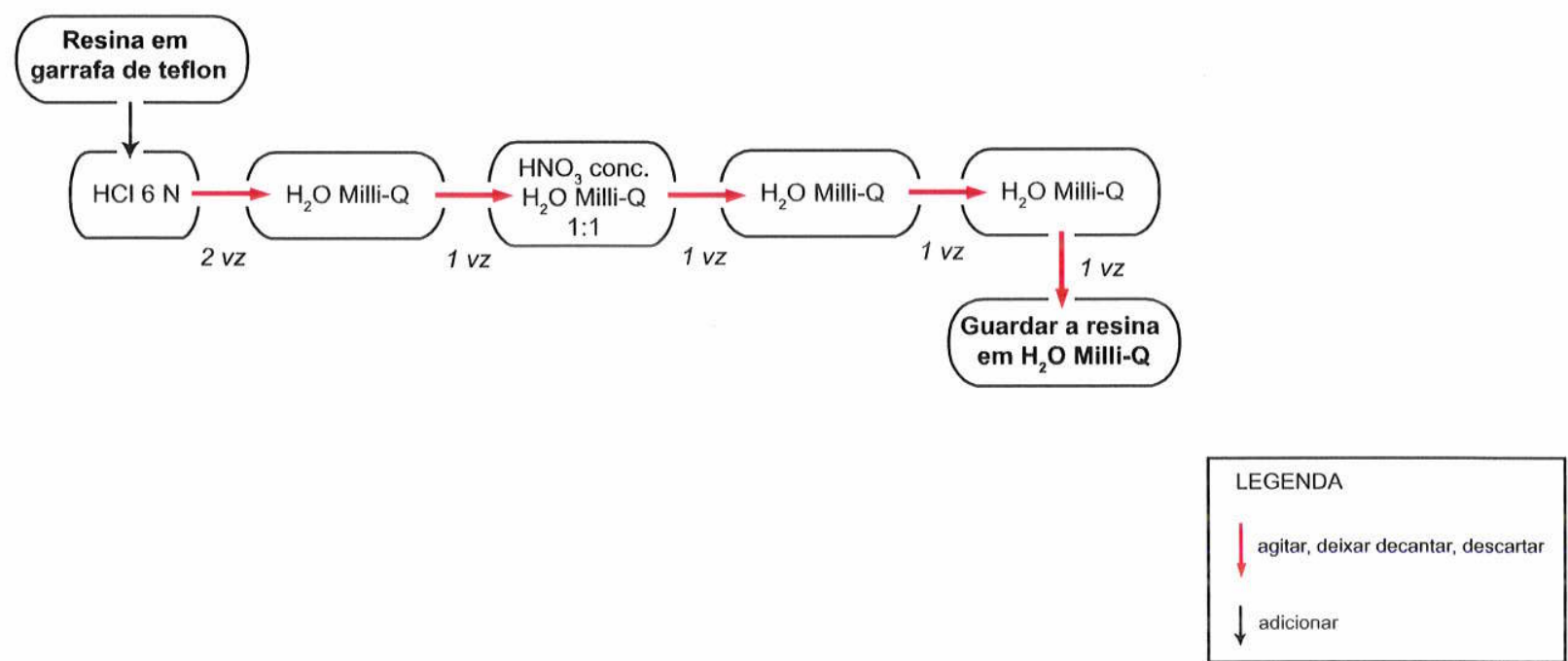

Figura 10. Fluxogramas ilustrando as etapas de lavagem das resinas Bio Rad $($ e Spectra/Gel $($ ) adotadas neste trabalho. O fluxograma 1 foi adotado para ambas as resinas, constituindo o esquema tradicionalmente realizado para resinas aniônicas utilizadas em outros métodos, no CPGeo. Os fluxogramas 2 e 3 representam os esquemas adotados no BGC e UMN, respectivamente. 


\subsection{SOBRE O PROCEDIMENTO DE CROMATOGRAFIA ADOTADO NO BGC}

A conclusão final é que, após quatro etapas de testes realizados conforme o procedimento descrito na figura 11, os resultados ainda não foram integralmente satisfatórios. Partindo de uma primeira etapa onde foram coletados apenas os intervalos pré-definidos para coleta de Th e $U$, tivemos excelente recuperação para $U(>90 \%)$ e valores erráticos para Th. A partir de então fracionamos toda a eluição de ambas as colunas, primária e secundária, para avaliar possível perda de Th em outras etapas (depósito, descarte ou ainda coleta de U). Ao mesmo tempo, trabalhamos em paralelo com um conjunto de amostras preparadas com hidróxido de Fe cuja função foi co-precipitar Th e $U$, talvez melhorando sua recuperação final.

Dos resultados da segunda etapa vimos que a excelente recuperação para $U$ no conjunto que não foi tratado com hidróxido de Fe foi reproduzida, mas notamos significativa redução nos valores do conjunto co-precipitado com Fe. Para Th, novamente, os valores de recuperação continuaram erráticos, flutuando entre $8-16 \%$ (sem co-precipitação) e 21-65\% (com co-precipitação). Esse comportamento levou-nos a não considerar a etapa de coprecipitação (ao menos no momento) para reproduzir o procedimento BGC. Assim, a avaliação dos picos de eluição para o conjunto sem tratamento com hidróxido de Fe permitiu determinar o melhor intervalo de coleta entre 8-22 mL para Th e 34-38 $\mathrm{mL}$ para $U$, na coluna primária, muito embora Th esteja sendo eliminado em pequenas frações durante a coleta de $\mathrm{U}$. $\mathrm{Na}$ coluna secundária, Th está sendo significativamente eliminado também na etapa de descarte, além do intervalo pré-definido, enquanto $U$ tem um pico ótimo entre $13-17 \mathrm{~mL}$. Ou seja, os intervalos de coleta de Th ainda precisam ser melhor calibrados.

Quando avaliados os resultados de recuperação, notamse persistentemente valores baixos de Th comparativamente à primeira etapa, os quais poderiam ser justificados por problemas externos à cromatografia. A quebra do espectrômetro do IGc/USP, ocorrida durante a leitura das amostras, implicou em um tempo de espera de aproximadamente 3 meses até que outro equipamento pudesse ser utilizado para apoiar o projeto (IGc/UNICAMP). Devido a isso, foi aventada a hipótese de hidrólise do $\mathrm{Th}^{4+}$ uma vez ser este um cátion fortemente ácido, cuja precipitação poderia ser facilitada em presença de meio ácido fraco (p.ex., $\mathrm{HCl} 0,1 \mathrm{~N}$ ).

A terceira etapa foi realizada para eliminar a probabilidade de hidrólise, repetindo-se as mesmas condições da primeira etapa (sem co-precipitação com $\mathrm{Fe}$ ) e com leitura imediata das aliquotas no ICP-MS. Foram feitas coletas totais para depósito, descarte, coleta de Th (duas frações, na coluna primária) e coleta de U. A hipótese de hidrólise do $\mathrm{Th}^{4+}$ foi descartada visto que as amostras apresentaram recuperação com valores mais elevados, semelhantes aos obtidos na primeira etapa de testes. Alguns resultados com recuperação acima de $100 \%$ foram obtidos em amostra que não foram tratadas em coluna (analisadas para verificar possivel 
hidrólise durante a dissolução, cf. item 3.3.1), podendo ser atribuídos a problemas instrumentais no ICP.MS. O mesmo padrão foi observado para a solução Fluka.

A última etapa de teste representou a tentativa de melhor recuperar e ajuste o pico de Th adequando-se a lavagem da resina Bio $\operatorname{Rad} \otimes$ conforme descrito no fluxograma 3 da figura 10. Os resultados mostraram total descalibração da coluna, agora com forte superposição dos picos de Th e U tanto na coluna primária quanto na secundária.

\subsection{SOBRE O PROCEDIMENTO DE CROMATOGRAFIA ADOTADO NA UMN}

Após três etapas de testes os resultados são ainda inconclusivos. Num primeiro momento conseguimos recuperar razoavelmente bem Th e $U$ usando a resina Spectra/Gel $\circledast$, conforme ditado no procedimento original. Devido às limitações de uso de $\mathrm{HClO}_{4}$ no $\mathrm{CPGeo}$, optamos por excluir a etapa de evaporação com esse ácido assumindo não existir matéria orgânica no padrão JCp-1; para o padrão JLs-1 consideramos que a matéria orgânica seria totalmente eliminada por calcinação pré-dissolução, como adotado neste trabalho. Aparentemente, essa atitude pode ter induzido às baixas recuperações obtidas para Th em ambos os padrões pois, na primeira etapa de teste, quando se usou o ácido perclórico, as recuperações de Th para as frações JCp-1 ([19] e [20]) foram de 82 e 94\%.

A recuperação persistentemente baixa de Th, especialmente para as frações JCp-1 (ver terceira etapa) em detrimento aos valores mais elevados para as frações JLs-1 nos levou a considerar que a exclusão de $\mathrm{HClO}_{4}$ do procedimento pode ter influenciado esses resultados. Ácido perclórico foi introduzido no procedimento para decompor possiveis traços de matéria orgânica que, se estiver presente na amostra, pode provocar "entupimento" na resina ou complexar Th (e/ou U?) impedindo a eluição mesmo em $\mathrm{pH}$ adequado. Para as frações JLs-1, onde sabidamente há matéria orgânica, temos estabelecido uma etapa de calcinação prédissolução com $\mathrm{HNO}_{3} 7 \mathrm{~N}$. Coincidentemente, os resultados de recuperação foram maiores sugerindo que talvez a calcinação já elimine toda, ou ao menos grande parte da matéria orgânica minimizando a importância do $\mathrm{HClO}_{4}$. Se consideradas as perdas em função da ainda deficiente calibração dos picos de coleta, o valor de recuperação final poderia ser aumentado satisfatoriamente.

Para U, o problema está essencialmente relacionado à ajuste no intervalo de coleta, pois nota-se frequente eluição de partes significativas nas etapas anteriores à sua coleta. Para um ajuste ideal será novamente tentado a acidificação da resina imediatamente antes e depois do depósito da amostra buscando aumentar a retenção do $U$ na resina. 
1. abertura da amostra

Procedimento de cromatografia líquida de troca iônica para $U$ e Th usando

resina Bio Rad AG 1-X8

- modificado do Berkeley Geochronological Center

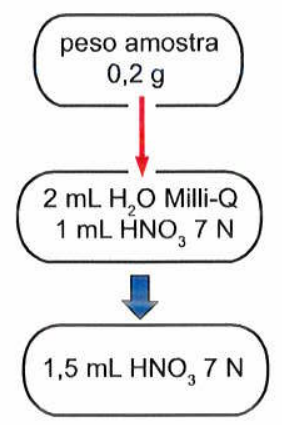

2. cromatografia na coluna primária - condicionamento -

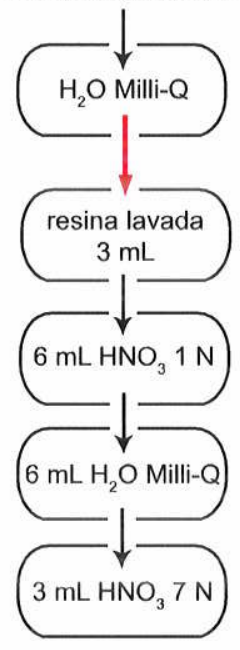

- rotina para coleta de $T h$ e $U$ -

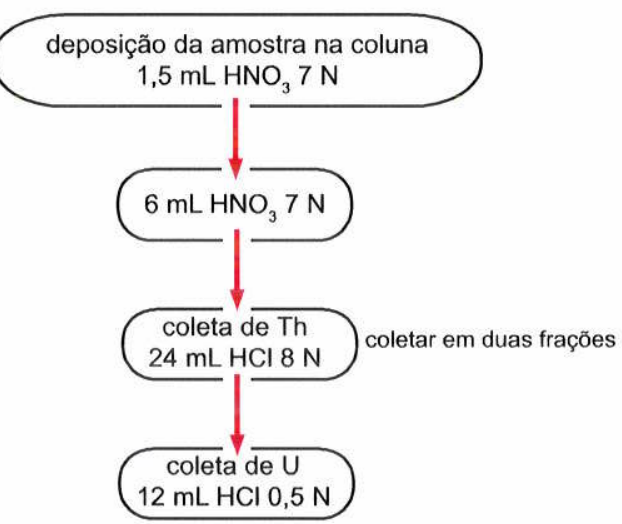

3. preparação para coluna secundária

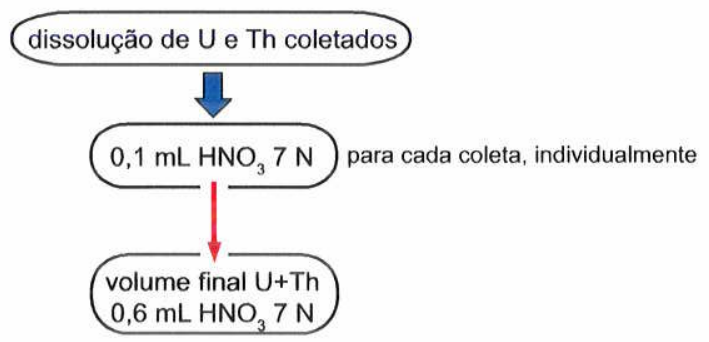

4. cromatografia na coluna secundária - condicionamento -

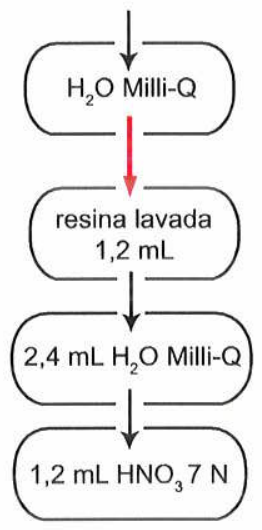

- rotina para coleta de Th e $U$ -

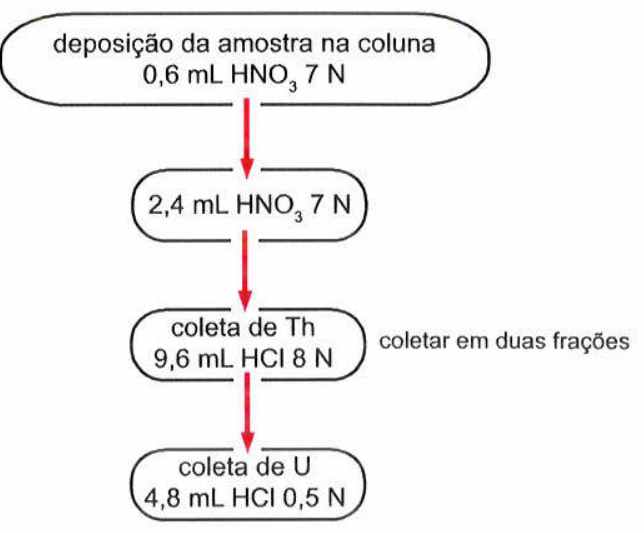

Figura 11. Fluxograma das etapas de cromatografia de troca iônica com a resina Bio Rad® AG 1-X8. 
1. abertura da amostra

Procedimento de cromatografia líquida de troca iônica para U e Th usando resina Spectra/Gel

- modificado da University of Minnesota

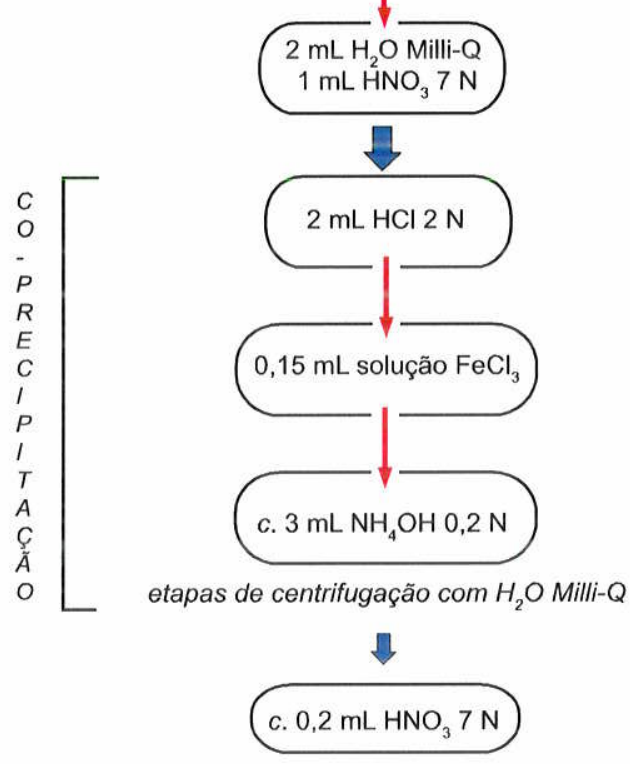

\section{2. cromatografia na coluna} - condicionamento -

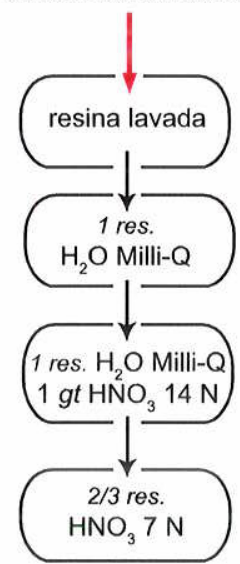

2. cromatografia na coluna (cont.) - rotina para coleta de Th e $U$.

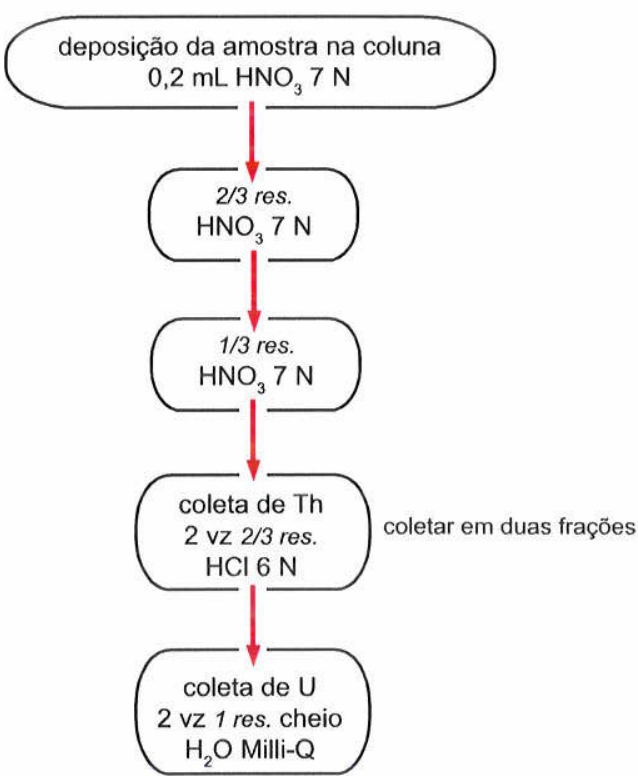

Figura 12. Fluxograma das etapas de cromatografia de troca iônica com a resina Spectra/Gel@ IE 1-X8. 


\subsection{SOBRE A PREPARAÇÃO DE SPIKES DE TH E U}

Consideramos que esta etapa está bem adiantada, faltando a determinação das concentrações por espectrometria de massa, o que esperamos seja possível até a apresentação dessa dissertação. As leituras serão feitas na Universidade de Brasília, em um espectrômetro MC-ICP-MS, por via úmida, por intermédio do Prof. Koji Kawashita.

\subsection{ETAPAS FUTURAS}

Como novas etapas idealizadas para avançar na implementação do método U-Th em carbonatos podemos enumerar:

1. Ajuste na calibração de Th no procedimento $B G C$, mantendo-se dois conjuntos cromatográficos sem co-precipitação com Fe. Para isso é necessário entender qual o exato comportamento de Th na resina Bio Rad para, se necessário, efetuar modificações em seu condicionamento que possam garantir melhor recuperação.

2. Ajuste na calibração de Th e $U$ (especialmente $U$ ) na calibração da coluna Spectra/Gel. Uma tentativa seria aumentar ligeiramente $\circ \mathrm{pH}$ na resina com adição controlada de $\mathrm{HNO}_{3}$ concentrado (50 $\mu \mathrm{L} / 1$ gota) imediatamente antes e depois do depósito da amostra e observar se $U$ permanece retido até a etapa de eluição com $\mathrm{H}_{2} \mathrm{O}$.

3. Preparação prévia da amostra com $\mathrm{HClO}_{4}$ para garantir nenhum traço de matéria orgânica que, caso presente mesmo em quantidades minimas, pode "encapsular" The $\mathrm{U}$ ou ainda impedir o fluxo na resina influenciando a recuperação. Apesar de sugerido originalmente no procedimento UMN essa condição pode ser estendida para o procedimento BGC.

4. Testes com as resinas U/TEVA® e TRU® deverão ser planejados, combinados ou não com as resinas aniônicas Bio $\operatorname{Rad} \otimes$ ou Spectra/Gelß, visando comparar rapidez, custos, grau de recuperação e outros parâmetros com os procedimentos aqui discutidos.

5. Leitura das concentrações e composições isotópicas dos spikes ${ }^{229} \mathrm{Th},{ }^{233} \mathrm{U}$ e ${ }^{236} \mathrm{U}$.

6. Testes de branco laboratorial a serem conduzidos quando da calibração dos spikes.

7. Elaboração das planilhas de correção de dados brutos, incluindo parâmetros intrínsecos às técnicas tais como: variação estatística das razões isotópicas medidas, fracionamento de massa, erros de pesagem de spikes e amostras, estimativas de brancos, constantes de decaimento, etc.).

8. Rotineirização do método com sucessivas análises de padrões de referência com espectrometria de massa combinada à diluição isotópica. 


\section{REFERÊNCIAS}

Aizawa, S. 2008. Determination of trace elements in carbonate reference samples by instrumental neutron activation analysis. Journal of Radioanalytical and Nuclear Chemistry, 278: 349-352.

Allègre, C.J. 2008. Isotope Geology. Cambridge Ed., 512 pp.

Chai, J., Oura, Y., Ebihara, M. 2003. Comparison of RNAA and ICP-MS for the determination of ultra-traces of Th and $U$ in geological and cosmochemical samples. Journal of Radioanalytical and Nuclear Chemistry, 255(3): 471-475.

Chen, J.H., Edwards, L., Wasserburg, G.J. 1986. ${ }^{238} \mathrm{U},{ }^{234} \mathrm{U}$ and ${ }^{232} \mathrm{Th}$ in seawater. Earth and Planetary Science Letters, 80: 241-251.

Collins, C.H., Braga, G.L., Bonato, P.S. 1995. Introdução a Métodos Cromatográficos. $6^{a}$ edição, Campinas: Editora Unicamp, 279 p.

Dickin, A.P. 1995. Radiogenic Isotope Geology. Cambridge Ed., 490 pp.

Edwards, L., Chen, J.H., Wasserburg, G.J. 1986/87. ${ }^{238} \mathrm{U}-{ }^{234} \mathrm{U}-{ }^{230} \mathrm{Th}^{232} \mathrm{Th}$ systematics and the precise measurement of time over the past 500,000 years. Earth and Planetary Science Letters, 81: 175-192.

Faure, G. Mensing, T.M. 2005. Isotopes - Principles and Apllications. $3^{\mathrm{a}}$ Ed., John Willey \& Sons, $897 \mathrm{pp}$.

Filgueiras, S.A.C. 1984. Dissolução de óxido misto de tório e urânio em solução de ácido nítrico - ácido fluorídrico. Dissertação de Mestrado, Centro de Desenvolvimento da Tecnologia Nuclear da NUCLEBRÁS/CDTN n 473, Belo Horizonte, 132 pp.

Hellstrom, J. 2003. Rapid and accurate U/Th dating using parallel ion-counting multi-collector ICP-MS. Journal of Analytical Atomic Spectrometry, 18: 1346-1351.

Hoffman, P.F., Schrag, D.P., 2002. The Snow Ball hypothesis: testing the limits of global change. Terra Nova, 14: 129-155.

Imai, N., Terashima, S., Itoh, S., Ando, A. 1996. Sedimentary rock series. Geostandards Newsletter, 20: 165-216.

Inoue, M., Nohara, M., Okai, T., Suzuki, A., Kawahata, H. 2004. Concentrations of trace elements in carbonate reference materials coral JCp-1 and giant clam JCt-1 by Inductively Coupled Plasma-Mass Spectrometry. Geostandards and Geoanalytical Research, 28: 411416.

Kemp, A.J., Brown, C.J. 1990. Microwave digestion of carbonate rock samples for chemical analysis. Analyst, 115: 1197-1199.

Ketcham, R.A. 1996. An improved method for determination of heat production with gamma-ray scintillation spectrometry. Geochemical Geology, 130: 175-194. 
Lopes, M.J.O., Filgueiras, S.A.C. 1985. Dissolução de $\mathrm{ThO}_{2}$ e $(\mathrm{Th}, \mathrm{U}) \mathrm{O}_{2}$ em solução de ácido nítrico e ácido fluorídrico. VI Congresso Brasileiro de Engenharia Química, Campinas, 14 pp.

Ohde, T. 2002. http://riodb02.ibase.aist.go.jp/geostand/welcomej.html.

Ohno, T., Takafuni, H. 2007. Simultaneous determination of mass-dependent isotopic fractionation and radiogenic isotope variation of strontium in geochemical samples by multiple-collector-ICP-mass spectrometry. Analytical Sciences, 23:

Potts, P.J. 1987. Handbook of Silicate Analysis. Blackie (Chapman Hall) Ed. 830 pp.

Richards, D.A., Bottrell, S.H., Cliff, R.A., Ströhle, K., Rowe, P. 1998. U-Pb dating of speleothem of Quaternary age. Geochimica and Cosmochimica Acta, 62: 3683-3688.

Sharp, W.D., Ludwig, K.R., Chadwick, O.A., Amundson, R., Glaser, L.L. 2003. Dating fluvial terraces by ${ }^{230} \mathrm{Th} /{ }^{234} \mathrm{U}$ on pedogenic carbonate, Wind River Basin, Wyoming. Quaternary Research, 59: 139-150.

Watanabe, Y., Nakai, S. 2006a. Accurate U-Th radioactive disequilibrium analyses of carbonate rock samples using commercially available $U$ and Th reagents and multi-collector ICP-MS. Microchimica Acta, 156: 289-295.

Watanabe, Y., Nakai, S. 2006b. U-Th radioactive disequilibrium analyses for JCp-1, coral reference distributed by the Geological Survey of Japan. Geochemical Journal, 40: 537 541.

Yokoyama, T., Makishima, A, Nakamura, E. 1999. Separation of thorium and uranium from silicate rock samples using two commercial extraction chromatographic resins. Analytical Chemistry, 71: 135-141.

Zini, J. 2010. Uso das cromatografias de extração e de troca iônica na separação de tório e terras raras de um resíduo gerado na unidade de purificação de tório. Aplicação das terras raras como catalisadores na geração de hidrogênio. Dissertação de Mestrado, IPEN/USP, São Paulo, 172 pp. 
Anexo I - Dados de leitura no ICP-MS das diversas alíquotas analisadas durante os testes de calibração das colunas cromatográficas do BGC e da UMN.

Primeira etapa de teste BGC (medidos no IGC-USP)

$\begin{array}{ccccc}\text { Amostra/Alíquota } & \text { Th (ppb) } & \mathbf{U} \text { (ppb) } & \text { Th (cps) } & \mathbf{U}(\mathbf{c p s}) \\ \text { JCp-1 [1] } & 0.79 & 103 & 12716 & 1614235 \\ \text { JCp-1 [3] } & 1.22 & 99.1 & 19607 & 1549970 \\ \text { JCp-1 [4] } & 1.57 & 105 & 25339 & 1637565 \\ \text { JLs-1 [1] } & 0.46 & 62.2 & 7462 & 972280 \\ \text { JLs-1 [2] } & 0.44 & 72.3 & 7051 & 1130644 \\ \text { JLs-1 [3] } & 0.55 & 66 & 8902 & 1033014 \\ \text { JLs-1 [4] } & 0.55 & 62.8 & 8912 & 982640\end{array}$

Curva de calibração

$\begin{array}{ccccc}\text { Branco } & 0 & 0 & -8 & 13 \\ \text { Padrão 1 } & 0.1 & 0.5 & 1610 & 7821 \\ \text { Padrão 2 } & 0.25 & 5 & 4027 & 78213 \\ \text { Padrão 3 } & 0.5 & 10 & 8054 & 156427 \\ \text { Padrão 4 } & 1 & 20 & 16108 & 312854 \\ \text { Padrão 5 } & 1.5 & 35 & 24162 & 547494\end{array}$

Segunda etapa de teste BGC (medidos no IGc-USP)

$\begin{array}{ccccc}\text { Amostra/Alíquota } & \text { Th (ppb) } & \mathbf{U} \text { (ppb) } & \text { Th (cps) } & \mathbf{U} \text { (cps) } \\ \mathrm{JCp}-1 \text { [5] / A1 } & 0.008 & 0.001 & 141 & 17 \\ \mathrm{JCp}-1 \text { [5] / B1 } & 0.005 & 0.001 & 88 & 17 \\ \mathrm{JCp}-1 \text { [5] / B2 } & 0.005 & 0.029 & 88 & 484 \\ \mathrm{JCp}-1 \text { [5] / B3 } & 0.002 & 1.663 & 35 & 27754 \\ \mathrm{JCp}-1 \text { [5] / C1 } & 0.06 & 4.548 & 1056 & 75907 \\ \mathrm{JCp}-1 \text { [5] / C2 } & 0.235 & 0.198 & 4147 & 3302 \\ \mathrm{JCp}-1 \text { [5] / C3 } & 0.013 & 0.125 & 223 & 2083 \\ \mathrm{JCp}-1 \text { [6] / A1 } & 0.005 & 0.001 & 88 & 17 \\ \mathrm{JCp}-1 \text { [6] / B1 } & 0.002 & 0 & 35 & 10 \\ \mathrm{JCp}-1 \text { [6] / B2 } & 0.005 & 0.013 & 88 & 217 \\ \mathrm{JCp}-1 \text { [6] / B3 } & 0.001 & 1.191 & 18 & 19877 \\ \mathrm{JCp}-1 \text { [6] / C1 } & 0.097 & 4.077 & 1706 & 68041 \\ \mathrm{JCp}-1 \text { [6] / C2 } & 0.203 & 0.163 & 3577 & 2717 \\ \mathrm{JCp}-1 \text { [6] / C3 } & 0.007 & 0.093 & 122 & 1549 \\ \mathrm{JCp}-1 \text { [7] / A1 } & 0 & 0 & 10 & 11 \\ \mathrm{JCp}-1 \text { [7] / B1 } & 0.128 & 0.012 & 2254 & 200 \\ \mathrm{JCp}-1 \text { [7] / B2 } & 0.002 & 0.27 & 35 & 4506 \\ \mathrm{JCp}-1 \text { [7] / C1 } & 0.144 & 1.032 & 2541 & 17231 \\ \mathrm{JCp}-1 \text { [7] / C2 } & 0.015 & 0.034 & 270 & 564\end{array}$


Segunda etapa de teste BGC (medidos no IGc-USP) cont.

$\begin{array}{ccccc}\text { Amostra/Alíquota } & \text { Th (ppb) } & \text { U (ppb) } & \text { Th (cps) } & \text { U (cps) } \\ \text { JCp-1 [8] / A1 } & 0.002 & 0.002 & 35 & 33 \\ \mathrm{JCp}-1 \text { [8] / B1 } & 0.046 & 0 & 810 & 10 \\ \mathrm{JCp}-1 \text { [8] / B2 } & 0.002 & 0.08 & 35 & 1335 \\ \mathrm{JCp}-1 \text { [8] / C1 } & 0.21 & 0.45 & 3692 & 7507 \\ \mathrm{JCp}-1 \text { [8] / C2 } & 0.028 & 0.018 & 489 & 296 \\ \mathrm{JCp}-1 \text { [9] / A1 } & 0.006 & 0.005 & 105 & 83 \\ \mathrm{JCp}-1 \text { [9] / B1 } & 0.002 & 0 & 35 & 11 \\ \mathrm{JCp}-1 \text { [9] / B2 } & 0.006 & 0.645 & 105 & 10765 \\ \mathrm{JCp}-1 \text { [9] / B3 } & 0.003 & 4.087 & 53 & 68210 \\ \mathrm{JCp}-1 \text { [9] / C1 } & 0.089 & 3.664 & 1576 & 61146 \\ \mathrm{JCp}-1 \text { [9] / C2 } & 0.324 & 0.14 & 5703 & 2343 \\ \mathrm{JCp}-1 \text { [9] / C3 } & 0.06 & 0.094 & 1057 & 1561 \\ \mathrm{JCp}-1 \text { [10] / A1 } & 0.004 & 0 & 70 & 11 \\ \mathrm{JCp}-1 \text { [10] / B1 } & 0.001 & 0 & 18 & 11 \\ \mathrm{JCp}-1 \text { [10] / B2 } & 0.002 & 0.399 & 35 & 6659 \\ \mathrm{JCp}-1 \text { [10] / B3 } & 0.001 & 2.822 & 18 & 47098 \\ \mathrm{JCp}-1 \text { [10] / C1 } & 0.06 & 2.795 & 1051 & 46646 \\ \mathrm{JCp}-1 \text { [10] / C2 } & 0.26 & 0.102 & 4585 & 1703 \\ \mathrm{JCp}-1 \text { [10] / C3 } & 0.059 & 0.073 & 1032 & 1220 \\ \mathrm{JCp}-1 \text { [11] / A1 } & 0.002 & 0 & 35 & 11 \\ \mathrm{JCp}-1 \text { [11] / B1 } & 0.004 & 2.61 & 70 & 43560 \\ \mathrm{JCp}-1 \text { [11] / B2 } & 0.006 & 13.23 & 105 & 220802 \\ \mathrm{JCp}-1 \text { [11] / C1 } & 0.976 & 7.245 & 17195 & 120911 \\ \mathrm{JCp}-1 \text { [11] / C2 } & 0.099 & 0.223 & 1739 & 3730 \\ \mathrm{JCp}-1 \text { [11] / C3 } & 0.005 & 0.142 & 92 & 2370 \\ \mathrm{JCp}-1 \text { [12] / A1 } & 0.002 & 0 & 35 & 11 \\ \mathrm{JCp}-1 \text { [12] / B1 } & 0.003 & 1.605 & 53 & 26787 \\ \mathrm{JCp}-1 \text { [12] / B2 } & 0.008 & 13.9 & 141 & 231984 \\ \mathrm{JCp}-1 \text { [12] / C1 } & 1.318 & 7.453 & 23208 & 124390 \\ \mathrm{JCp}-1 \text { [12] / C2 } & 0.068 & 0.1192 & 1194 & 3211\end{array}$

Curva de calibração

$\begin{array}{ccccc}\text { Branco } & 0 & 0 & 31 & 7 \\ \text { Padrão 1 } & 0.1 & 0.5 & 1702 & 8516 \\ \text { Padrão 2 } & 0.25 & 5 & 4267 & 81297 \\ \text { Padrão 3 } & 0.5 & 10 & 8816 & 169765 \\ \text { Padrão 4 } & 1 & 20 & 16712 & 323457 \\ \text { Padrão 5 } & 1.5 & 35 & 27109 & 589536\end{array}$

Segunda etapa de teste BGC (medidos no IGc-UNICAMP)

$\begin{array}{ccccc}\text { Amostra/Alíquota } & \text { Th (ppb) } & \mathbf{U} \text { (ppb) } & \text { Th (cps) } & \text { U (cps) } \\ \text { JCp-1 [5] / C4 } & 0.025 & 0.118 & 1309 & 8681 \\ \text { JCp-1 [5] / D1 } & 0 & 0.094 & 378 & 6354 \\ \text { JCp-1 [5] / D2 } & 0 & 0.088 & 315 & 6235 \\ \text { JCp-1 [5] / D3 } & 0 & 0.099 & 141 & 6626\end{array}$


Segunda etapa de teste BGC (medidos no IGc-UNICAMP) cont.

\begin{tabular}{|c|c|c|c|c|}
\hline Amostra/Alíquota & Th (ppb) & $U(p p b)$ & Th (cps) & $U$ (cps) \\
\hline $\mathrm{JCp}-1[5] / \mathrm{D} 4$ & 0.011 & 0.086 & 663 & 5886 \\
\hline$J C p-1[5] / E 1$ & 0.029 & 4.253 & 1468 & 315323 \\
\hline $\mathrm{JCp}-1$ [5] / E2 & 0 & 85.3 & 900 & 6108210 \\
\hline $\mathrm{JCp}-1[5] / \mathrm{E} 3$ & 0 & 7.709 & 521 & 544035 \\
\hline $\mathrm{JCp}-1[5] / \mathrm{E} 4$ & 0.016 & 0.387 & 854 & 26885 \\
\hline $\mathrm{JCp}-1[5]$ / E5 & 0 & 0.084 & 258 & 5628 \\
\hline JCp-1 [5] / E6 & 0 & 0.042 & 137 & 2837 \\
\hline $\mathrm{JCp}-1[6] / \mathrm{C} 4$ & 0.031 & 0.109 & 1499 & 7865 \\
\hline$J C p-1[6] / D 1$ & 0 & 0.082 & 316 & 5310 \\
\hline $\mathrm{JCp}-1[6] / \mathrm{D} 2$ & 0 & 0.085 & 287 & 5640 \\
\hline $\mathrm{JCp}-1[6] / \mathrm{D} 3$ & 0 & 0.089 & 325 & 5992 \\
\hline $\mathrm{JCp}-1[6] / \mathrm{D} 4$ & 0 & 0.076 & 264 & 5069 \\
\hline $\mathrm{JCp}-1[6] / \mathrm{E} 1$ & 0 & 1.092 & 539 & 141281 \\
\hline $\mathrm{JCp}-1[6] / \mathrm{E} 2$ & 0 & 89.3 & 480 & 5898160 \\
\hline$J C p-1[6] / E 3$ & 0 & 3.266 & 286 & 233579 \\
\hline$J C p-1[6] / E 4$ & 0 & 0.371 & 331 & 24714 \\
\hline JCp-1 [6] / E5 & 0 & 0.088 & 542 & 6101 \\
\hline$J C p-1[6]$ / E6 & 0 & 0.047 & 442 & 3114 \\
\hline $\mathrm{JCp}-1[7] / \mathrm{C} 3$ & 0 & 0.03 & 214 & 1946 \\
\hline $\mathrm{JCp}-1[7] / \mathrm{C} 4$ & 0.011 & 0.029 & 585 & 1824 \\
\hline $\mathrm{JCp}-1[7] / \mathrm{D} 1$ & 0 & 97.2 & 980 & 6546590 \\
\hline $\mathrm{JCp}-1[7] / \mathrm{D} 2$ & 0 & 2.923 & 222 & 200508 \\
\hline JCp-1 [7] / D3 & 0 & 0.233 & 430 & 16066 \\
\hline JCp-1 [7] / D4 & 0 & 0.372 & 328 & 5602 \\
\hline JCp-1 [8] / C3 & 0 & 0.014 & 188 & 926 \\
\hline JCp-1 [8] / C4 & 0 & 0.013 & 494 & 878 \\
\hline $\mathrm{JCp}-1$ [8] / D1 & 0 & 94.005 & 581 & 5446185 \\
\hline $\mathrm{JCp}-1[8] / \mathrm{D} 2$ & 0 & 12.38 & 175 & 828636 \\
\hline $\mathrm{JCp}-1[8] / \mathrm{D} 3$ & 0 & 0.372 & 190 & 24098 \\
\hline JCp-1 [8] / D4 & 0 & 0.081 & 117 & 5490 \\
\hline JCp-1 [9] / C4 & 0.067 & 0.083 & 3200 & 6294 \\
\hline JCp-1 [9] / D1 & 0.013 & 0.073 & 728 & 5063 \\
\hline JCp-1 [9] / D2 & 0 & 0.069 & 512 & 4759 \\
\hline JCp-1 [9] / D3 & 0 & 0.069 & 409 & 4652 \\
\hline $\mathrm{JCp}-1$ [9] / D4 & 0 & 0.065 & 216 & 4262 \\
\hline JCp-1 [9] / E1 & 0.017 & 1.193 & 936 & 85583 \\
\hline JCp-1 [9] / E2 & 0 & 35.1 & 480 & 2349820 \\
\hline$J C p-1[9] / E 3$ & 0 & 22.3 & 440 & 1491380 \\
\hline JCp-1 [9] / E4 & 0 & 2.819 & 319 & 184659 \\
\hline JCp-1 [9] / E5 & 0 & 0.518 & 331 & 35919 \\
\hline JCp-1 [9] / E6 & 0 & 0.154 & 264 & 10072 \\
\hline $\mathrm{JCp}-1$ [10]/C4 & 0.077 & 0.065 & 3627 & 4968 \\
\hline JCp-1 [10] / D1 & 0.015 & 0.061 & 781 & 4042 \\
\hline $\mathrm{JCp}-1[10]$ / D2 & 0 & 0.056 & 401 & 3852 \\
\hline JCp-1 [10] / D3 & 0 & 0.056 & 363 & 3702 \\
\hline $\mathrm{JCp}-1[10] / \mathrm{D} 4$ & 0 & 0.054 & 290 & 3514 \\
\hline $\mathrm{JCp}-1$ [10]/ E1 & 0.011 & 1.197 & 675 & 84962 \\
\hline
\end{tabular}


Segunda etapa de teste BGC (medidos no IGc-UNICAMP) cont.

$\begin{array}{ccccc}\text { Amostra/Alíquota } & \text { Th (ppb) } & \mathbf{U} \text { (ppb) } & \text { Th (cps) } & \mathbf{U} \text { (cps) } \\ \mathrm{JCp}-1 \text { [10] / E2 } & 0 & 42.6 & 430 & 2907910 \\ \mathrm{JCp}-1 \text { [10] / E3 } & 0 & 20.3 & 420 & 1387650 \\ \mathrm{JCp}-1 \text { [10] / E4 } & 0 & 2.183 & 444 & 147655 \\ \mathrm{JCp}-1 \text { [10] / E5 } & 0 & 0.45 & 192 & 28425 \\ \mathrm{JCp}-1 \text { [10] / E6 } & 0 & 0.127 & 195 & 8371 \\ \mathrm{JCp}-1 \text { [11] / C4 } & 0 & 0.152 & 211 & 10329 \\ \mathrm{JCp}-1 \text { [11] / D1 } & 0 & 68.1 & 510 & 4732330 \\ \mathrm{JCp}-1 \text { [11] / D2 } & 0 & 2.836 & 142 & 196199 \\ \mathrm{JCp}-1 \text { [11] / D3 } & 0 & 0.136 & 177 & 9370 \\ \mathrm{JCp}-1 \text { [11] / D4 } & 0 & 0.044 & 154 & 2904 \\ \mathrm{JCp}-1 \text { [12] / C3 } & 0 & 0.166 & 342 & 11515 \\ \mathrm{JCp}-1 \text { [12] / C4 } & 0.023 & 0.155 & 1075 & 10282 \\ \mathrm{JCp}-1 \text { [12] / D1 } & 0 & 74.1 & 1180 & 5256640 \\ \mathrm{JCp}-1 \text { [12] / D2 } & 0 & 2.776 & 175 & 183877 \\ \mathrm{JCp}-1 \text { [12] / D3 } & 0 & 0.138 & 246 & 9018 \\ \mathrm{JCp}-1 \text { [12] / D4 } & 0 & 0.047 & 187 & 3019\end{array}$

\section{Curva de calibração}

$\begin{array}{ccccc}\text { Branco } & 0 & 0 & 213 & 12 \\ \text { Padrão 1 } & 0.042 & 0.992 & 1898 & 68750 \\ \text { Padrão 2 } & 0.087 & 1.887 & 3716 & 130734 \\ \text { Padrão 3 } & 0.225 & 4.817 & 9270 & 333741 \\ \text { Padrão 4 } & 0.484 & 9.716 & 19725 & 673154 \\ \text { Padrão 5 } & 1.039 & 17.575 & 42072 & 1217653\end{array}$

Terceira etapa de teste BGC (medidos no IGc-UNICAMP)

$\begin{array}{ccccc}\text { Amostra/Alíquota } & \text { Th (ppb) } & \mathbf{U} \text { (ppb) } & \text { Th (cps) } & \mathbf{U} \text { (cps) } \\ \text { JCp-1 [13] / A } & 0.02 & 0.056 & 341 & 1428 \\ \text { JCp-1 [13] / B } & 0.02 & 0.915 & 268 & 17452 \\ \text { JCp-1 [13] / C1 } & 0.94 & 3.18 & 40932 & 230160 \\ \text { JCp-1 [13] / C2 } & 0.09 & 0.271 & 4329 & 20811 \\ \text { JCp-1 [13] / D } & 0.01 & 84.77 & 694 & 6354085 \\ \text { Fluka [1] / A } & 0.02 & 0.024 & 727 & 1624 \\ \text { Fluka [1] / B } & 0.01 & 0.007 & 678 & 502 \\ \text { Fluka [1] / C1 } & 6.7 & 0.003 & 265884 & 214 \\ \text { Fluka [1] / C2 } & 0.5 & 0.002 & 20192 & 164 \\ \text { Fluka [1] / D } & 0.12 & 0.003 & 4745 & 175 \\ \text { JCp-1 [14] / A } & 0.04 & 0.066 & 1682 & 4934 \\ \text { JCp-1 [14] / B } & 0.06 & 0.283 & 2552 & 19784 \\ \text { JCp-1 [14] / C } & 0.4 & 1.31 & 19099 & 101912 \\ \text { JCp-1 [14] / D } & 0.02 & 92.35 & 889 & 6884496 \\ \text { Fluka [2] / A } & 0.1 & 0.002 & 4141 & 105 \\ \text { Fluka [2] / B } & 0.07 & 0.001 & 2839 & 99 \\ \text { Fluka [2] / C } & 6.52 & 0.001 & 255581 & 92\end{array}$


Terceira etapa de teste BGC (medidos no IGc-UNICAMP) cont.

$\begin{array}{ccccc}\text { Amostra/Alíquota } & \text { Th (ppb) } & \mathbf{U}(\mathbf{p p b}) & \text { Th (cps) } & \mathbf{U}(\mathbf{c p s}) \\ \text { Fluka [2] / D } & 0.44 & 0.002 & 17366 & 107 \\ \text { JCp-1 [15] } & 2.4 & 99.8 & 105980 & 7301820 \\ \text { JCp-1 [16] } & 1.4 & 98 & 62640 & 7385500 \\ \text { JLs-1 [5] } & 1.52 & 66.04 & 8227 & 594285 \\ \text { JLs-1 [6] } & 1.15 & 65.87 & 6814 & 646163\end{array}$

\section{Curva de calibração}

$\begin{array}{ccccc}\text { Branco } & 0 & 0 & 99 & 4 \\ \text { Padrão 1 } & 0.043 & 1.024 & 1985 & 74472 \\ \text { Padrão 2 } & 0.09 & 2.008 & 4040 & 145956 \\ \text { Padrão 3 } & 0.236 & 5.072 & 10420 & 368710 \\ \text { Padrão 4 } & 0.482 & 10.04 & 21209 & 729871 \\ \text { Padrão 5 } & 0.981 & 20.393 & 43041 & 1482512 \\ \text { Padrão 6 } & 5.605 & 99.309 & 245555 & 7219538\end{array}$

Quarta etapa de testes BGC (medidos no IGc-UNICAMP)

$\begin{array}{ccccc}\text { Amostra/Alíquota } & \text { Th (ppb) } & \mathbf{U} \text { (ppb) } & \text { Th (cps) } & \mathbf{U} \text { (cps) } \\ \text { JCp-1 [17] / A } & 0.13 & 0.001 & 2787 & 33 \\ \text { JCp-1 [17] / B } & 0.03 & 5.3 & 379 & 153898 \\ \text { JCp-1 [17] / C1 } & 0.52 & 5.39 & 25051 & 390697 \\ \text { JCp-1 [17] / C2 } & 0.21 & 0.38 & 9269 & 26273 \\ \text { JCp-1 [17] / D } & 0.1 & 60.9 & 3943 & 4078395 \\ \text { JLs-1 [7] / A } & 0.43 & 0.001 & 10262 & 33 \\ \mathrm{JLs}-1 \text { [7] / B } & 0.04 & 0.72 & 476 & 18920 \\ \mathrm{JLs}-1 \text { [7] / C1 } & 1.16 & 1.31 & 53767 & 90491 \\ \mathrm{JLs}-1 \text { [7] / C2 } & 0.56 & 0.1 & 26512 & 6849 \\ \mathrm{JLs}-1 \text { [7] / D } & 0.23 & 41.9 & 10522 & 2926082 \\ \mathrm{JCp}-1 \text { [18] / A } & 0.02 & 0.001 & 184 & 46 \\ \mathrm{JCp}-1 \text { [18] / B } & 0.02 & 0.73 & 620 & 50745 \\ \mathrm{JCp}-1 \text { [18] / C } & 0.41 & 1.83 & 20734 & 139874 \\ \mathrm{JCp}-1 \text { [18] / D } & 0.15 & 63.4 & 6623 & 4321783 \\ \mathrm{JLs}-1 \text { [8] / A } & 0.02 & 0 & 475 & 42 \\ \text { JLs-1 [8] / B } & 0.03 & 0.85 & 970 & 57605 \\ \text { JLs-1 [8] / C } & 0.93 & 1.37 & 47996 & 104437 \\ \text { JLs-1 [8] / D } & 0.21 & 40.6 & 9215 & 2753048\end{array}$

Curva de calibração

$\begin{array}{ccccc}\text { Branco } & 0 & 0 & 43 & 12 \\ \text { Padrão 1 } & 0.047 & 0.971 & 2018 & 80389 \\ \text { Padrão 2 } & 0.085 & 1.99 & 4155 & 164789 \\ \text { Padrão 3 } & 0.208 & 4.996 & 11072 & 413619 \\ \text { Padrão 4 } & 0.428 & 9.913 & 23476 & 820700 \\ \text { Padrão 5 } & 0.886 & 19.934 & 49287 & 1650306\end{array}$


Primeira etapa de testes UMN (medidos no IGc-UNICAMP)

$\begin{array}{ccccc}\text { Amostra/Alíquota } & \text { Th (ppb) } & \mathbf{U}(\mathbf{p p b}) & \text { Th (cps) } & \mathbf{U} \text { (cps) } \\ \text { JCp-1 [19] /coleta Th } & 1.79 & 6.4 & 75933 & 450820 \\ \text { JCp-1 [19] /coleta U } & 0.03 & 66.42 & 1150 & 4565054 \\ \text { JCp-1 [20] /coleta Th } & 2.05 & 6.49 & 82685 & 433681 \\ \text { JCp-1 [20] /coleta U } & 0.02 & 68.17 & 767 & 4600238\end{array}$

Curva de calibração

$\begin{array}{ccccc}\text { Branco } & 0 & 0 & 99 & 4 \\ \text { Padrão 1 } & 0.043 & 1.024 & 1985 & 74472 \\ \text { Padrão 2 } & 0.09 & 2.008 & 4040 & 145956 \\ \text { Padrão 3 } & 0.236 & 5.072 & 10420 & 368710 \\ \text { Padrão 4 } & 0.482 & 10.04 & 21209 & 729871 \\ \text { Padrão 5 } & 0.981 & 20.393 & 43041 & 1482512 \\ \text { Padrão 6 } & 5.605 & 99.309 & 245555 & 7219538\end{array}$

Segunda etapa de testes UMN (medidos no IGc-UNICAMP)

$\begin{array}{ccccc}\text { Amostra/Aliquota } & \text { Th (ppb) } & \mathbf{U} \text { (ppb) } & \text { Th (cps) } & \mathbf{U} \text { (cps) } \\ \text { JCp-1 [21] / A } & 0.04 & 14.4 & 2346 & 556467 \\ \text { JCp-1 [21] / B } & 0.2 & 7.58 & 11500 & 332938 \\ \text { JCp-1 [21] / C } & 0 & 71.5 & 408 & 3109305 \\ \text { JCp-1 [21] / D } & 0 & 0.07 & 200 & 3047 \\ \text { JLs-1 [9] / A } & 0.02 & 21.3 & 1297 & 846167 \\ \text { JLs-1 [9] / B } & 0.69 & 11.3 & 37794 & 480291 \\ \text { JLs-1 [9] / C } & 0.04 & 101 & 2201 & 4373940 \\ \text { JLs-1 [9] / D } & 0 & 0.08 & 716 & 3643 \\ \text { JLs-1 [10] / A } & 0.03 & 7.42 & 1625 & 289370 \\ \text { JLs-1 [10] / B } & 0.45 & 4.94 & 24331 & 206065 \\ \text { JLs-1 [10] / C } & 0.02 & 49.9 & 1158 & 2082043 \\ \text { JLs-1 [10] / D } & 0 & 0.04 & 319 & 1799 \\ \text { JLs-1 [11] / A } & 0.02 & 1.28 & 1166 & 49778 \\ \text { JLs-1 [11] / B } & 0.4 & 3.71 & 22018 & 158457 \\ \text { JLs-1 [11] / C } & 0 & 55.3 & 434 & 2353398 \\ \text { JLs-1 [12] / A } & 0.01 & 1.67 & 708 & 65541 \\ \text { JLs-1 [12] / B } & 1.8 & 2.09 & 96566 & 86780 \\ \text { JLs-1 [12] / C } & 0.03 & 58 & 1663 & 2396421\end{array}$

\section{Curva de calibração}

$\begin{array}{ccccc}\text { Branco } & 0 & 0 & 200 & 6 \\ \text { Padrão 1 } & 0.323 & 1.006 & 17854 & 42540 \\ \text { Padrão 2 } & 0.628 & 1.969 & 34490 & 83268 \\ \text { Padrão 3 } & 1.053 & 3.306 & 57673 & 139780 \\ \text { Padrão 4 } & 1.627 & 5.035 & 88997 & 212903\end{array}$


Terceira etapa de teste UMN (medidos no IGc-UNICAMP)

\begin{tabular}{|c|c|c|c|c|}
\hline Amostra/Alíquota & Th (ppb) & $\mathbf{U}(\mathrm{ppb})$ & Th (cps) & $\mathbf{U}(\mathrm{cps})$ \\
\hline$J C p-1[22] / A$ & 0.03 & 21.4 & 764 & 870515 \\
\hline $\mathrm{JCp}-1$ [22] / B1 & 0.34 & 8.74 & 11383 & 392321 \\
\hline $\mathrm{JCp}-1[22] / \mathrm{B} 2$ & 0.08 & 0.36 & 2877 & 16662 \\
\hline $\mathrm{JCp}-1$ [22] / B3 & 0 & 0.3 & 260 & 13739 \\
\hline$J C p-1[22] / C 1$ & 0 & 49.6 & 144 & 2257949 \\
\hline $\mathrm{JCp}-1[22] / \mathrm{C} 2$ & 0 & 0.28 & 60 & 13044 \\
\hline $\mathrm{JCp}-1[22] / \mathrm{C} 3$ & 0 & 0.02 & 115 & 721 \\
\hline $\mathrm{JCp}-1$ [23] / A & 0 & 23.1 & 234 & 947616 \\
\hline $\mathrm{JCp}-1$ [23] / B1 & 0.29 & 7.15 & 10011 & 327147 \\
\hline $\mathrm{JCp}-1$ [23] / B2 & 0.1 & 0.35 & 3569 & 16179 \\
\hline $\mathrm{JCp}-1$ [23] / B3 & 0.02 & 0.31 & 598 & 14328 \\
\hline $\mathrm{JCp}-1[23] / \mathrm{C} 1$ & 0 & 50.3 & 221 & 2314831 \\
\hline $\mathrm{JCp}-1[23] / \mathrm{C} 2$ & 0 & 0.36 & 95 & 16462 \\
\hline $\mathrm{JCp}-1[23] / \mathrm{C} 3$ & 0 & 0.02 & 113 & 750 \\
\hline$J C p-1[24] / A$ & 0 & 28 & 173 & 1193876 \\
\hline $\mathrm{JCp}-1[24] / \mathrm{B} 1$ & 0.33 & 7.77 & 11388 & 359516 \\
\hline $\mathrm{JCp}-1$ [22] / B2 & 0.05 & 0.34 & 1613 & 15412 \\
\hline $\mathrm{JCp}-1[24] / \mathrm{B} 3$ & 0 & 0.33 & 195 & 14929 \\
\hline $\mathrm{JCp}-1[24] / \mathrm{C} 1$ & 0 & 48.2 & 114 & 2193602 \\
\hline JCp-1 [24] / C2 & 0 & 0.26 & 72 & 11472 \\
\hline $\mathrm{JCp}-1[24] / \mathrm{C} 3$ & 0 & 0.02 & 79 & 668 \\
\hline JLs-1 [13] / A & 0 & 24 & 144 & 1023373 \\
\hline JLs-1 [13] / B1 & 0.8 & 8.23 & 29068 & 393143 \\
\hline JLs-1 [13] / B2 & 0.05 & 0.35 & 1770 & 15893 \\
\hline JLs-1 [13] / B3 & 0 & 0.33 & 212 & 14807 \\
\hline JLs-1 [13] / C1 & 0 & 47.7 & 235 & 2186600 \\
\hline JLs-1 [13] / C2 & 0 & 0.76 & 113 & 34750 \\
\hline JLs-1 [13] / C3 & 0 & 0.03 & 125 & 1484 \\
\hline JLs-1 [14] / A & 0 & 36.4 & 178 & 1568767 \\
\hline JLs-1 [14] / B1 & 0.74 & 4.33 & 26362 & 203102 \\
\hline JLs-1 [14] / B2 & 0.04 & 0.23 & 1296 & 10600 \\
\hline JLs-1 [14] / B3 & 0 & 0.16 & 195 & 7577 \\
\hline JLs-1 [14] / C1 & 0 & 26 & 138 & 1209998 \\
\hline JLs-1 [14] / C2 & 0 & 0.13 & 81 & 5879 \\
\hline JLs-1 [14] / C3 & 0 & 0.01 & 68 & 505 \\
\hline
\end{tabular}

Curva de calibração

$\begin{array}{lcccc}\text { Branco } & 0.048 & 0 & 4 & 0.4 \\ \text { Padrão 1 } & 0.077 & 1.013 & 1011 & 46805 \\ \text { Padrão 2 } & 0.106 & 2.006 & 2052 & 92728 \\ \text { Padrão 3 } & 0.2 & 5.02 & 5360 & 232011 \\ \text { Padrão 4 } & 0.346 & 9.637 & 10502 & 445411 \\ \text { Padrão 5 } & 0.68 & 19.878 & 22324 & 918751 \\ \text { Padrão 6 } & 4.391 & - & 153348 & -\end{array}$

